University of Tennessee Health Science Center

UTHSC Digital Commons

$12-2012$

\title{
Metabotropic Glutamate Receptor 5 in the Medial Prefrontal Cortex: Role in Cocaine Sensitization and Addiction
}

Kristin Marie Timmer

University of Tennessee Health Science Center

Follow this and additional works at: https://dc.uthsc.edu/dissertations

Part of the Medical Molecular Biology Commons, Medical Neurobiology Commons, Neurosciences Commons, and the Substance Abuse and Addiction Commons

\section{Recommended Citation}

Timmer, Kristin Marie, "Metabotropic Glutamate Receptor 5 in the Medial Prefrontal Cortex: Role in Cocaine Sensitization and Addiction" (2012). Theses and Dissertations (ETD). Paper 272.

http://dx.doi.org/10.21007/etd.cghs.2012.0321.

This Dissertation is brought to you for free and open access by the College of Graduate Health Sciences at UTHSC Digital Commons. It has been accepted for inclusion in Theses and Dissertations (ETD) by an authorized administrator of UTHSC Digital Commons. For more information, please contact jwelch30@uthsc.edu. 


\title{
Metabotropic Glutamate Receptor 5 in the Medial Prefrontal Cortex: Role in Cocaine Sensitization and Addiction
}

\author{
Abstract \\ Cocaine sensitization is associated with cocaine-induced hyperexcitability of pyramidal projection \\ neurons within the medial prefrontal cortex (mPFC). Such hyperexcitability presumably results in \\ increased glutamatergic input to reward-affiliated brain regions such as the ventral tegemental area (VTA) \\ and nucleus accumbens (NAc), consequently facilitating drugseeking behavior. Metabotropic glutamate \\ receptor 5 (mGluR5) has been implicated in cocaine addiction and demonstrated to increase neuronal \\ excitability, therefore, the aim of the present study was to investigate the effect of intra-mPFC mGluR5 \\ manipulation on behavioral and neurochemical sensitization and drug-seeking. Bilateral cannulae were \\ implanted into the MPFC of male Sprague-Dawley rats and mGluR5 antagonist MTEP $(15 \mathrm{nmol} / \mathrm{side})$ or \\ saline was microinjected into the region five minutes prior to a challenge cocaine injection. Our data \\ showed that intra-mPFC mGluR5 blockade via MTEP prevented late, but not early, behavioral \\ sensitization. Further, intra-mPFC mGluR5 activation via DHPG (30 uM) increased mPFC and NAc \\ glutamate levels in sensitized animals during early and late withdrawal, respectively. Finally, we observed \\ a nonsignificant trend toward an MTEP-induced reduction in drug-seeking following the presentation of a \\ cocaine-associated cue in animals that had been trained to selfadminister cocaine. Taken together, our \\ data suggest mPFC mGluR5 plays a role in cocaine addiction, possibly through the modulation of mPFC \\ pyramidal neuronal excitability

\section{Document Type \\ Dissertation}

\section{Degree Name} \\ Doctor of Philosophy (PhD)

\section{Program} \\ Biomedical Sciences \\ Research Advisor \\ Jeffrey Steketee, Ph.D.

\section{Keywords} \\ cocaine, medial prefrontal cortex, metabotropic glutamate receptor 5

\section{Subject Categories} \\ Medical Molecular Biology | Medical Neurobiology | Medical Sciences | Medicine and Health Sciences | \\ Mental and Social Health | Neurosciences | Substance Abuse and Addiction

\section{Comments} \\ One year embargo expired December 2013
}


Metabotropic Glutamate Receptor 5 in the Medial Prefrontal Cortex: Role in Cocaine Sensitization and Addiction

\author{
A Dissertation \\ Presented for \\ The Graduate Studies Council \\ The University of Tennessee \\ Health Science Center
}

\begin{abstract}
In Partial Fulfillment
Of the Requirements for the Degree

Doctor of Philosophy

From The University of Tennessee
\end{abstract}

By

Kristin Marie Timmer

December, 2012 
Copyright (C) 2012 by Kristin M. Timmer. All rights reserved. 


\section{Acknowledgements}

I would like to thank my advisor, Dr. Jeff Steketee, for his guidance and support throughout this process, as well as my outstanding committee, Drs. Matthew Ennis, Kristin Hamre, Rennolds Ostrom, and Wen Lin Sun for their input, suggestions, and evaluation. I am thankful for my lab buddy, Kyle Summers, for his exceptional conversation and collaboration on the self-administration project, and former post-doc Kun "Luke" Liu for teaching me microdialysis. I would like to thank my husband, Steve, for existing, as I could not have been this happy spending my life with anyone else. Last but absolutely not least, I would like to thank my children, Jack and Cassidy, for motivating me to complete this work. 


\begin{abstract}
Cocaine sensitization is associated with cocaine-induced hyperexcitability of pyramidal projection neurons within the medial prefrontal cortex (mPFC). Such hyperexcitability presumably results in increased glutamatergic input to reward-affiliated brain regions such as the ventral tegemental area (VTA) and nucleus accumbens (NAc), consequently facilitating drug-seeking behavior. Metabotropic glutamate receptor 5 (mGluR5) has been implicated in cocaine addiction and demonstrated to increase neuronal excitability, therefore, the aim of the present study was to investigate the effect of intra-mPFC mGluR5 manipulation on behavioral and neurochemical sensitization and drug-seeking. Bilateral cannulae were implanted into the $\mathrm{mPFC}$ of male Sprague-Dawley rats and mGluR5 antagonist MTEP (15 nmol/side) or saline was microinjected into the region five minutes prior to a challenge cocaine injection. Our data showed that intramPFC mGluR5 blockade via MTEP prevented late, but not early, behavioral sensitization. Further, intra-mPFC mGluR5 activation via DHPG (30 uM) increased mPFC and NAc glutamate levels in sensitized animals during early and late withdrawal, respectively. Finally, we observed a nonsignificant trend toward an MTEP-induced reduction in drug-seeking following the presentation of a cocaine-associated cue in animals that had been trained to self-administer cocaine. Taken together, our data suggest $\mathrm{mPFC}$ mGluR5 plays a role in cocaine addiction, possibly through the modulation of mPFC pyramidal neuronal excitability.
\end{abstract}




\section{Table of Contents}

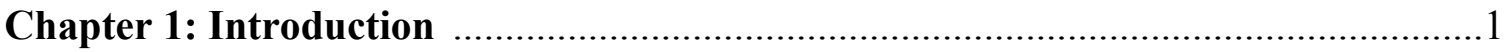

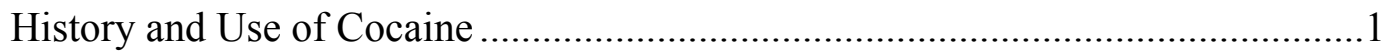

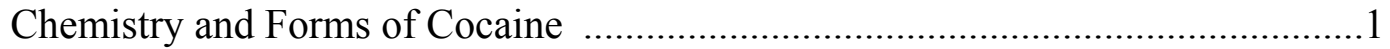

Pharmacokinetics and Metabolism of Cocaine ………......................................2

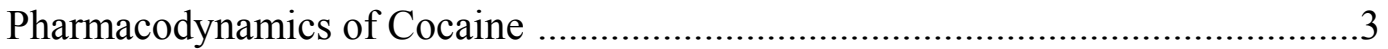

Medical Consequences of Cocaine Use …………................................................ 3

Euphorogenic Effects of Cocaine ……………................................................

Animal Models of Addiction .......................................................................

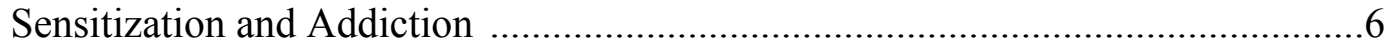

Brain Regions that Mediate Sensitization ........................................................

Cellular and Neurochemical Adaptations of Sensitization .....................................

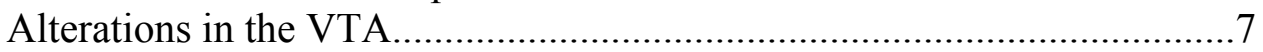

Alterations in the NAc ........................................................................

Involvement of the $\mathrm{mPFC}$ in Sensitization and Addiction ...................................

mPFC mGluR5 and Cocaine Addiction ...........................................................12

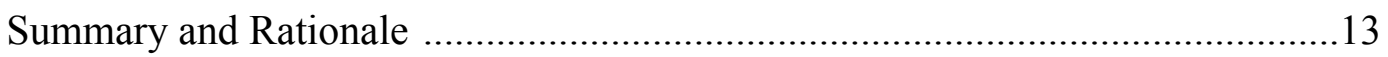

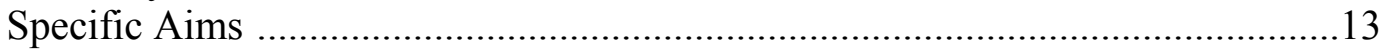

\section{Chapter 2: Examination of a Role for Metabotropic Glutamate Receptor 5 in the}

Medial Prefrontal Cortex in Cocaine Sensitization in Rats .......................................14

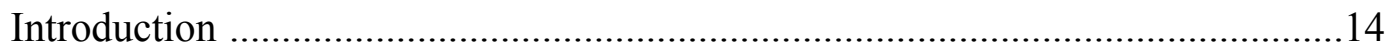

Materials and Methods ................................................................................15

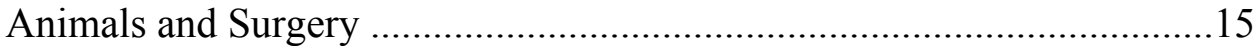

Injections and Behavior ..................................................................15

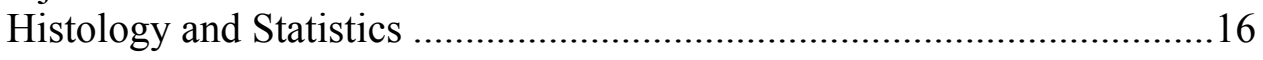

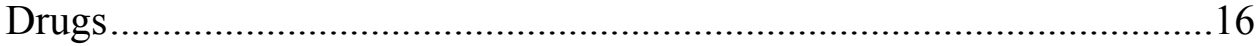

Experimental Design...........................................................................16

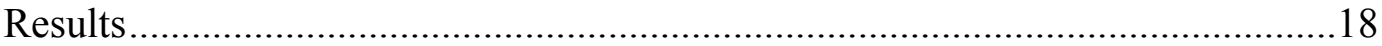

Group I mGluR Stimulation in the mPFC Induces Cross-Sensitization

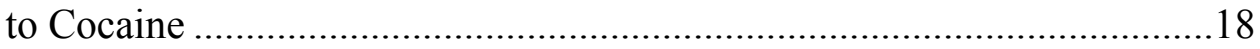

Cross-Sensitization Is Mediated by mGluR5 ............................................18

VTA AMPA Receptor Blockade Inhibits DHPG-Induced Cross-

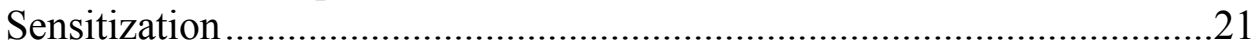

mPFC mGluR5 Blockade and Cocaine Sensitization ...............................21

mGluR5 Activation Alone Does Not Produce a Sensitized Response in

Sensitized Animals .........................................................................25

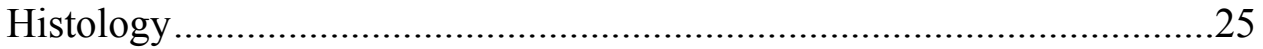

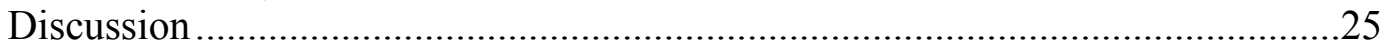


Chapter 3: Metabotropic Glutamate Receptor 5 in the Medial Prefrontal Cortex: Role in Mesocorticolimbic Glutamate Release in Cocaine Sensitization ...................30

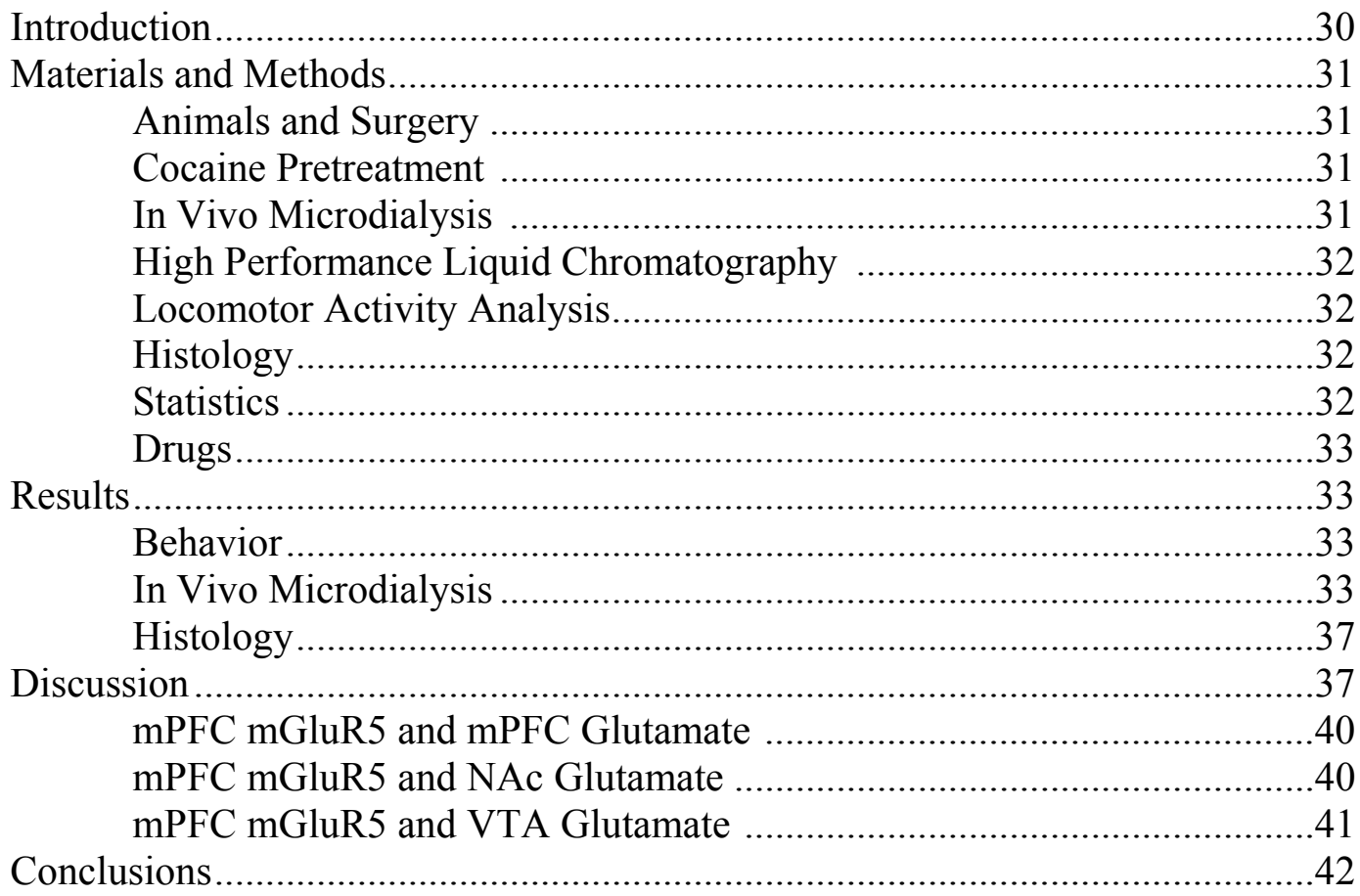

\section{Chapter 4: Role of Metabotropic Glutamate Receptor 5 in the Medial Prefrontal} Cortex on Drug-Seeking Behavior

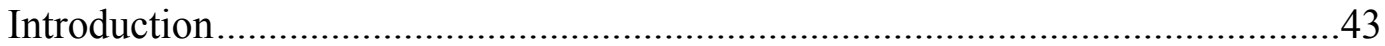

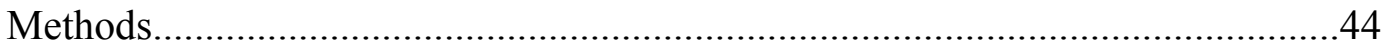

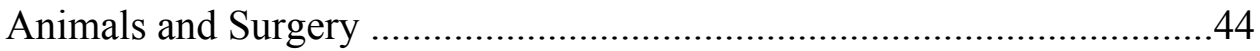

Cocaine Self-Administration Training ..............................................44

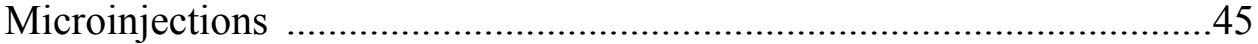

Histology and Statistics..............................................................45

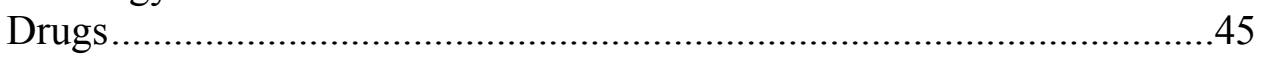

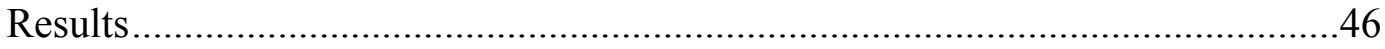

Repeated Training Increased Cue-Induced Cocaine

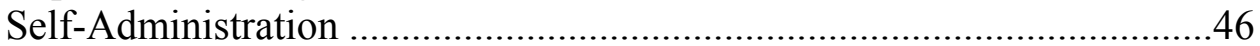

Effect of Intra-mPFC mGluR5 Blockade on Cue-Induced

Drug-Seeking ........................................................................46

Effect of Intra-mPFC mGluR5 Blockade on Cocaine-Induced

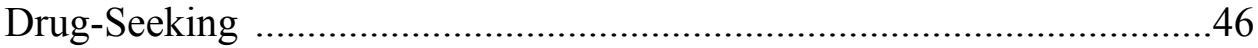

Differential Effect of mPFC mGluR5 Blockade on

High- and Low-Responding Rats ..................................................46

Discussion 
Chapter 5: General Discussion

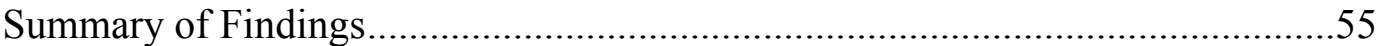

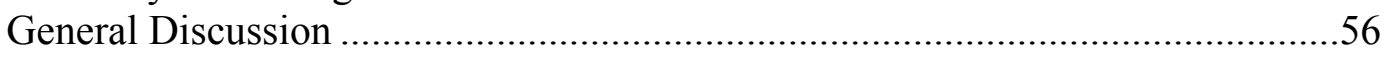

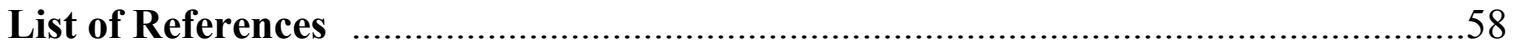

Vita 


\section{List of Figures}

Figure 1. Locomotor Response to a Challenge Injection of Cocaine ......................19

Figure 2. DHPG-Induced Cross-Sensitization Is Mediated by mGluR5 ................20

Figure 3. VTA AMPAR Blockade Prevents DHPG-Induced Cross-Sensitization

Figure 4. Effect of mPFC mGluR5 Blockade on the Initiation of

Sensitization

Figure 5. Effect of mPFC mGluR5 Blockade on the Expression of

Sensitization

Figure 6. Microinjection Placement in the mPFC and the VTA .26

Figure 7. Effect of Repeated Cocaine Exposure on Cocaine-Induced Locomotion

Figure 8. Effect of Intra-mPFC mGluR5 Activation on mPFC Glutamate Levels

Figure 9. Effect of Intra-mPFC mGluR5 Activation on NAc Glutamate

Levels

Figure 10. Effect of Intra-mPFC mGluR5 Activation on VTA Glutamate

Levels

Figure 11. Microdialysis Probe Placement in the mPFC, NAc, and VTA .39

Figure 12. Effect of Self-Administration Training on Responses

Figure 13. Effect of Intra-mPFC mGluR5 Activation on Cue-Induced

Drug-Seeking

Figure 14. Effect of Intra-mPFC mGluR5 Activation on Cocaine-Induced Drug-

Seeking

Figure 15. Effect of Intra-mPFC mGluR5 Activation on Cue-Induced Drug-

Seeking on High-and Low-Responding Rats

Figure 16. Effect of Intra-mPFC mGluR5 Activation on Cocaine-Induced Drug-

Seeking on High- and Low-Responding Rats 


\section{Chapter 1. Introduction}

\section{History and Use of Cocaine}

Cocaine was first isolated by the German chemist Albert Niemann in 1855, however, archeological evidence suggests dried leaves of the Erythroxylon coca shrub from which cocaine derives have been used for recreational and medicinal purposes by indigenous South Americans as far back as 3000 BC (Boghdadi and Henning, 1997; Johanson and Fischman, 1989; Warner, 1993). Cocaine gained popularity in Europe and the United States in the late nineteenth century, and the drug became available in a wide variety of products such as cigarettes, crystals, liquors, and the popular beverage Coca Cola (Boghdadi and Henning, 1997; Das, 1993; Johanson and Fischman, 1989). Cocaine was also added to a variety of therapeutic concoctions such as toothache, headache, and stomach remedies (Johanson and Fischman, 1989).

Cocaine use in the United States came to a slow halt following the Harrison Narcotic Act of 1914 (Boghdadi and Henning, 1997; Das and Laddu, 1993), making cocaine far less accessible and tarnishing its image as a safe and useful substance. Further dissuasion from cocaine use stemmed from increased public suspicion regarding its toxicity (Johanson and Fischman, 1989). Because cocaine was present in such a wide range of consumer products and medicines, there was great opportunity for adverse effects to manifest and people were becoming skeptical of its benignity. Cocaine remained largely absent from American popular culture until its resurgence in the late seventies, which was augmented in part by the advent of a form of cocaine that could be smoked ("crack") (Warner, 1993).

While cocaine use has since declined slightly from its peak in the early eighties, the National Survey on Drug Use and Health (NSDUH) estimates 1.9 million current users in 2008, with 18-25 year olds being more likely to use than any other age group. The 2008 NSDUH additionally suggests that 1.4 million Americans were dependent on some form of cocaine, as determined by met Diagnostic and Statistical Manual of Mental Disorders criteria. The 2008 Drug Abuse Warning Network report revealed that cocaine was responsible for a fourth of the two million drug-related emergency room visits that occurred that year. Finally, relapse rates hover around $60 \%$ for cocaine and $85 \%$ for crack, suggesting that current treatments warrant some improvement (Statistical data from National Institute of Drug Abuse website: www.nida.org).

\section{Chemistry and Forms of Cocaine}

Cocaine is an alkaloid that derives from the leaves of the Erythroxylon shrub, or coca plant, which grows in the Andes mountains of South America (Johanson and Fischman, 1989). Cocaine accounts for 1\% of the weight of coca leaves and chewing the leaves has been a common form of administration for millennia. However, low gastrointestinal absorption and the relatively low concentration of cocaine in the leaves 
results in noticeable, but comparably minimal, effects (Warner, 1993). By contrast, when combined with hydrochloric acid (cocaine hydrochloride), cocaine becomes a watersoluble salt that can consequently be injected or nasally insufflated, resulting in far greater drug absorption. Cocaine hydrochloride may also be dissolved in water, mixed with sodium bicarbonate, and heated, resulting in a solid substance that can be smoked, most commonly in a glass pipe or cigarette (Khalsa et al., 1992). Heating this form of cocaine produces a popping sound that earned it the street name "crack". Due to its lower cost and greater accessibility, crack has surpassed traditional cocaine in popularity and is now the most commonly used form of the drug (Boghdadi and Henning, 1997).

\section{Pharmacokinetics and Metabolism of Cocaine}

Cocaine can be smoked, injected, or nasally insufflated. The drug reaches the cerebral circulation in 6-8 seconds when smoked, 1-2 minutes when intravenously injected, and 3-5 minutes when absorbed through the nasal mucous membranes (Johanson and Fischman, 1989; Warner, 1993). Peak plasma levels are higher and achieved more quickly when cocaine is smoked or injected than when it is snorted; seconds for the former and up to an hour for the latter (Johanson and Fischman, 1989) (Boghdadi and Henning, 1997). The delay is due, in part, to cocaine's vasoconstrictive action on the nasal mucosa that slows the drug's absorption (Warner, 1993). However, this impediment also results in the prolonged presence of cocaine in the plasma, sometimes up to 6 hours, while subjects who intravenously administered the drug reported a significant decrease in the effects just 40 minutes after the injection (Javaid et al., 1978).

The plasma half-life of cocaine ranges from 30-90 minutes (Javaid et al., 1983) (Warner, 1993), however, its clearance from other tissues can be substantially slower (Johanson and Fischman, 1989). Approximately 95\% of cocaine is metabolized into benzoylecgonine, ecgonine methyl ester, or norcocaine (Warner, 1993). The vast majority (80-90\%) of cocaine is metabolized into ecgonine methyl ester and benzoylecgonine via enzymatic and nonenzymatic hydrolysis, respectively (Johanson and Fischman, 1989; Warner, 1993). The plasma half-lives of benzoylecgonine and ecgonine methyl ester are four and seven hours, respectively, however they can remain in the urine for up to two weeks. Benzoylecgonine urine concentrations are 50-100 times higher than those of cocaine or ecgonine methyl ester, so the metabolite is consequently targeted in cocaine screening tests, which most commonly employ gas chromatography/ mass spectrometry (Boghdadi and Henning, 1997; Warner, 1993). A small amount of cocaine is metabolized into norcocaine via N-demethylation in the liver (Warner, 1993). This metabolite can be potentially toxic to individuals with cholinesterase deficiencies, resulting in life-threatening complications (Hoffman et al., 1992). 


\section{Pharmacodynamics of Cocaine}

The two primary pharmacologic actions of cocaine are the blockade of sodium channels and the prevention of monoamine reuptake (Boghdadi and Henning, 1997). The blockade of fast sodium channels in neuronal and cardiac cells ultimately attenuates depolarization and action potential conduction (Benowitz, 1993; Boghdadi and Henning, 1997). This may lead to arrhythmia, which is associated with stroke and sudden death (Benchimol et al., 1978). Myocardial infarction can also be induced through cocaine's blockade of norepinephrine reuptake, which can lead to increased heart rate and blood pressure. Cocaine's sodium channel occlusion has resulted in its use as a topical anesthetic. In the past, it was used most often in ophthalmological settings, but was later found to induce corneal epithelial sloughing (Johanson and Fischman, 1989). Presently, it is utilized almost exclusively as an anesthetic during respiratory tract surgeries in a 4\% concentration with very few adverse effects (Johanson and Fischman, 1989).

Virtually all drugs of abuse increase dopaminergic transmission in rewardassociated brain regions, such as the ventral tegmental area (VTA) and nucleus accumbens (NAc). Cocaine prevents monoamine reuptake by blocking transporters on presynaptic terminals, resulting in increases of a given neurotransmitter in the synaptic cleft (Benowitz, 1993). Since brain areas such as the VTA and NAc have a high concentration of dopamine transporters, cocaine increases dopamine in these regions and it is this action that accounts for its addictive potential (Fleming et al., 1990).

\section{Medical Consequences of Cocaine Use}

Both sporadic and chronic cocaine use can lead to wide range of health conditions (Boghdadi and Henning, 1997). In the central nervous system, strokes (Levine et al., 1991) seizures (Dhuna et al., 1991), and movement disorders (Hegarty et al., 1991) can occur in first-time users, as well as seasoned addicts who have never experienced any cocaine-related complications in the past. Cocaine-induced cardiac problems are numerous, including arrhythmia (Benchimol et al., 1978), endocarditis (Chambers et al., 1987), myocardial infarction (Isner et al., 1986), cardiomyopathy (Om et al., 1992), and ruptured aorta (Barth et al., 1986).

Pulmonary consequences can occur following any route of cocaine administration, but are most likely to result from smoking crack cocaine (Boghdadi and Henning, 1997). Respiratory complications include, but are not limited to, inhalation injuries (Boghdadi and Henning, 1997), vascular abrasions and bleeding (Bailey et al., 1994) (Murray et al., 1988), and edema (Hoffman and Goodman, 1989).

Gastrointestinal complications primarily result from cocaine's vasoconstrictive actions on gastric arteries (Boghdadi and Henning, 1997) and comprise gastroduodenal ulcers (Kram et al., 1992), intestinal tears Freudenberger 1990 (Freudenberger et al., 1990), and colitis (Brown et al., 1994). 
In the kidney, cocaine use can result in acute rhabdomyolysis, renal infarction, and acute renal failure (Boghdadi and Henning, 1997; Merigian and Roberts, 1987) (Kramer and Turner, 1993). Rhabdomyolysis, a condition whereby skeletal muscle components such as myoglobin leak into the bloodstream and compromise renal function, accounts for one fourth of cocaine-related emergency room cases (Boghdadi and Henning, 1997). The vasoconstrictive action of cocaine and resultant muscle ischemia is thought to be primarily responsible for this condition, however, excessive amounts of cocaine may also induce direct muscle deterioration (Boghdadi and Henning, 1997; Nolte, 1991).

Since cocaine easily and rapidly crosses the placenta, use during pregnancy can have tragic effects on the fetus. These complications include spontaneous abortion (Chasnoff et al., 1985), stillbirth, placenta previa (Chasnoff et al., 1989), congenitial abnormalities (Handler et al., 1991), and premature birth (Handler et al., 1991). Once born, the neonate may suffer seizures, tachycardia, and cocaine withdrawal (Boghdadi and Henning, 1997; Burkett et al., 1990).

Cocaine possesses intense euphorigenic properties due to its ability to increase dopamine in the reward circuit (discussed in greater detail later), but it also can result in less pleasurable psychiatric conditions such as depression, agitation, psychosis, delirium and delusions. In some cases, these altered psychiatric states can have devastating consequences like accidents, suicide and homicide (Warner, 1993). Due to cocaineinduced impairments in judgment, users are also at risk for contracting sexually transmitted diseases such as HIV. HIV transmission, along with hepatitis, is also increased in intravenous cocaine users.

\section{Euphorogenic Effects of Cocaine}

As previously discussed, one of cocaine's primary actions is monoamine transporter blockade, which leads to increases in monamines (dopamine, norepinephrine, and serotonin) in the synaptic cleft. While cocaine binds with five and three times greater affinity to the serotonin and norepinephrine transporter, respectively, a large body of evidence suggests the rewarding element of cocaine use derives from the drug's effects on the dopamine transporter (White and Kalivas, 1998). While data imply cocaine's action at the serotonin and norepinephrine transporters plays a significant role in setting the stage for addiction (Steketee, 2003; White and Kalivas, 1998), experiments in which these two transporter types were manipulated have not shown a relationship between their function and euphoria or drug-seeking behavior (White and Kalivas 1998). By contrast, dopamine transporter knockout mice do not exhibit locomotor sensitization (discussed in the following section) in response to repeated cocaine (Giros et al., 1996). Furthermore, dopamine release in the nucleus accumbens is a consequence of nearly all drugs of abuse (Kauer, 2004). 


\section{Animal Models of Addiction}

The two most widely used methods for studying addiction are the contingent and noncontingent models. In the noncontingent paradigm, cocaine is repeatedly administered to the animal by the experimenter while in contingent paradigms, the animal is trained to self-administer cocaine. Behavioral sensitization is the most commonly studied phenomenon using the noncontingent method and refers to the increase in drug-induced locomotor activity observed following repeated drug exposure. The majority of my project focuses on sensitization, so it will be discussed in greater detail in the following sections. In self-administration models, relapse (via reinstatement) or drug-seeking can be measured. In self-administration experiments, laboratory animals are trained to respond (lever-press, nose poke) to a cue in order to obtain an intravenous drug injection (Shaham et al., 2003). Generally, animals are considered to have learned the task when they are reliably responding at the appropriate times, however, specific goal criteria varies among labs and experiments. After animals have learned, they either undergo extinction training wherein responding only results in an intravenous saline injection, or return to their home cages for a certain period of time (days to weeks) before being placed back in the selfadministration chambers. In the former and more common condition, the experimenter is studying reinstatement; in the latter, drug-seeking is being assessed. Reinstatement, considered by many to be the most valid model for relapse, consists of re-exposing the extinguished animal to drug or presenting it with a cue previously associated with drug. The animal is then again placed in the self-administration chamber and its response activity is recorded (responses at this stage only deliver intravenous saline). The overarching goal of most reinstatement studies is to determine whether various pharmacological or environmental manipulations can reduce the risk of relapse. The goal of drug-seeking experiments is generally the same, but the methodology differs in that the animal does not learn to dissociate the self-administration chamber and the drug. The downside of this is that the relapse-prevention medium under scrutiny may not need to be as effective to produce a significant effect as it would if tested under a reinstatement paradigm. However, evidence suggests that neuroadaptations occur in rodents following extinguishment (Knackstedt et al., 2010) and such adaptations may result in a neural landscape that differs significantly from that of an addicted individual. Consequently, a relapse-prevention tool effective in one state may not generalize to another.

While the self-administration paradigm is currently considered the most valid model in the addiction field, there has been a fair amount of debate regarding the validity of sensitization. Perhaps the most common qualm is skepticism about whether the neural underpinnings of sensitization parallel those that occur in addiction, however, a recent review suggests substantial overlap between the two models (Steketee and Kalivas, 2011). Nonetheless, given the controversy, we decided to conduct a similar investigation of the role mPFC mGluR5 in drug-seeking using the self-administration paradigm to further corroborate both the role of mPFC mGluR5 in addiction as well as the relevance of sensitization as a model of addiction. 


\section{Sensitization and Addiction}

Behavioral sensitization to cocaine was first observed in 1932 and refers to the increase in locomotor activity in response to cocaine following repeated cocaine exposure (Steketee, 2003). Sensitization also occurs in response to other drugs of abuse, such as amphetamine, nicotine, alcohol, and morphine (Robinson and Becker, 1986; Steketee and Kalivas, 2011). The role of sensitization in addiction is presently controversial, however, a good deal of evidence suggests common mechanisms mediate both processes (Robinson and Berridge, 1993). There is also significant overlap between studies of sensitization (Steketee and Kalivas, 2011) and those of reinstatement, a model considered by many to validly depict relapse. It has additionally been shown that animals that exhibit a strong sensitized response to a drug are more likely to relapse in a self-administration paradigm (DeVries et al., 1998). Furthermore, cross-sensitization occurs between various drugs of abuse, indicating sensitization derives from mechanisms characteristic of a general addicted neural state (Steketee, 2003). Finally, both sensitization and addiction share the qualities of longevity and susceptibility to individual differences (Tzschentke and Schmidt, 2003). Addiction is a lifelong struggle and sensitization can be observed for at least a year following the last exposure to a drug, suggesting sensitization is a fundamental element of the resilient neuroadaptations that occur following repeated drug use. Sensitization cannot be observed in every animal that is repeatedly exposed to a drug, just like every individual who uses a drug will not become an addict. Factors such as frequency of exposure, gender, age, and genetics influence sensitization and addiction (Steketee and Kalivas, 2011).

Sensitization is generally divided into two stages: initiation and expression. Initiation refers to the development of sensitization that occurs during the first few exposures to the drug. The VTA is believed to play a significant role in this phase, seeing as its inactivation prevents sensitization (Koob et al., 1981) and a number of early modifications occur in this region following initial drug encounters (Kauer, 2004) (Carlezon and Nestler, 2002; Thomas and Malenka, 2003). Expression can be further divided into an early and late phase. Early expression is usually considered to be between one and fourteen days from the last drug exposure while late expression is twenty-one days and beyond following the last drug exposure. The nucleus accumbens is thought to be the seat of lasting, drug-induced modifications that mediate the expression of sensitization (Steketee and Kalivas, 2011).

Sensitization is typically measured through observing drug-induced locomotor activity. Experiments usually consist of two groups of animals: one that receives repeated, consecutive daily injections of drug (over x number of days; four, in our studies) and one that receives an equivalent amount of saline for an equivalent amount of time. After a certain time point following the last injection (our experiments look at seven, fourteen, or twenty-one days), a challenge injection of drug is administered and locomotor activity is measured for a certain amount of time (120 minutes in our lab). If sensitization has occurred, a significantly greater amount of locomotor activity in the drug group would be expected relative to saline controls. 


\section{Brain Regions that Mediate Sensitization}

Sensitization derives from alterations in the mesocorticolimbic (MCL), or reward, circuit in the brain, consisting of the VTA, NAc and medial prefrontal cortex (mPFC). The hippocampus, amygdala, laterodorsal tegmentum and the paraventricular nucleus are additionally believed to be involved in sensitization, but probably via interaction with the MCL circuit (Steketee and Kalivas, 2011). Dopaminergic projections from the VTA to the NAc are perhaps the most crucial and well-studied element of the MCL circuit, as they are the source of dopamine release in the NAc which, as previously mentioned, is necessary for a drug to be subjectively evaluated as rewarding. The mPFC sends glutamatergic projections to the VTA and the NAc (Sesack and Pickel, 1992), and the importance of these projections in the regulation of addictive behavior is beginning to come to light. The VTA and NAc also send reciprocal dopaminergic and GABAergic projections, respectively, back to the mPFC (Oades and Halliday, 1987).

Lesion studies have been a useful, albeit first-pass, method for determining the necessity of certain brain structures for the sensitization process. Inactivation of the VTA and the NAc via radiofrequency or 6-hydroxydopamine diminished the sensitized locomotor response to amphetamine (Koob et al., 1981), while ibotenic acid mPFC lesions prevented behavioral cocaine sensitization( $\mathrm{Li}$ et al., 1999). The VTA has been shown to be essential for the initiation of sensitization, while the NAc is deemed vital for expression. Consistent with this, the $\mathrm{mPFC}$ can be subdivided into several regions that each project predominantly to different brain structures and lesioning the mPFC area projecting to the VTA prevents the initiation of sensitization, while lesioning the area projecting to the NAc prevents expression (Pierce et al., 1998) (Steketee, 2003).

\section{Cellular and Neurochemical Adaptations of Sensitization}

A wide range of studies have demonstrated alterations in MCL brain structures following repeated and acute cocaine exposure. These changes are believed to underlie the unmanageable drug-seeking behavior observed in addicts, so an understanding of the nature and temporal profile of these adaptations is critical to the development of pharmacotherapies to treat addiction and prevent relapse. In the following sub-sections, I will delineate documented changes in the VTA and the NAc. Since the basis of my project rests on alterations in the $\mathrm{mPFC}$, I will cover these in the next section.

\section{Alterations in the VTA}

At present, most noted alterations in the VTA are thought to be transient, functioning primarily to mediate the early stages of sensitization (White and Kalivas, 1998). In support of this, dopamine levels in response to cocaine were found to be initially elevated in sensitized rats but were indistinguishable from controls by fourteen days post-exposure, however, behavioral sensitization could still be observed at this time point (Kalivas and Duffy, 1993). Additionally, repeated intra-VTA administration of the 
dopamine re-uptake inhibitor GBR 12909 induced a sensitization to cocaine that was not significantly different from that elicited in animals that received repeated cocaine, suggesting enhanced VTA dopamine levels lead to sensitization (Cornish and Kalivas, 2001). Some relationships between dopamine receptors and sensitization in the VTA have been observed, as well. Repeated intra-VTA injections of D1 receptor agonist SKF38393 induces cross-sensitization to a cocaine challenge in drug-naive rats (Pierce et al., 1996). D1 receptor knock-out mice do not exhibit increased locomotor activity in response to acute cocaine or sensitization to a higher dose of repeated cocaine, however, it was ironically found that these mice displayed some (albeit nonsignificant) sensitization to a lower dose of repeated cocaine (Karlsson et al., 2008). Finally, it has been suggested that dopamine autoreceptors are less sensitive following cocaine sensitization (Henry and White, 1991; White and Kalivas, 1998).

In addition to dopamine, elevated glutamate levels have been observed in sensitized rats following a challenge cocaine injection administered twenty-one days from the last sensitizing injection (Kalivas and Duffy, 1998). Glutamatergic transmission in the VTA also appears to be augmented in sensitized rats, as evidenced by an increase in neuronal firing following in vivo iontophoretic glutamate application (White et al., 1995). Single-cell recording found VTA dopamine neurons to be more sensitive to iontophoretically administered AMPA in sensitized versus saline animals (Zhang et al., 1997). Increased levels of GluR1 and NMDAR1 were observed in the VTA of sensitized rats (Fitzgerald et al., 1996) and intra-VTA injections of NMDAR antagonists block the development of sensitization (Kalivas and Alesdatter, 1993). Data suggest a single exposure to cocaine can potentiate synaptic AMPA currents on dopaminergic projection neurons in the VTA (Ungless et al., 2001). This potentiation was demonstrated to last for at least five, but not more than ten, days post-exposure, further corroborating a transient, but necessary, role for the VTA in sensitization. This cocaine-induced increase in VTA neuronal excitability was later found to depend on an inhibition of GABA-ergic synapses that occurs following repeated cocaine, and could be prevented by the administration of GABA agonist diazepam (Liu et al., 2005).

Taken together, these data suggest cocaine exposure induces a short-lived plasticity in VTA dopaminergic output neurons that serves to increase input to target regions, such as the NAc and $\mathrm{mPFC}$. It is assumed that this transient increase in dopaminergic transmission sets the stage for more lasting alterations in other rewardassociated brain structures.

\section{Alterations in the NAc}

In contrast to the VTA, cocaine-induced changes in the NAc are generally believed to be longer lasting and may consequently play a greater role in the unmanageable drug-seeking behavior observed in addiction. Several studies have demonstrated AMPA alterations in the NAc following repeated cocaine exposure, suggesting glutamatergic transmission in the NAc may play an important role in relapse. An increase in locomotor activity was observed following intra-NAc microinjections of 
AMPA in sensitized animals relative to saline controls at 14 to 21 days withdrawal (Pierce et al., 1996). Intra-NAc AMPA injections were also found to increase drugseeking behavior following a 28-day withdrawal period in sensitized rats (Suto et al., 2004). Moreover, administration of an AMPA receptor antagonist was found to prevent reinstatement when injected directly into the NAc (Cornish and Kalivas, 2000). Further, an increase in GluR1 was observed in the NAc at 21 (but not 1) days cocaine withdrawal in sensitized rats (Churchill et al., 1999). A later study found an increase in NMDA receptor subunits NR1, NR2A, and NR2B at the delayed (21 day), but not immediate (1 day) time point (Schumann and Yaka, 2009). Finally, in NAc brain slices of sensitized mice, a strong, AMPA-mediated long-term potentiation was observed following an extended period of withdrawal, however, a single administration of cocaine rapidly abolished this LTP and instead induced LTD (Kourrich et al., 2007).

Basal glutamate levels in the NAc are reduced following repeated cocaine (Baker et al., 2002), while a challenge injection of cocaine was found to increase glutamate in the NAc of sensitized animals relative to controls (Reid and Berger, 1996). This decrease in basal glutamate is hypothesized to be due, in part, to a cocaine-induced disruption in the function of the cysteine-glutamate anti-porter (Baker et al., 2003), which appears plausible given that $\mathrm{N}$-acetyl-cysteine can restore glutamate levels and prevent reinstatement (Baker et al., 2003) and sensitization (Madayag et al., 2007). This data in combination with the abovementioned AMPA receptor alterations suggest repeated cocaine may induce a potentiated state in NAc synapses characterized by low glutamate levels that serves to heighten contrast between a drug-abstinent and a drug-using state, ultimately arming cocaine and its cues with greater influence over behavior (Steketee and Kalivas, 2011).

Contrary to what one might expect, there does not appear to be a great deal of cocaine-mediated dopamine alterations in the NAc, at least not relative to glutamate (White and Kalivas, 1998). That said, dopamine increases in the NAc have been observed following repeated cocaine (Kalivas and Duffy, 1990). A recent in vivo study demonstrated via fast-scan cyclic voltammetry a cocaine-induced dopamine increase in the NAc at 7 (but not 1) days withdrawal in sensitized rats (Addy et al., 2010). An increased sensitivity in D1, but not D2, receptors in the NAc was observed at 7 and 30 , but not 60, days withdrawal in sensitized rats (Henry and White, 1991).

\section{Involvement of the mPFC in Sensitization and Addiction}

The $\mathrm{mPFC}$ is perhaps most colloquially associated with the famous case of Phineas Gage, the nineteenth-century railway worker impaled through the skull by an iron rod during an explosion. While the injury did not leave Gage with any lasting impairments that were necessarily obvious to the casual observer, those who knew him before the accident were unanimous in attesting that he was "no longer Gage". Prior to the accident, Gage was reportedly careful, respectful, responsible, and business-minded--a demeanor that contrasted sharply with the reckless, crude and capricious disposition in its place following the injury. Due to Gage's irresponsibility and inability to comprehend 
the exchange of currency, he spent the last decade of his life working for Barnum's circus as an exhibit before he died from epilepsy in 1860, just twelve years after the accident. Later examination of Gage's skull and those of other individuals who sustained similar injuries revealed that the iron rod had most likely damaged Gage's prefrontal cortex, a brain region now implicated in attention, working memory, reward processing, emotional regulation, decision-making, impulsivity and inhibition, self-monitoring, and reversal learning (Perry et al., 2011).

The human prefrontal cortex can be divided into medial, lateral, and orbital regions (Perry et al., 2011). The medial region consists of the $\mathrm{mPFC}$ and anterior cingulate cortex (ACC), and most cortically based cocaine abuse research in humans and laboratory animals has focused on these regions. The lateral region of the PFC contains distinct dorsal and ventral areas, as well as an inferior frontal junction (Ridderinkhof et al., 2004). The 1PFC sends and receives projections from premotor regions, which ultimately originate in the motor cortex. This particular connectivity enables the PFC to influence behavior (Perry et al., 2011). The orbital region communicates with other areas of the PFC and receives a wide range of sensory input.

In rodents, reciprocal connections exist between the $\mathrm{MPFC}$ and the NAc, VTA, hypothalamus, hippocampus, amygdala, and other regions of the cortex (Dalley et al., 2004; Perry et al., 2011). The rat mPFC is generally subdivided into dorsal and ventral regions, with the former consisting of the precentral and anterior cingulate cortices and the latter encompassing the prelimbic, infralimbic, medial orbital, and ventral orbital regions. Unlike human $\mathrm{mPFC}$, there does not appear to be a connectivity-based IPFC correlate in rodents (Perry et al., 2011).

A growing base of human and laboratory animal studies point to a role of the $\mathrm{mPFC}$ in cocaine addiction. Imaging studies in human addicts generally show an increase in $\mathrm{mPFC}$ activity in response to or in expectation of cocaine, as well as following drugrelated cues (Goldstein and Volkow, 2011; Kufahl et al., 2008; Kufahl et al., 2005). In rodents, $\mathrm{mPFC}$ lesions induced prior to repeated cocaine exposure prevented behavioral sensitization (Li et al., 1999; Tzschentke and Schmidt, 1998) and cocaine injections administered directly into the $\mathrm{MPFC}$ induced reinstatement in previously trained rats (Park et al., 2002). As previously mentioned, obliteration of projections from the mPFC to the NAc and VTA abolishes the expression and initiation of sensitization, respectively. Taken together, these studies suggest the mPFC is essential in mediating the pathological neuroadaptations that follow repeated cocaine.

Increasing amounts of data suggest neurochemical and electrophysiological alterations occur in the $\mathrm{mPFC}$ following repeated cocaine exposure. Cocaine-mediated $\mathrm{mPFC}$ dopamine levels are decreased during early sensitization but increased during late sensitization and the reverse is true for glutamate levels (Williams and Steketee, 2005) (Williams and Steketee, 2004). Relatedly, mPFC dopamine D2 and Group II metabotropic glutamate receptor (mGluR) function was found to be reduced in rats following repeated cocaine exposure (Beyer and Steketee, 2002; Xie and Steketee, 2009). Additionally, a reduction in a Group II mGluR-mediated form of mPFC long-term 
depression (LTD) was observed in slices from rats repeatedly treated with cocaine (Huang et al., 2007). Repeated cocaine was shown to alter the excitability of mPFC pyramidal projection neurons during early and late withdrawal (Nasif et al., 2005), a phenomenon the authors attributed to a decrease in membrane afterhyperpolarization and an increase in L-type calcium channel activity (Ford et al., 2009; Hu, 2007). Together, these studies suggest repeated cocaine induces early and late changes in the mPFC at the neurotransmitter and cellular level that may ultimately alter mesolimbic transmission in a manner that facilitates drug-seeking.

The role of the $\mathrm{mPFC}$ in executive function and its projections to addictionrelated regions like the VTA and NAc easily inspires the question of whether $\mathrm{mPFC}$ dysfunction contributes to the loss-of-control over drug-seeking behavior seen in cocaine addicts. Indeed, imaging studies have demonstrated an overall reduction in $\mathrm{mPFC}$ function in addicts that can be remedied by drug exposure (Goldstein and Volkow, 2011). Cocaine addicts showed a reduction in ACC activity relative to non-addicts during the inhibitory-control-measuring Go/no-go task that correlated with poorer performance (Kaufman et al., 2003). Further, cocaine addicts' performance on the Stroop task, a measure of overall mPFC function, was significantly lower than that of non-addicts (Bolla et al., 2004) and pre-rehabilitation Stroop performance was found to predict treatment outcome (Brewer et al., 2008; Goldstein and Volkow, 2011). Addicts' deficiencies in the Go/no-go task and associated ACC hypoactivity could be corrected via intravenous cocaine administration (Garavan et al., 2008). A similar rectification was observed in the Stroop task following oral methylphenidate, a mild stimulant and DAT antagonist (Goldstein et al., 2010). Cocaine addicts also appear to place less value on non-drug rewards than non-addicts. For example, one study assessing this found significantly less $\mathrm{mPFC}$ activation following the acquisition of a monetary reward in addicts relative to controls (Goldstein et al., 2007). This is consistent with the relatively large number of animal studies that demonstrate consistent selection of drug over nondrug rewards following repeated cocaine exposure, even when the non-drug rewards are vital to the animal's survival (Goldstein and Volkow, 2011). Taken together, this evidence suggests repeated cocaine exposure results in an $\mathrm{mPFC}$ that is generally less responsive to non-drug-related stimuli. If this is the case, treatments for cocaine addiction designed to rectify cocaine-induced adaptations in the $\mathrm{mPFC}$ will be markedly more promising than those that do not. Therefore, an understanding of the changes that occur in the $\mathrm{mPFC}$ following repeated cocaine exposure is necessary. To gain such an understanding, the mechanisms generating the marked polarization in $\mathrm{MPFC}$ excitability between cocaine-related and unrelated scenarios should be uncovered. Given that glutamate is the most pervasive and influential excitatory transmitter in the brain and responsible for virtually all forms of plasticity, cocaine-induced alterations in the $\mathrm{mPFC}$ glutamatergic system could conceivably lead to the lasting adaptations observed in addicts. 


\section{mPFC mGluR5 and Cocaine Addiction}

As previously mentioned, mPFC glutamate levels are elevated in response to cocaine during early withdrawal but return to baseline by late sensitization (Williams and Steketee, 2004), suggesting that transient neurotransmitter changes may pave the way for more permanent receptor alterations. Also mentioned earlier, studies have demonstrated alterations in intrinsic pyramidal cell membrane properties (Nasif et al., 2005), ion channel attributes (Ford et al., 2009), intracellular signaling (Bowers et al., 2004), plasticity and Group II mGluR function following repeated cocaine exposure, suggesting that long-term aberrations in $\mathrm{mPFC}$ excitability may predominantly be mediated via changes in pyramidal projection cells. Consequently, when we set out to examine potential cocaine-induced alterations in the $\mathrm{mPFC}$ glutamate system, we wanted to focus on an element capable of effecting long-term changes in the cell.

mGluR5 is a member of the Group I mGluR family that also includes mGluR1. Selectively located in corticolimbic regions, these Gq/G11-coupled receptors are predominantly postsynaptic in the $\mathrm{mPFC}$ and generally serve to increase the excitability of pyramidal neurons (Homayoun and Moghaddam, 2010; Kew and Kemp, 2005). There are three primary reasons we were interested in the role of mGluR5 in cocaine-induced mPFC alterations. First, mGluR5-null mice do not exhibit a sensitized locomotor response to repeated cocaine (Chiamulera et al., 2001) and several studies have shown that systemic mGluR5 antagonism prevents various facets of addiction in rodents, such as reinstatement and sensitization (Martin-Fardon and Weiss, 2012); (Platt et al., 2008). mGluR5 manipulation in reward-related brain regions has also affected addictive behavior in rodents. For example, NAc mGluR5 blockade prevented and mGluR5 stimulation augmented cocaine-seeking behavior in a self-administration paradigm (Wang et al., 2012). Another intriguing study that selectively knocked down mGluR5 in D1-expressing neurons found that, while the affected mice still self-administered cocaine, cue-induced reinstatement was impaired, leading the authors to surmise that mGluR5 activation on D1-expressing cells is necessary for the assignment of drug-related importance to previously neutral stimuli (Novak et al., 2010).

Secondly, as previously mentioned, alterations in mPFC pyramidal cell excitability and consequent changes in communication between the $\mathrm{mPFC}$ and the NAc and VTA may contribute significantly to resilient drug-seeking behavior observed in addicts. mGluR5 activation in thalamic, hippocampal, and nigral slices induces excitatory postsynaptic potentials (EPSPs) and can lead to depolarization and increased firing frequency (Awad et al., 2000; Homayoun and Moghaddam, 2010). Given that mPFC projection neurons are hyperexcitable in response to cocaine following repeated cocaine exposure, increased mGluR5 activation may contribute to this excitability.

Relatedly, our third reason for investigating mGluR5 is its purported modulatory influence on neuronal firing. One study demonstrated that in vivo mGluR5 blockade via antagonist MPEP in the $\mathrm{mPFC}$ prevented firing of roughly $50 \%$ of pyramidal neurons (Homayoun and Moghaddam, 2006). The authors noted that MPEP preferentially prevented the firing of cells that possessed a greater baseline firing level (Homayoun and 
Moghaddam, 2010), which they attested suggests mGluR5 may greatly influence the overall regional output. As mentioned earlier, repeated cocaine exposure appears to result in an $\mathrm{mPFC}$ that is hypoactive in response to non-drug stimuli, but hyperactive in response to cocaine and its cues. That said, it is tempting to speculate that pharmacological mGluR5 inhibition or modulation could ultimately attenuate the influence of cocaine-related stimuli on drug-seeking behavior by reducing the excessive firing of $\mathrm{mPFC}$ pyramidal neurons that ensues when an addicted individual encounters such stimuli. Of clinical importance is the evidence suggesting mGluR5 modulation (not antagonism) can fine tune elements of neuronal behavior without disrupting overall transmission as would occur with ionotropic glutamate receptors, and such modulatory drugs have shown promise in attenuating drug-seeking behavior in animals (Olive, 2009). Consequently, further research into the role of mGluR5 in cocaine-induced neuroplastic changes in the mPFC could lead to safe and effective pharmacotherapies for addiction.

\section{Summary and Rationale}

A functional $\mathrm{mPFC}$ enables an organism to effectively evaluate its environment and make advantageous long-and short-term decisions. Evidence suggests repeated cocaine leads to lasting changes in the $\mathrm{mPFC}$ and it is possible that these alterations are responsible for addicts' inability to regulate drug-seeking behavior. Adaptations in $\mathrm{mPFC}$ pyramidal projection neurons can result in increased and decreased output to the VTA and NAc in response to different types of stimuli. Given that glutamate is the most abundant excitatory neurotransmitter in the brain and glutamatergic transmission mediates the vast majority of neural plasticity, the current project focuses on the role of mGluR5 in cocaine-induced mPFC neuroadaptations. mGluR5-null mice do not sensitize to cocaine and mGluR5 antagonism has been repeatedly shown to reduce drug-seeking behavior in laboratory animals. Further, mGluR5 stimulation has been demonstrated to exert both a modulatory and an excitatory effect on the cell. Therefore, the current project described below focuses on the effect of mPFC mGluR5 manipulations on cocaine sensitization, self-administration, and neurotransmission in the mPFC, VTA and NAc. We hypothesize mPFC mGluR5 activation contributes to pyramidal neuronal excitability in sensitized animals and consequently influences behaviors and neurochemical profiles associated with cocaine addiction.

\section{Specific Aims}

1) To examine the effects intra-mPFC mGluR5 manipulation on behavioral sensitization to cocaine

2) To compare mPFC, VTA and NAc glutamate levels in response to intra-mPFC mGluR5 stimulation in sensitized and control animals

3) To test the ability of mPFC mGluR5 antagonism to attenuate drug-seeking behavior in a self-administration paradigm 


\section{Chapter 2. Examination of a Role for Metabotropic Glutamate Receptor 5 in the Medial Prefrontal Cortex in Cocaine Sensitization in Rats}

\section{Introduction}

Chronic cocaine exposure has been shown to induce enduring neuroadaptations that collectively result in the loss of control over drug-seeking behavior despite multitudinous adverse consequences (Nestler, 2005). Behavioral sensitization, the augmented locomotor response to cocaine following repeated exposure, has been shown to have predictive validity for other indicators of addiction such as reinstatement, possibly due to shared cocaine-induced modifications in neurocircuitry (Kalivas et al., 1998; Robinson and Berridge, 1993; Steketee and Kalivas, 2011). The human medial prefrontal cortex's (mPFC) mediation of executive processes such as decision-making, long-term planning, impulse control and outcome prediction, along with its dense connectivity with the ventral tegmental area (VTA) and nucleus accumbens (NAc) (D'Esposito and Chen, 2006) raised interest as to whether chronic cocaine exposure induces alterations in this region. Indeed, studies subsequently found that neurochemical and electrophysiological modifications (Huang et al., 2007; Nasif et al., 2005; Steketee, 2005) occur in the mPFC following sensitization. Of particular relevance to this study is the evidence suggesting $\mathrm{mPFC}$ pyramidal neurons are hyperexcitable in response to cocaine in sensitized animals (Nasif et al., 2005). Glutamatergic output from the mPFC to the VTA and NAc is necessary for the initiation and expression of sensitization (Li et al., 1999) respectively, and so it is plausible that heightened excitatory input to such limbic structures represents a critical neuroadaptation that follows repeated cocaine exposure. Consequently, an understanding of the mechanisms that induce physiological changes in mPFC pyramidal cells could uncover avenues for the pharmacological prevention of relapse.

In rodents, behavioral sensitization is observable as early as 1 day and at least as late as 1 year post repeated cocaine exposure however the processes that give rise to it are believed to change over time (Steketee, 2005). Cocaine-induced glutamate release in the $\mathrm{mPFC}$, for example, is elevated in sensitized rats 1 and 7 days following repeated cocaine treatment, but returns to pre-drug exposure levels by 30 days post-exposure (Williams and Steketee, 2004). These early changes in neurotransmitter levels may be critical towards generating enduring alterations in $\mathrm{mPFC}$ responsivity. Indeed, $\mathrm{mPFC}$ Group II metabotropic glutamate receptor function is reduced during late sensitization, which should decrease inhibitory tone onto pyramidal neurons (Xie and Steketee, 2008). Thus, this suggests that, in the mPFC, changes in glutamate levels may mediate early sensitization, while glutamate receptor modifications may mediate late sensitization (Steketee, 2005).

Group I metabotropic glutamate receptors (mGluRs) are primarily located postsynaptically in the $\mathrm{mPFC}$ and serve to increase the excitability of pyramidal projection neurons (Kew and Kemp, 2005). Group I mGluRs are Gq/G11-coupled and contain two subtypes: mGluR1 and mGluR5 (Kew and Kemp, 2005)). mGluR5 knock- 
out mice do not exhibit cocaine sensitization and allosteric modulators of this receptor have proven effective agents for preventing relapse to cocaine in animal studies (Kenny et al., 2003; Olive, 2009). Additionally, stimulation of Group I mGluRs has been shown to result in increased mPFC glutamate levels, which could, in turn, augment neuronal excitability (Bandrowski et al., 2003; Melendez and Kalivas, 2003). Collectively, this suggests that activation of mPFC Group I mGluRs may play a role in the behavioral sensitization to cocaine. Therefore, to better understand the contribution of mPFC Group I mGluRs to sensitization, experiments in this report tested whether repeated activation of Group I mGluRs in the mPFC could induce cross-sensitization to cocaine and whether this cross-sensitization was dependent on glutamatergic input from the mPFC to the VTA. Furthermore, selective mGluR1 and mGluR5 antagonists were co-administered with DHPG to determine which receptor was mediating cross-sensitization. Finally, the effects of mPFC Group I mGluR antagonism on the initiation and expression of cocaine sensitization were assessed.

\section{Materials and Methods}

\section{Animals and Surgery}

Male Sprague Dawley rats (Harlan, Indianapolis, IN) weighing 250-300 grams at the time of surgery were housed under a 12-hour light/dark cycle and given free access to food and water. Animals were anesthetized with a ketamine $(80 \mathrm{mg} / \mathrm{kg})$ and xylazine $(6.0$ $\mathrm{mg} / \mathrm{kg}$ ) cocktail ( $1.0 \mathrm{ml} / \mathrm{kg}$ ) and placed in a stereotaxic apparatus (Kopf Instruments). An incision was made in the scalp and the skin was pulled back to expose the skull. The area was disinfected and burr holes were drilled into the skull. Three stainless steel screws that would later anchor the dental acrylic (Jet-Set, Lang Dental, Germany) skullcap were inserted into the burr holes. Guide cannulae were bilaterally implanted $1 \mathrm{~mm}$ above the $\mathrm{mPFC}(\mathrm{A} / \mathrm{P}+3.2 \mathrm{~mm}, \mathrm{M} / \mathrm{L} \pm 0.6 \mathrm{~mm}, \mathrm{D} / \mathrm{V}-3.5 \mathrm{~mm})$ and/or VTA $(\mathrm{A} / \mathrm{P}-4.8 \mathrm{~mm}, \mathrm{M} / \mathrm{L}$ $\pm 0.6 \mathrm{~mm}, \mathrm{D} / \mathrm{V}-7.4 \mathrm{~mm}$ ) and dental acrylic was applied to secure them. Obturators (14 $\mathrm{mm}, 32$ gauge stainless steel) were inserted into the cannulae to prevent their blockade. Animals were housed individually following surgery and given one week to recover prior to the start of experiments. All procedures were carried out in accordance with the National Institutes of Health Guide for the Care and Use of Laboratory Animals and approved by the University of Tennessee Health Science Center Animal Resources Advisory Committee.

\section{Injections and Behavior}

Animals were placed in activity chambers $(45 \times 24 \times 19 \mathrm{~cm})$ for 60 min prior to injections to allow for proper adaptation. Drugs were administered into the $\mathrm{mPFC}$ and/or VTA using a Sage syringe pump that held two $1 \mu 1$ syringes attached to stainless steel injectors $(15 \mathrm{~mm}, 32$ gauge) by PE 20 tubing and delivered drug at a rate of $0.5 \mu \mathrm{l} / \mathrm{min}$ and a volume of $0.5 \mu 1 /$ side. Injectors were left in place for $20 \mathrm{~s}$ following injections and 
obturators were again inserted. In the experiments where a systemic injection followed a microinjection, cocaine $(15 \mathrm{mg} / \mathrm{kg})$ or saline $(1.0 \mathrm{ml} / \mathrm{kg})$ was injected intraperitoneally 5 minutes after the microinjection. Animals were then placed back in the activity chambers and locomotor activity was monitored through a Digiscan system (Accuscan, Columbus, $\mathrm{OH}, \mathrm{USA}$ ) as previously described (Beyer and Steketee 2002). Data were collected for 120 min post-injection and organized into 15 min bins.

\section{Histology and Statistics}

Following studies, animals were heavily anesthetized with sodium pentothal (333 $\mathrm{mg} / \mathrm{kg}$ ) and perfused by intracardiac administration of phosphate-buffered saline $(50 \mathrm{ml})$ and $10 \%$ formaldehyde $(50 \mathrm{ml})$. Brains were sectioned, mounted onto gelatin-coated slides, stained with cresyl violet, and viewed through a light microscope to verify cannulae and injector placement as determined by a rat brain atlas (Paxinos and Watson 1997). The time-course of the locomotor activity was analyzed using a two-way (treatment and time) repeated measure (time) ANOVA. Multiple comparisons were made using a modified least significant differences test (Milliken and Johnson 1984).

\section{Drugs}

Cocaine hydrochloride was purchased from Sigma Chemical Co. (St. Louis, MO, USA). (s)-3, 5-DHPG (dihydroxyphenylglycine), MTEP hydrochloride (3((2-methyl-4thiazolyl)ethynyl)pyridine hydrochloride), CNQX (6-cyano-7-nitroquinoxaline-2,3dione), and YM 298198 hydrochloride (6-Amino-N-cyclohexyl-3-methylthiazolo[3,2a]benzimidazole-2-carboxamide hydrochloride) were all purchased from TOCRIS Bioscience (Ellisville, MO, USA). All drugs were diluted with isotonic saline (0.9 units sodium chloride). DHPG dosages were determined based on dose-response experiments conducted in our lab. Dosages of MTEP, YM298198, and CNQX were selected based on previous reports (Kumaresan et al., 2009; Titley et al., 2010; Torregrossa et al., 2008)

\section{Experimental Design}

\section{Cross-Sensitization Experiments}

Daily DHPG/Cocaine Test. This set of experiments was designed to measure whether repeated intra-mPFC microinjections of the Group I mGluR agonist DHPG could induce cross-sensitization to systemic cocaine in naïve animals. DHPG (15 $\mathrm{nmol} / \mathrm{side}$ ) or saline was microinjected into the mPFC once daily for 4 consecutive days. Seven days following the final injection, a challenge injection of cocaine was delivered $(15 \mathrm{mg} / \mathrm{kg}$, i.p.) and locomotor activity was monitored for $120 \mathrm{~min}$.

$D H P G+M T E P$ and $D H P G+Y M 298198$. This set of experiments determined which of the two Group I mGluR subtypes (mGluR1 or mGluR5) was responsible for 
DHPG-induced cross-sensitization to cocaine. In the experiments examining the role of mGluR5 in DHPG-induced cross-sensitization, DHPG (15 nmol/side) alone, DHPG+Group I mGluR antagonist MTEP (15 nmol/side), MTEP (15 nmol/side) alone, or saline was microinjected into the mPFC for 4 consecutive days and motor activity in response to a systemically administered challenge injection of cocaine was assessed 7 days following the final microinjection.

In the experiments examining the role of mGluR1 in DHPG-induced crosssensitization, DHPG (15 nmol/side), DHPG+Group I mGluR1 antagonist YM298198 (15 $\mathrm{nmol} / \mathrm{side})$, YM298198 alone ( $15 \mathrm{nmol} / \mathrm{side})$, or saline was microinjected into the $\mathrm{mPFC}$ for 4 consecutive days and motor activity in response to a systemically administered challenge injection of cocaine was assessed 7 days following the final microinjection. Separate groups of animals were used for the MTEP and YM298198 experiments.

Daily Cocaine/DHPG Test. These experiments were designed to determine whether intra-mPFC DHPG produced a sensitized motor response in cocaine-sensitized rats relative to saline controls. Data from these experiments was also used to rule out the possibility that a single dose of DHPG induces heightened motor activity. In these experiments, rats were treated with systemic cocaine $(15 \mathrm{mg} / \mathrm{kg}$, i.p.) or saline for 4 consecutive days. Following 7 or 21 days post-cocaine exposure, DHPG was infused into the $\mathrm{mPFC}$ and motor activity was monitored for $120 \mathrm{~min}$.

\section{VTA Experiments}

These experiments measured the effects of VTA AMPA receptor antagonism on intra-mPFC DHPG-induced cross-sensitization to cocaine. The AMPA receptor antagonist CNQX ( $1 \mathrm{nmol} / \mathrm{side}$ ) or saline was microinjected into the VTA 5 min prior to microinjections of DHPG or saline into the MPFC for four consecutive days. A challenge injection of cocaine was administered 7 days following the final microinjection and motor activity was monitored for $120 \mathrm{~min}$.

\section{Sensitization Experiments}

Initiation. This set of experiments measured the effects of mGluR5 antagonism on the initiation of cocaine sensitization. On the first day of initiation experiments, animals were placed in the activity chambers for $60 \mathrm{~min}$ before either mGluR5 antagonist MTEP $(15 \mathrm{nmol} / \mathrm{side})$ or saline was microinjected into the $\mathrm{mPFC}$ five minutes prior to an i.p. injection of saline. Locomotor activity was then monitored for $120 \mathrm{~min}$ and these data were later analyzed for the purpose of determining any nonspecific effects of the antagonists. On the second day of initiation experiments, animals were placed in activity chambers for $60 \mathrm{~min}$ and then received an $\mathrm{mPFC}$ microinjection of either MTEP or saline that preceded by $5 \mathrm{~min}$ a systemic injection of saline or cocaine $(15 \mathrm{mg} / \mathrm{kg}$, i.p.). Locomotor activity was then recorded for $120 \mathrm{~min}$. On the $3^{\text {rd }}-5^{\text {th }}$ days of these experiments, animals received the same treatment they received on the second day and were immediately placed back in their home cages following injections. Motor activity in 
response to a challenge injection of saline or cocaine was measured six or seven days following the final microinjection, respectively.

Expression. This set of experiments measured the effects of mGluR5 antagonism on the expression of cocaine sensitization at 7 and 21 of abstinence. Animals were given cocaine $(15 \mathrm{mg} / \mathrm{kg}$, i.p.) or saline injections for 4 consecutive days. Seven or 21 days following the last of the daily cocaine injections, mGluR5 antagonist MTEP (15 $\mathrm{nmol} /$ side) or saline was microinjected into the $\mathrm{mPFC}$ five min prior to a challenge injection of cocaine $(15 \mathrm{mg} / \mathrm{kg}$, i.p.), and motor activity was monitored for $120 \mathrm{~min}$. A day prior to the cocaine challenge, animals received an $\mathrm{MPFC}$ microinjection of either saline or MTEP (15 nmol/side) 5 min prior to a systemic injection of saline and locomotor activity was monitored for $120 \mathrm{~min}$.

\section{Results}

\section{Group I mGluR Stimulation in the mPFC Induces Cross-Sensitization to Cocaine}

Animals that had received once daily $\mathrm{mPFC}$ microinjections of the Group 1 mGluR agonist DHPG over 4 consecutive days were significantly more active in response to cocaine 1 week later than were their saline counterparts (Treatment $\mathrm{F}$ $(1,14)=6.425, \mathrm{p}=0.0238$; Time $\mathrm{F}(7,98)=25.54, \mathrm{p}<0.0001$; Interaction $\mathrm{F}(7,98)=3.213$, $\mathrm{p}=0.0042$ ), as evidenced through the monitoring of motor activity (photocell counts) in response to a challenge injection of cocaine $(15 \mathrm{mg} / \mathrm{kg}$, i.p.) over a $120 \mathrm{~min}$ period (Figure 1). The mean cocaine-induced activity level measured from DHPG-pretreated animals was comparable to that from cocaine-sensitized animals, suggesting that Group I mGluR stimulation in the mPFC results in cross-sensitization to cocaine.

\section{Cross-Sensitization Is Mediated by mGluR5}

In replication of the experiments above, repeated injections of DHPG into the $\mathrm{mPFC}$ induced cross-sensitization to cocaine (Figure 2). Co-administration of DHPG and the mGluR5 antagonist MTEP inhibited cross-sensitization (Treatment $\mathrm{F}(3,26)=3.518$, $\mathrm{p}=0.0290$; Time $\mathrm{F}(7,182)=51.67, \mathrm{p}<0.0001$; Interaction $\mathrm{F}(21,182)=2.734, \mathrm{p}=0.0002$; Figure 2a). By contrast, co-administration of DHPG with mGluR1 antagonist YM298198 did not inhibit cross sensitization (Figure 2b). Taken together, these findings suggest the observed DHPG-induced cross-sensitization is mediated by mGluR5. Note: The average locomotor activity of the MTEP group was not significantly different from the DHPG group during the first time point due to the high activity level of one animal. The removal of this animal's data from the analysis reveals significant difference between these two groups, however, the absence of infection or inaccurate injector placement in the animal precluded its elimination. 


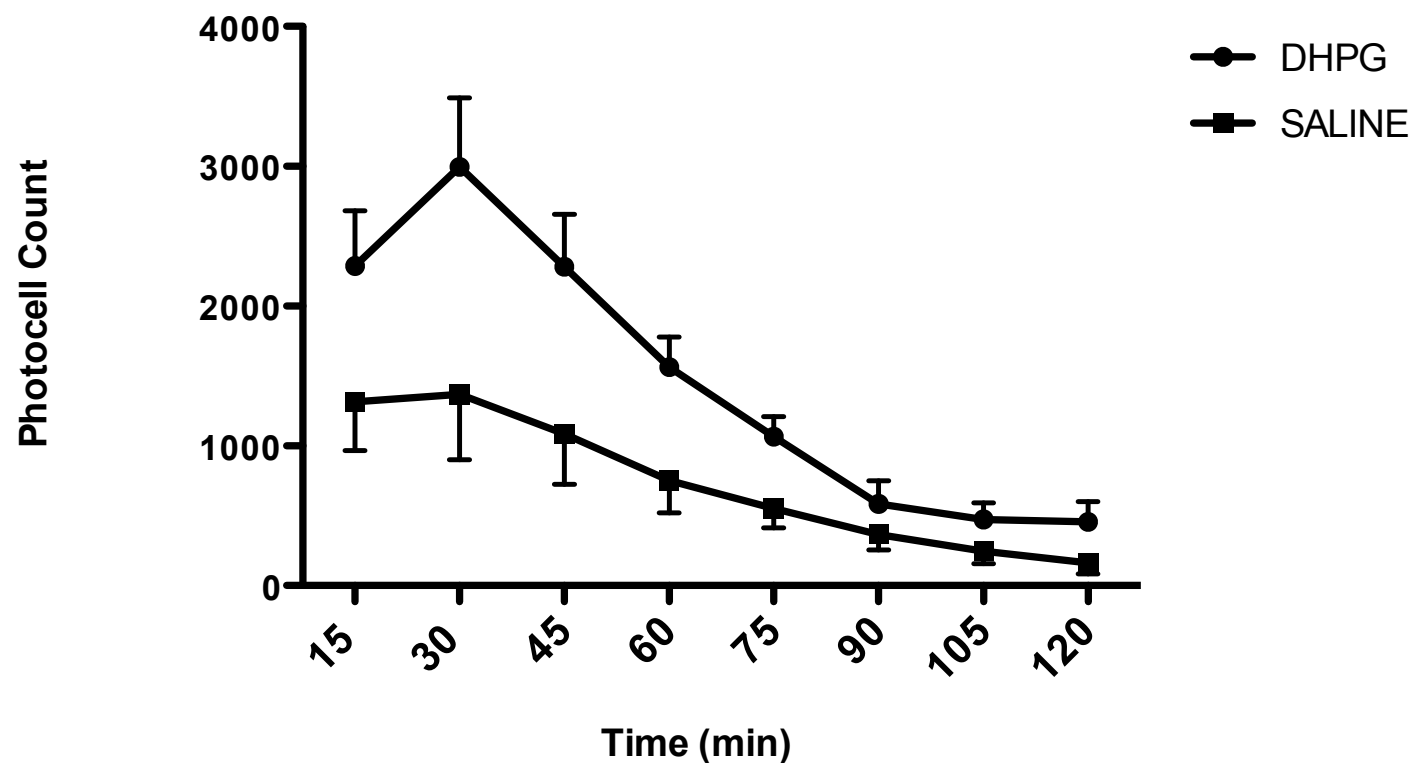

Figure 1. Locomotor Response to a Challenge Injection of Cocaine. Locomotor response (photocell counts) to a challenge injection of cocaine $(15 \mathrm{mg} / \mathrm{kg}$, i.p.) is shown over a 120 min time period. Animals received $\mathrm{mPFC}$ microinjections of DHPG (15 $\mathrm{nmol} /$ side $)(\mathrm{n}=8)$ or saline $(\mathrm{n}=8)$ for 4 consecutive days 7 days prior to the cocaine challenge. ${ }^{*} p<0.05$ compared to saline. 

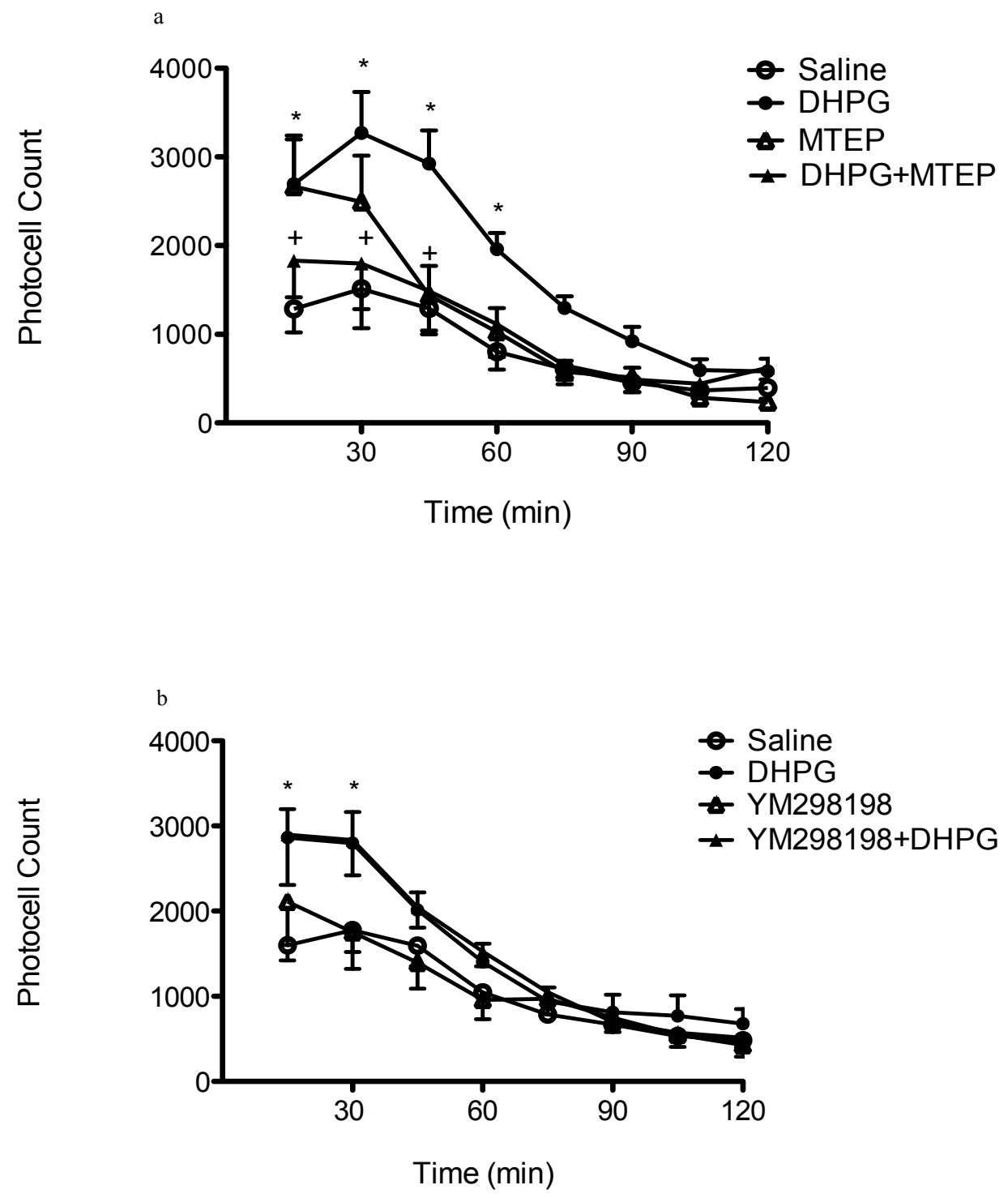

Figure 2. DHPG-Induced Cross-Sensitization Is Mediated by mGluR5. a) Locomotor response to a challenge injection of cocaine is shown over a $120 \mathrm{~min}$ time period. Animals received mPFC microinjections of DHPG+MTEP (15 nmol/side) ( $\mathrm{n}=8)$, DHPG $(15 \mathrm{nmol} /$ side $)(\mathrm{n}=8)$, MTEP $(15 \mathrm{nmol} / \mathrm{side})(\mathrm{n}=8)$, or saline $(\mathrm{n}=8)$ for 4 consecutive days one week prior to the cocaine challenge. ${ }^{*} \mathrm{p}<0.05$ compared to saline. ${ }^{+} \mathrm{p}<0.05$ compared to DHPG.b) Locomotor response to a challenge injection of cocaine is shown over a 120 min time period. Animals received mPFC microinjections of DHPG+YM198298 (15 $\mathrm{nmol} / \mathrm{side})(\mathrm{n}=8)$, DHPG (15 nmol/side) $(\mathrm{n}=8)$, YM198298 (15 nmol/side) $(\mathrm{n}=8)$, or saline $(\mathrm{n}=8)$ for 4 consecutive days one week prior to the cocaine challenge. ${ }^{*} \mathrm{p}<0.05$ compared to saline. 


\section{VTA AMPA Receptor Blockade Inhibits DHPG-Induced Cross-Sensitization}

Group I mGluR activation within the mPFC may be important for recruiting the VTA, which is critical for sensitization (Kalivas, 2001). Thus, the AMPA receptor antagonist CNQX or saline was microinjected into the VTA 5 min prior to intra-mPFC DHPG or saline to test whether DHPG-induced cross-sensitization relied on activation of the VTA (Figure 3). In agreement with this idea, intra-VTA CNQX blocked crosssensitization induced by intra-mPFC DHPG, AMPA receptor activation in the VTA is necessary for $\mathrm{mPFC}$ DHPG-mediated cross-sensitization (Treatment $\mathrm{F}(3,21)=5.607$, $\mathrm{p}=0.0005$; Time $\mathrm{F}(7,147)=73.85, \mathrm{p}<0.0001$; Interaction $\mathrm{F}(21,147)=4.460, \mathrm{p}<0.0001)$ (Figure 3).

\section{mPFC mGluR5 Blockade and Cocaine Sensitization}

Given that mPFC mGluR5 inhibition was sufficient to prevent the DHPG-induced cross-sensitization, it was important to test whether the initiation and/or expression of cocaine sensitization similarly relied on mGluR5 in the mPFC. mGluR5 inhibition via mPFC microinjections of MTEP was not sufficient to prevent the initiation of cocaine sensitization . Motor activity in response to a challenge injection of cocaine did not significantly differ between animals that had received saline or MTEP prior to their sensitizing cocaine injections; all animals that had received repeated cocaine exhibited a sensitized response to the cocaine challenge, indicating that mGluR5 blockade in the $\mathrm{mPFC}$ is not sufficient to prevent the establishment of cocaine sensitization (Figure 4).

mGluR5 in the mPFC appears necessary for late, but not early, expression of sensitization. Animals received repeated i.p. injections of saline or cocaine $(15 \mathrm{mg} / \mathrm{kg}) 7$ (Figure 5a) or 21 days (Figure 5b) prior to the cocaine challenge. Animals received an mPFC microinjection of either saline or mGluR5 antagonist MTEP 5 min prior to the cocaine challenge. Animals that had received repeated cocaine exhibited a sensitized response to the challenge regardless of whether they received an $\mathrm{mPFC}$ microinjection of saline or MTEP at 7 days (Treatment $F(3,23)=2.408, p=0.0931$; Time $F(7,161)=107.5$, $\mathrm{p}<0.0001$; Interaction $\mathrm{F}(21,161)=6.121, \mathrm{p}<0.0001)(\mathrm{a})$, while only animals that received repeated cocaine and a saline microinjection before the cocaine challenge exhibited a sensitized response at 21 days (Treatment $\mathrm{F}(3,25)=3.515$, $\mathrm{p}=0.0297$; Time $\mathrm{F}(7$. $175)=82.25, p<0.0001$; Interaction $F(21,175)=6.195, p<0.0001)$ (b). Our results suggest mGluR5 antagonism in the mPFC is sufficient to prevent the expression of sensitization at 21 , but not 7 days from the last cocaine injection, suggesting mGluR5 activity in the $\mathrm{mPFC}$ plays a role in the expression of late sensitization, but is not involved in early expression. 


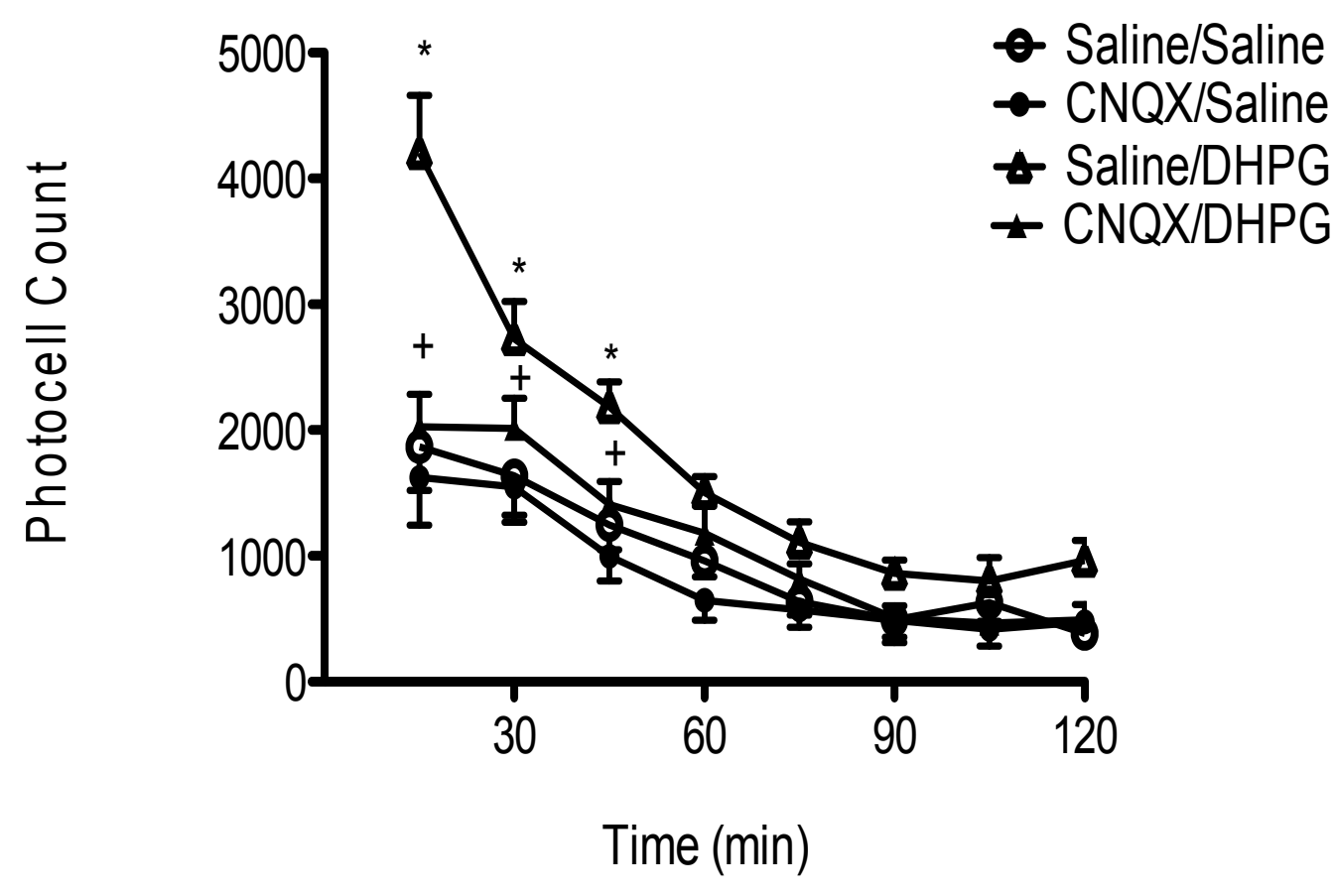

Figure 3. VTA AMPAR Blockade Prevents DHPG-Induced Cross-Sensitization. Locomotor response to a challenge injection of cocaine in shown over a $120 \mathrm{~min}$ time period. Animals received four consecutive daily intra-VTA microinjections of saline or CNQX (1 nmol/side) followed by an intra-mPFC microinjection of saline or DHPG (15 $\mathrm{nmol} /$ side) five minutes later. ${ }^{*} \mathrm{p}<0.05$ compared to saline. $+\mathrm{p}<0.05$ compared to DHPG. Saline/saline: $\mathrm{n}=6$; saline/CNQX: $\mathrm{n}=6$; saline/DHPG: $\mathrm{n}=6$; DHPG/CNQX: $\mathrm{n}=7$. 


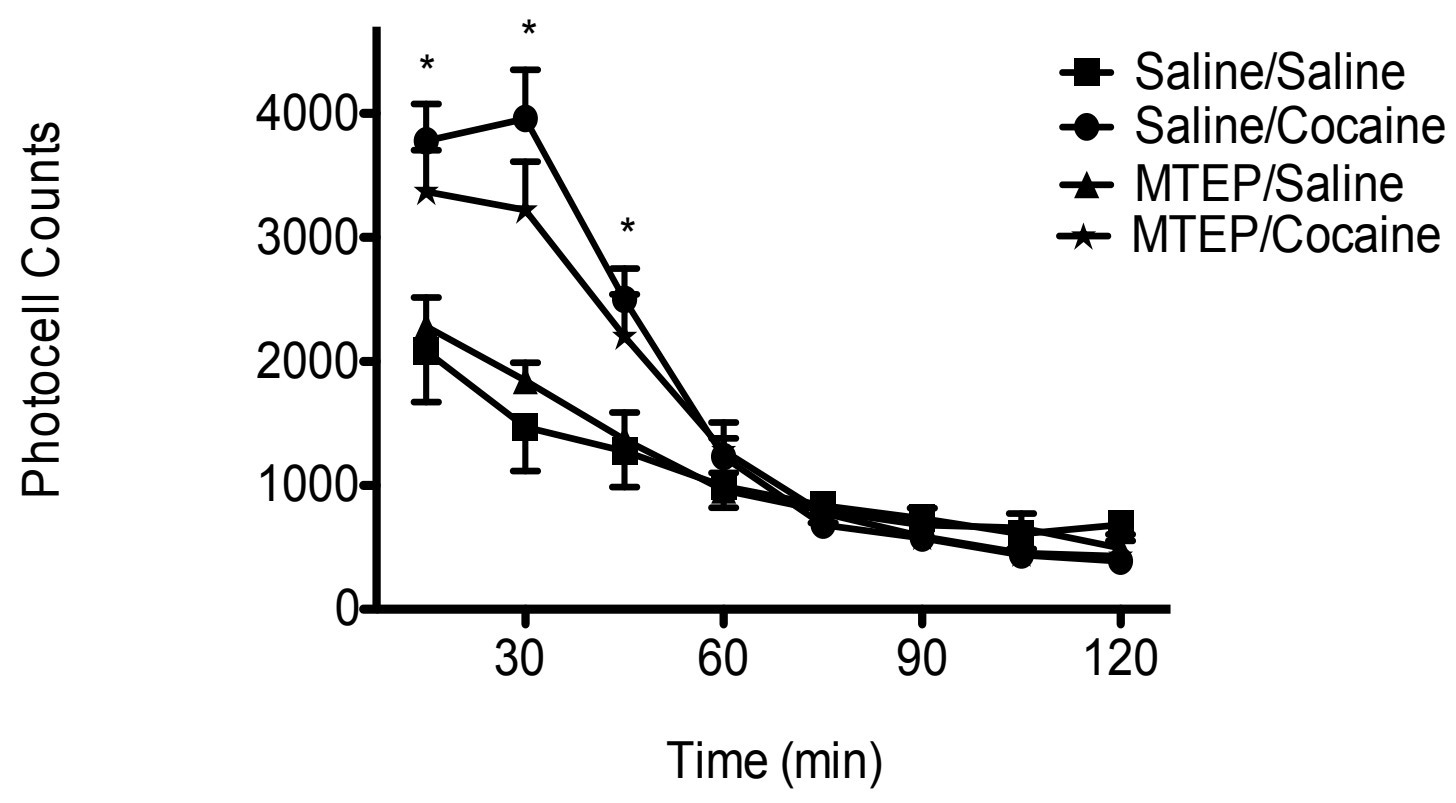

Figure 4. Effect of mPFC mGluR5 Blockade on the Initiation of Sensitization. Locomotor response to a challenge injection of cocaine is shown over a $120 \mathrm{~min}$ time period. Animals received an $\mathrm{mPFC}$ microinjection of MTEP $(15 \mathrm{nmol} / \mathrm{side})$ or saline 5 min prior to systemic cocaine or saline for 4 consecutive days one week prior to the cocaine challenge ( $\mathrm{n}=8$ for all groups). ${ }^{*} \mathrm{p}<0.05$ compared to saline. 

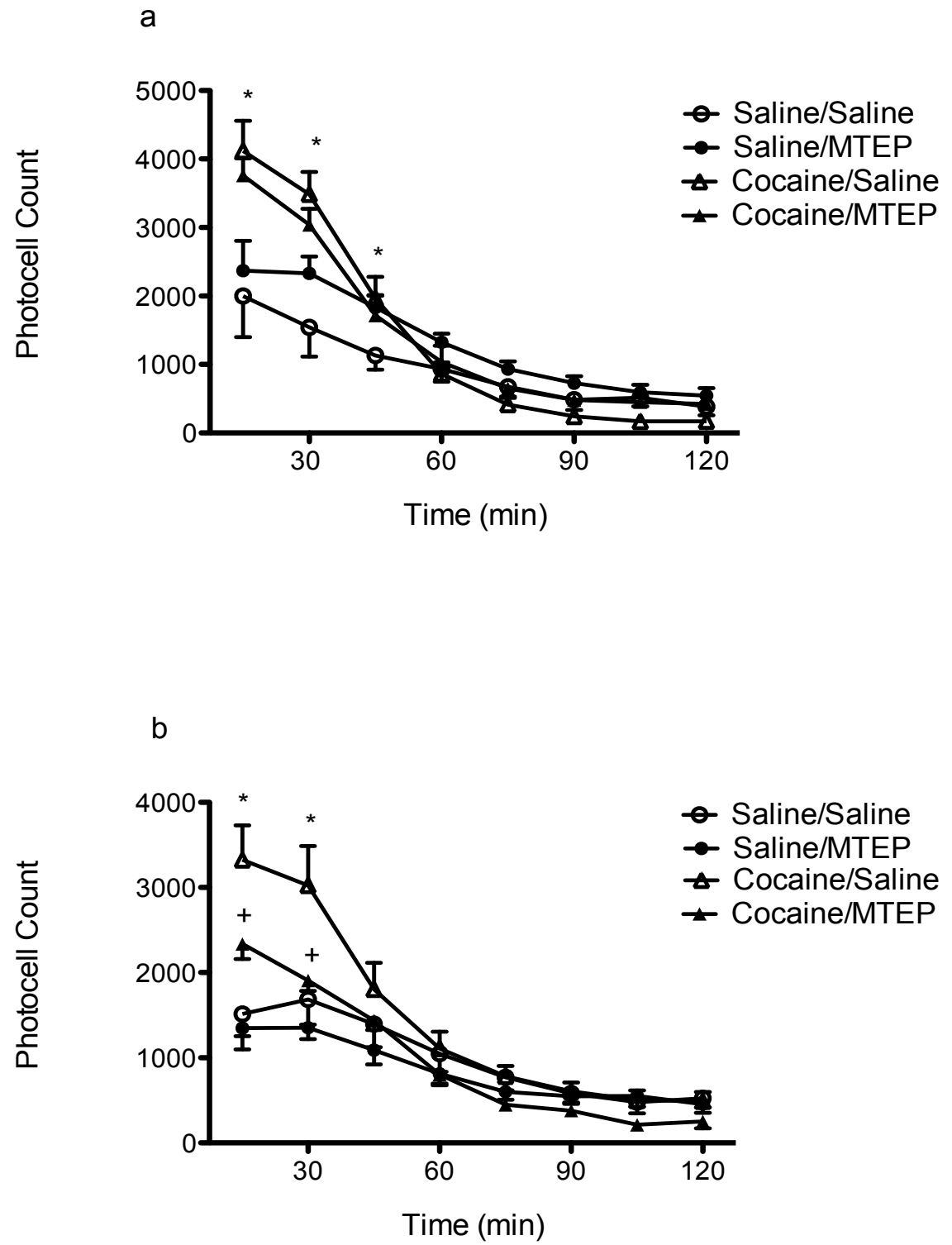

Figure 5. Effect of mPFC mGluR5 Blockade on the Expression of Sensitization.

Locomotor response to a challenge injection of cocaine $(15 \mathrm{mg} / \mathrm{kg}$, i.p.) is shown over a $120 \mathrm{~min}$ time period. Animals received systemic injections of cocaine $(15 \mathrm{mg} / \mathrm{kg}$, i.p.) or saline for four consecutive days 7 (a) or 21 (b) days prior to the cocaine challenge. On the day of the challenge, animals received an mPFC microinjection of MTEP $(15 \mathrm{nmol} / \mathrm{side})$ or saline five minutes prior to cocaine $\left(15 \mathrm{mg} / \mathrm{kg}\right.$, i.p.). ${ }^{*} \mathrm{p}<0.05$ compared to saline/saline. $+\mathrm{p}<0.05$ compared to cocaine/saline. Saline/saline: $\mathrm{n}=9$; saline/cocaine: $\mathrm{n}=10$; MTEP/saline: $\mathrm{n}=7$; MTEP/cocaine: $\mathrm{n}=9$. 


\section{mGluR5 Activation Alone Does Not Produce a Sensitized Response in Sensitized Animals}

Given that intra-mPFC administration of DHPG induced cross-sensitization to cocaine, we tested whether DHPG could elicit a sensitized response in cocaine-sensitized rats. Locomotor activity in response to a challenge mPFC DHPG microinjection did not differ between saline- and cocaine-treated rats at 7 or 21 days following the last cocaine exposure (data not shown). Based on this data, it appears that mGluR5 activation in the $\mathrm{mPFC}$ is not sufficient to elicit a sensitized behavioral response in animals sensitized to cocaine.

\section{Histology}

Histological analysis was performed on the brains of all animals in the study, as described in the methods. Injector sites of animals included in the analysis were located in the prelimbic ( $\mathrm{Cg} 3$ area) or infralimbic regions of the prefrontal cortex (Figure 6a, c). The majority of injector placements were $+3.20 \mathrm{~mm}$ from Bregma. Injector locations for animals included in the VTA experiments were in the VTA, at -5.2 and $-5.3 \mathrm{~mm}$ from Bregma (Figure 6b, d). Within each experimental group, several animals were eliminated from analysis due to infection or incorrect cannulae placement ( $n=24$ total).

\section{Discussion}

The present studies demonstrate that repeated mGluR5 activation in the $\mathrm{mPFC}$ induces a cross-sensitization to cocaine that can be prevented through AMPA receptor blockade in the VTA, suggesting glutamatergic transmission from the mPFC to the VTA is necessary for this cross-sensitization to occur. Furthermore, mPFC mGluR5 blockade prevents the expression of late, but not early, cocaine sensitization, which may indicate that modifications in $\mathrm{mPFC}$ mGluR5 represent one lasting neuroadaptation that results from repeated cocaine exposure.

We found that repeated local activation of group I mGluRs in the mPFC lead to cross-sensitization to cocaine in naïve rats. Further investigation showed that mGluR5, rather than mGluR1, was responsible for this effect and VTA AMPA receptor antagonism prevented it. Our results suggest glutamatergic input from mPFC pyramidal neurons to the VTA mediated the cross-sensitization we observed in response to repeated intra-mPFC DHPG. Glutamate in the VTA is known to be necessary for the initiation of sensitization (Kalivas and Alesdatter, 1993). In addition, sensitization is associated with enhanced glutamate release in the VTA and insertion of AMPA receptors lacking the GluR2 subunit (Fitzgerald et al., 1996; Kalivas and Duffy, 1998). Furthermore, repeated AMPA injections into the VTA (Dunn et al., 2005) have been shown to induce crosssensitization to cocaine. Similarly, as was shown in the present report, repeated $\mathrm{mPFC}$ mGluR5 stimulation and subsequent glutamate release in the VTA may have activated AMPA receptors on VTA dopaminergic output neurons, resulting in dopamine 

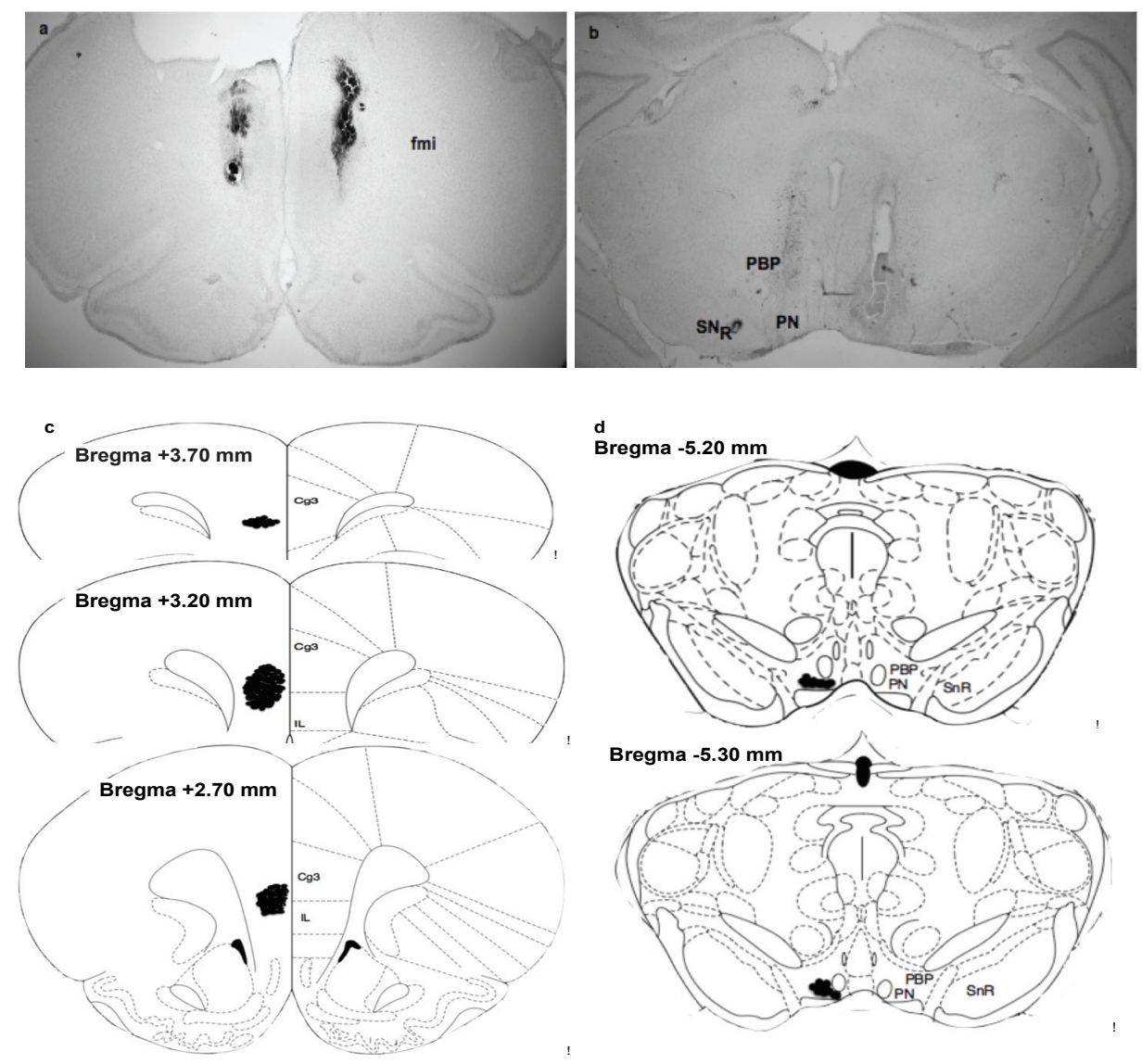

Figure 6. Microinjection Placement in the mPFC and the VTA. Representative photomicrographs and stereotaxic atlas schematics of injection sites in the $\mathrm{mPFC}(\mathrm{a}, \mathrm{c})$ and VTA $(b, d)$. Top panels show injector placement in cresyl violet-stained coronal sections from representative brains. Bottom panels show illustrations of injector placement from all animals included in the analysis. Illustrations were derived from 'The Rat Brain in Stereotaxic Coordinates' (Paxinos and Watson, 1997). fmi=forceps minor of the corpus callosum; $\mathrm{PBP}=$ parabrachial pigmented nucleus; $\mathrm{SNr}=$ substantia nigra reticulata; $\mathrm{PN}=$ paranigral nucleus $\mathrm{Cg} 3=$ cingulate cortex, area 3; $\mathrm{IL}=$ infralimbic cortex. 
release in the nucleus accumbens (Giorgetti et al., 2001), a critical event common to virtually all drugs of abuse (Kuhar, 1991). Therefore, repeated mPFC DHPG administration may mimic some key processes that occur in response to repeated cocaine exposure and lead to sensitization, however, the mechanisms that fuel these processes may differ, as discussed below.

One surprising aspect of our results is that while mGluR5 activation in the mPFC via DHPG is sufficient to induce sensitization, these receptors are not necessary for the initiation of sensitization to cocaine, as evidenced by the failure of the mGluR5 antagonist MTEP to prevent initiation of cocaine-induced sensitization. One possible explanation for this is that while mGluR5 activation of pyramidal projection neurons to the VTA can induce sensitization, cocaine is capable of activating VTA dopaminergic cells independent of mPFC involvement. Indeed, intra-VTA cocaine administration has been shown to induce sensitization, as has the intra-VTA administration of the dopamine re-uptake inhibitor GBR 12909 (Cornish and Kalivas, 2001; Steketee, 1998). Through dopamine transporter blockade, cocaine increases dopamine levels in the VTA. This elevation in dopamine leads to glutamate release via activation of dopamine D1 receptors that consequently activates dopaminergic output neurons in the VTA (Cornish and Kalivas, 2001; Kalivas and Duffy, 1998). Furthermore, the systemic administration of cocaine may result in the activation of $\mathrm{mPFC}$ pyramidal neurons in ways that do not involve, or at least are not limited to, the stimulation of mGluR5. Thus, selective mGluR5 blockade in the mPFC may not be sufficient to block initiation because dopaminergic projection neurons in the VTA are receiving glutamatergic input through means independent of mGluR5 activation in the mPFC.

In contrast to the initiation experiments, our expression studies revealed that mGlur5 in the mPFC is necessary for the long-term expression of cocaine sensitization, but its stimulation alone is not sufficient to elicit a sensitized locomotor response in cocaine-sensitized animals.

Our results show that mGluR5 blockade in the mPFC did not prevent the expression of sensitization at 7 days following repeated cocaine exposure, but did prevent it at 21 days. This may have occurred because cocaine-evoked mPFC glutamate levels are elevated during early sensitization (measured at 7-days after daily cocaine treatment) but return to baseline by late sensitization (30-days post cocaine exposure) (Williams and Steketee, 2004). mGluR5 blockade during early sensitization may not have been sufficient to decrease the excitability of mPFC pyramidal neurons because, in the presence of cocaine, there was enough glutamate available to stimulate AMPA receptors. However, when cocaine-induced glutamate levels normalize during late sensitization, mGluR5 may have a greater influence over neuronal excitability and its blockade at this point may reduce firing to a degree that prevents expression. A related possibility is that other cocaine-induced neurotransmitter and/or receptor changes that occur in the $\mathrm{mPFC}$ during late sensitization depend on mGluR5 function and mGluR5 antagonism at this stage could affect expression. This possibility is discussed in greater detail below. A third reason why mGluR5 blockade may have prevented late but not early expression is that the elevations in cocaine-induced glutamate levels during early sensitization may have 
lead to increased activation of the peri-synaptically located mGluR5 and subsequent changes in receptor number, function, or downstream signaling that effectively altered mGluR5 regulation over neuronal firing in the $\mathrm{mPFC}$. Such cellular modifications may not have been in place until late sensitization.

While blockade of mGluR5 could prevent the expression of late sensitization, stimulation of these receptors with DHPG failed to produce a sensitized locomotor response in animals previously sensitized to cocaine. This result suggests that stimulation of mPFC mGluR5 is not sufficient to produce a locomotor response. While mGluR5 may result in activation of VTA neurons and dopamine release in the NAc, locomotor activity likely requires a greater level of dopamine that may only be achievable through the dopamine transporter blockade produced by cocaine.

Some evidence indicates that mGluR5s, including those in the mPFC, may contribute to cocaine sensitization. Most importantly, mGluR5-null mice do not sensitize to or self-administer cocaine (Chiamulera et al., 2001). Additionally, mGluR5 stimulation results in an increase in mPFC neuronal excitability (Bandrowski et al., 2003; Marek and Zhang, 2008). The goal of the experiments delineated in this report was to uncover a possible role for mPFC mGluR5 in cocaine sensitization that could eventually shed more light on the mechanisms underlying the increased excitability of $\mathrm{mPFC}$ pyramidal neurons following repeated cocaine exposure. Support for an increase in intrinsic $\mathrm{mPFC}$ neuronal excitability comes from evidence demonstrating an increase in L-type calcium channel current (Nasif et al., 2005) and number (Ford et al., 2009) following repeated cocaine administration.

A decrease in inhibitory tone is suggested by studies showing a reduction in mPFC Group II mGluR (Xie and Steketee, 2008), D2 (Beyer and Steketee, 2002; Liu and Steketee, 2011) and GABAB (Steketee and Beyer, 2005) receptor function following repeated cocaine exposure (Bowers et al., 2004). An increase in excitatory drive may result from the elevation in $\mathrm{mPFC}$ dopamine levels that occurs during late sensitization (Williams and Steketee, 2005). Evidence suggests mPFC pyramidal neurons fluctuate between states of high and low excitability and dopamine D1 and D2 receptors play opposing roles in the regulation of these states. D1 receptor activation is believed to increase and then maintain the high excitability state while D2 receptor stimulation is thought to convert pyramidal cells from the high to the low excitability state (Seamans and Yang, 2004; Steketee, 2005). The combination of the reduction in dopamine D2 receptor function and increase in intrinsic neuronal excitability may pave the way for increased dopamine D1 tone and the consequent perpetuation of a high-excitability state in $\mathrm{mPFC}$ pyramidal projection neurons. It has been suggested that mGluR5 is essential for maintaining neuronal firing in the mPFC (Homayoun and Moghaddam, 2010). The prevention of late-stage expression shown in the present study raises the question of whether the regulatory role of $\mathrm{mPFC}$ mGluR5 serves to perpetuate the high-activity state that could result from loss of D2 receptor function following repeated cocaine exposure (Beyer and Steketee, 2002; Bowers et al., 2004). In this scenario, no drug-induced alterations would necessarily have to take place in mGluR5, however, its activation would nevertheless be critical for late expression. Acute mPFC mGluR5 blockade 
immediately prior to cocaine exposure during late sensitization would prevent or attenuate the glutamatergic transmission to the NAc required for expression. Further studies should address whether repeated cocaine leads to changes in mPFC mGluR5 function or coupling, or if mGluR5 simply holds greater influence over pyramidal cell firing due to changes in other receptors or neurotransmitters following sensitization.

A caveat of the present study is the possibility that intra-mPFC-administered drugs activated off-target receptors and the consequent stimulation of these receptors was partially responsible for the effects we observed. While DHPG has proved to be highly selective for Group I mGluRs, it has been shown that it can interact with NMDA receptors under certain conditions (Wisniewski and Car, 2002)). mGluR5 antagonist MTEP is preceded by 2-methyl-6-(phenylethynyl) pyridine hydrochloride (MPEP). In addition to being a selective, noncompetitive mGluR5 antagonist, evidence suggests MPEP acts on mGluR1d and NMDA receptors (Lea and Faden, 2006). By contrast, MTEP has far less potential for off-target effects and is considered the most selective and least problematic of all mGluR5 antagonists (Lea and Faden, 2006)). YM298198 is a potent mGluR1 antagonist with very few off-target effects (Fukunaga et al., 2007). While we recognize the possibility of an unintended site playing a role in our results, our failure to observe DHPG-induced cross-sensitization in animals that additionally received mGluR5 antagonist MTEP suggests mGluR5 in the mPFC was primarily responsible for our findings. AMPA receptor antagonist $\mathrm{CNQX}$ also acts as a weak antagonist at the glycine site of NMDA receptors, however, since our goal was to suppress mPFCmediated glutamatergic input to VTA dopaminergic projection neurons, this action would not compromise the integrity of our findings. Finally, the lack of significant difference in cocaine-induced locomotion between animals that received saline and those that received the drug alone (e.g. mPFC saline vs. mPFC YM298198) suggests the drugs we employed did not induce any measurable changes in behavior.

In conclusion, the experiments delineated in this paper show that mGluR5 activation in the $\mathrm{mPFC}$ can induce a cross-sensitization to cocaine that can be prevented through the blockade of AMPA receptors in the VTA. Furthermore, our studies show that mGluR5 inhibition in the MPFC prevents the expression of late, but not early, behavioral sensitization to cocaine. The suggested involvement of mGluR5 in late-stage sensitization is particularly important because the cocaine-induced changes that may be occurring in this receptor could potentially contribute to the persistence of drug-seeking behavior and propensity for relapse, especially since these alterations are taking place in the PFC. Taken together, the data demonstrate that mPFC mGluR5s are sufficient, but not necessary for the initiation of cocaine sensitization and necessary, but not sufficient for the expression of cocaine sensitization. These results suggest a possible role for $\mathrm{mPFC}$ mGluR5 in the maintenance of the sensitized state, and its associated drug-seeking behavior. 


\section{Chapter 3. Metabotropic Glutamate Receptor 5 in the Medial Prefrontal Cortex: Role in Mesocorticolimbic Glutamate Release in Cocaine Sensitization}

\section{Introduction}

Glutamatergic input from the medial prefrontal cortex (mPFC) to the ventral tegmental area (VTA) and the nucleus accumbens (NAc) is necessary for the initiation and expression, respectively, of the behavioral sensitization to cocaine (Pierce et al., 1998; Steketee, 2003)). It has been demonstrated that mPFC pyramidal projection neurons become hyperexcitable following repeated cocaine exposure (Nasif et al., 2005) (Ford et al., 2009) (Hu, 2007), an event that would ultimately result in increased glutamatergic input to the VTA and the NAc. Imaging studies in human addicts have shown a similar increase in mPFC activity in response to cocaine and related cues as well as a decrease in responsivity to non-drug stimuli (Goldstein and Volkow, 2011). This heightened neuronal attentiveness to cocaine and its cues at the expense of non-drug stimuli may play a significant role in the exceedingly high relapse rate of cocaine addicts. Thus, a comprehensive understanding of the regulation of $\mathrm{mPFC}$ cell excitability in the addicted brain could potentially lead to effective pharmacotherapies to reduce the risk of relapse.

Metabotropic glutamate receptor 5 (mGluR5), a Gq/G11-coupled Group I receptor abundant in corticolimbic regions, has been shown to influence neuronal excitability (Homayoun and Moghaddam, 2010; Kew and Kemp, 2005). mGluR5 stimulation in $\mathrm{mPFC}$, hippocampal, and nigral slices results in excitatory postsynaptic potentials (EPSPs), depolarization, and increased firing frequency (Marek and Zhang, 2008) (Fitzjohn et al., 1999; Homayoun and Moghaddam, 2010; Marino et al., 2001). By contrast, mGluR5 blockade in the mPFC reduced firing frequency by about fifty percent (Homayoun and Moghaddam, 2006). Moreover, the firing rate of neurons with the highest baseline firing rate was reduced following antagonist administration to a greater extent than that of neurons with a lower pre-antagonist firing rate (Homayoun and Moghaddam, 2006; Homayoun and Moghaddam, 2010) possibly suggesting mGluR5 activity can substantially influence the total output of the mPFC. In recent years, studies have implicated mGluR5 in cocaine addiction. mGluR5-null mice do not sensitize to cocaine (Chiamulera et al., 2001) and systemic administration of mGluR5 antagonists prevents sensitization and reinstatement (Martin-Fardon and Weiss, 2012; Platt et al., 2008). Selective manipulation of mGluR5 in reward-processing brain regions has also affected addiction-related behaviors. mGluR5 blockade in the NAc prevented drugseeking behavior, while mGluR5 stimulation enhanced it (Wang et al., 2012). In the $\mathrm{mPFC}$, repeated mGluR5 activation induced cross-sensitization to cocaine, while mGluR5 antagonism attenuated cocaine-induced locomotor activity in sensitized rats during late expression (Timmer and Steketee, 2012). Impaired cue-induced reinstatement was demonstrated following the selective knock-down of mGluR5 in dopamine D1 receptor-expressing neurons, suggesting mGluR5 is important in the formulation of associations between cocaine and previously unrelated stimuli (Novak et al., 2010). 
Taken together, the abovementioned evidence suggests mGluR5 activation in the $\mathrm{mPFC}$ may influence pyramidal cell output and consequently alter glutamatergic input to the VTA and NAc. The present study examined the effects of mPFC mGluR5 activation on glutamate levels in the mPFC, VTA, and NAc during early and late sensitization.

\section{Materials and Methods}

\section{Animals and Surgery}

All animal procedures were carried out in accordance with the National Institutes for Health Guide for the Care and Use of Laboratory Animals and all experiments were approved by the University of Tennessee Health Science Center Animal Resources Advisory Committee. Male Sprague-Dawley rats (Harlan, Indianapolis, IN) weighing 275-300 g at the time of surgery were housed under a 12-hour light/dark cycle and provided ad libitum access to food and water. Animals were anesthetized with a ketamine hydrochloride $(80 \mathrm{mg} / \mathrm{kg}$, i.p.) and xylazine $(6 \mathrm{mg} / \mathrm{kg}$, i.p.) cocktail and placed in a stereotaxic instrument (Kopf Instruments). Microdialysis cannulae (20 gauge, $14 \mathrm{~mm}$, stainless steel) were unilaterally placed $3 \mathrm{~mm}$ above the $\mathrm{mPFC}(\mathrm{A} / \mathrm{P}+3.2$, and $\mathrm{M} / \mathrm{L}+.6$ $\mathrm{mm}$ from bregma; $-1.5 \mathrm{~mm}$ from dura) and either the VTA (A/P -4.8 mm and $\mathrm{M} / \mathrm{L}+.6$ $\mathrm{mm}$ from bregma; $-5.4 \mathrm{~mm}$ from dura) or NAc (A/P $-1.4 \mathrm{~mm}$ and $\mathrm{M} / \mathrm{L}+1.4 \mathrm{~mm}$ from bregma; $-5.0 \mathrm{~mm}$ from dura). Obturators ( $14 \mathrm{~mm}, 25$ gauge, stainless steel) were inserted in the cannulae to prevent occlusion. Animals were given at least seven days for recovery prior to the commencement of experiments.

\section{Cocaine Pretreatment}

Intraperitoneal injections of either cocaine $(15 \mathrm{mg} / \mathrm{kg})$ or saline $(1 \mathrm{~mL} / \mathrm{kg})$ were administered in the animals' home cages for four consecutive days, with the fourth injection day preceding the microdialysis experiment by one, seven, or twenty-one days. Distinct groups of animals were used for each condition.

\section{In Vivo Microdialysis}

Microdialysis probes ( $2 \mathrm{~mm}$ active membrane) were inserted into the cannulae and dialysis buffer $(2.7 \mathrm{mM} \mathrm{KCl}, 140 \mathrm{mM} \mathrm{NaCl}, 1.2 \mathrm{mM} \mathrm{CaCl}, 1.2 \mathrm{mM} \mathrm{MgCl} ; \mathrm{pH}: 7.4$ with phosphate-buffered saline) began infusing three hours prior to the start of sample collection. Samples were collected every 20 minutes in microcentrifuge tubes containing $10 \mathrm{uL}$ of $0.05 \mathrm{mM} \mathrm{HCL}$. Four initial baseline samples were collected prior to Group I mGluR agonist DHPG (dihydroxyphenylglycine; TOCRIS) infusion through the dialysis probe. Three concentration $(0.5 \mathrm{mM}, 5 \mathrm{mM}, 50 \mathrm{mM})$ of DHPG were infused in an increasing manner and four samples were collected during each concentration. Following collection, samples were stored at $-80^{\circ} \mathrm{C}$ prior to analysis. 


\section{High Performance Liquid Chromatography}

Sample glutamate levels were analyzed using a fluorescence spectrophotometer system as previously described (Xie and Steketee 2008). Samples were derivatized (20 $\mathrm{uL}$ sample $+20 \mathrm{uL}$ fluoraldehyde) and $25 \mathrm{uL}$ of the mixture was injected onto a reversedphase column. The mobile phase $(62 \mathrm{mM} \mathrm{NaH} 2 \mathrm{PO} 4,0.5 \% \mathrm{v} / \mathrm{v}$ tetrahydrofuran, $40 \% \mathrm{v} / \mathrm{v}$ methanol; $\mathrm{pH}=6.3$ with $6 \mathrm{~N} \mathrm{NaOH}$ ) flowed at a rate of $1 \mathrm{~mL} / \mathrm{min}$. Glutamate was detected at an excitation wavelength of $260 \mathrm{~nm}$ and an emission wavelength of $455 \mathrm{~nm}$. An external standard curve ranging from $0.5-25$ pmol served as a basis for glutamate concentration derivation.

\section{Locomotor Activity Analysis}

Cocaine-induced locomotor activity was measured in all animals between 1 and 3 days following experiments to ensure pretreatment effectiveness. Animals were placed in activity chambers $(45 \times 24 \times 19 \mathrm{~cm})$ for 60 min prior to cocaine administration (15 $\mathrm{mg} / \mathrm{kg}$, i.p.) to allow for adaptation, and then locomotor activity was monitored for 120 min following injection.

\section{Histology}

Subsequent to experiment completion, animals were deeply anesthetized with sodium pentothal $(333 \mathrm{mg} / \mathrm{kg})$ and intracardially perfused with phosphate-buffered saline $(50 \mathrm{~mL})$ followed by $4 \%$ formaldehyde. Brains were removed from the skull cavity and allowed to sit in a formaldehyde-filled vial for at least a week prior to sectioning. Coronal slices (100 um) were cut using a vibratome, mounted on gelatin-coated slides, and stained with cresyl violet. Probe placement was verified using light microscopy and a rat brain atlas (Paxinos and Watson 1997) and data from animals with incorrect probe placements were excluded from analysis

\section{Statistics}

Microdialysis data were converted to percentage-of-baseline values prior to analysis. The baseline for each data set was acquired by averaging the 3 most consistent values of the 4 initial baseline samples. Microdialysis data were analyzed using a twoway repeated measures analysis of variance (ANOVA) followed by a modified least significances (LSD) test (Milliken and Johnson 1984), if necessary. Behavioral data were analyzed using an unpaired t-test. 


\section{Drugs}

DHPG was purchased from Tocris Bioscience (Ellisville, MO, USA) and cocaine hydrochloride was purchased from Sigma Chemical Company (St. Louis, MO, USA). All drugs were diluted in saline $(0.9 \%$ sodium chloride $)$.

\section{Results}

\section{Behavior}

Figure 7 shows motor activity recorded in response to a challenge injection of cocaine administered within 72 hours following microdialysis experiments for saline- and cocaine-pretreated rats. Data from all three time points were pooled and analyzed using an unpaired t-test. Cocaine-pretreated rats were significantly more active in response to the cocaine challenge than saline-pretreated controls $(t=7.755, p<0.0001)$, suggesting that repeated cocaine induced sensitization.

\section{In vivo microdialysis}

Figure 8 illustrates the effects of intra-mPFC DHPG infusion $(0.5,5$ and $50 \mathrm{uM})$ on mPFC glutamate levels in sensitized and non-sensitized rats at 1, 7, and 21 days following the last injection of cocaine or saline. The data were initially analyzed using a two-way repeated measures ANOVA. When an interaction effect was observed, further analysis using a modified least significant differences (LSD) test (Milliken and Johnson 1984) was carried out to determine the time point(s) at which the difference occurred.

Intra-mPFC DHPG administration increased mPFC glutamate levels at 7 days post-injection in rats that had previously received repeated cocaine but not saline (Figure 8a) (Interaction: $F(14,364)=2.64, p=0.0010$; Treatment: $F(1,364)=8.440, p=0.0074$; Time: $\mathrm{F}(14,364)=1.977, \mathrm{p}=0.0186)$. No significant differences in extracellular mPFC glutamate levels were observed between two groups at 1 (Figure 8b) or 21 (Figure 8c) days post-injection, however, an interaction effect approached significance at 1 day withdrawal ( 1 Day: Interaction: $F(14,336)=1.703, p=0.0534$; Treatment: $F(1$, $336)=4.948, \mathrm{p}=0.0358$; Time: $\mathrm{F}(14,336)=2.161, \mathrm{p}=0.009)$ (21-Days: Interaction: $\mathrm{F}(14$, $322)=1.424, \mathrm{p}=0.1399$; Treatment: $\mathrm{F}(1,322)=0.02453, \mathrm{p}=0.8769$; Time: $\mathrm{F}(14$, $322)=1.978, \mathrm{p}=0.0189$ )Baseline glutamate levels between cocaine- and saline-pretreated rats did not differ significantly at any of the three time points.

Figure 9 shows the effects of intra-mPFC DHPG administration $(0.5,5$ and 50 $\mathrm{uM}$ ) on glutamate levels in the NAC in cocaine- and saline-pretreated rats at 1,7 and 21 days post-injection. Data were analyzed using a two-way repeated measures ANOVA followed by a LSD test when appropriate. 


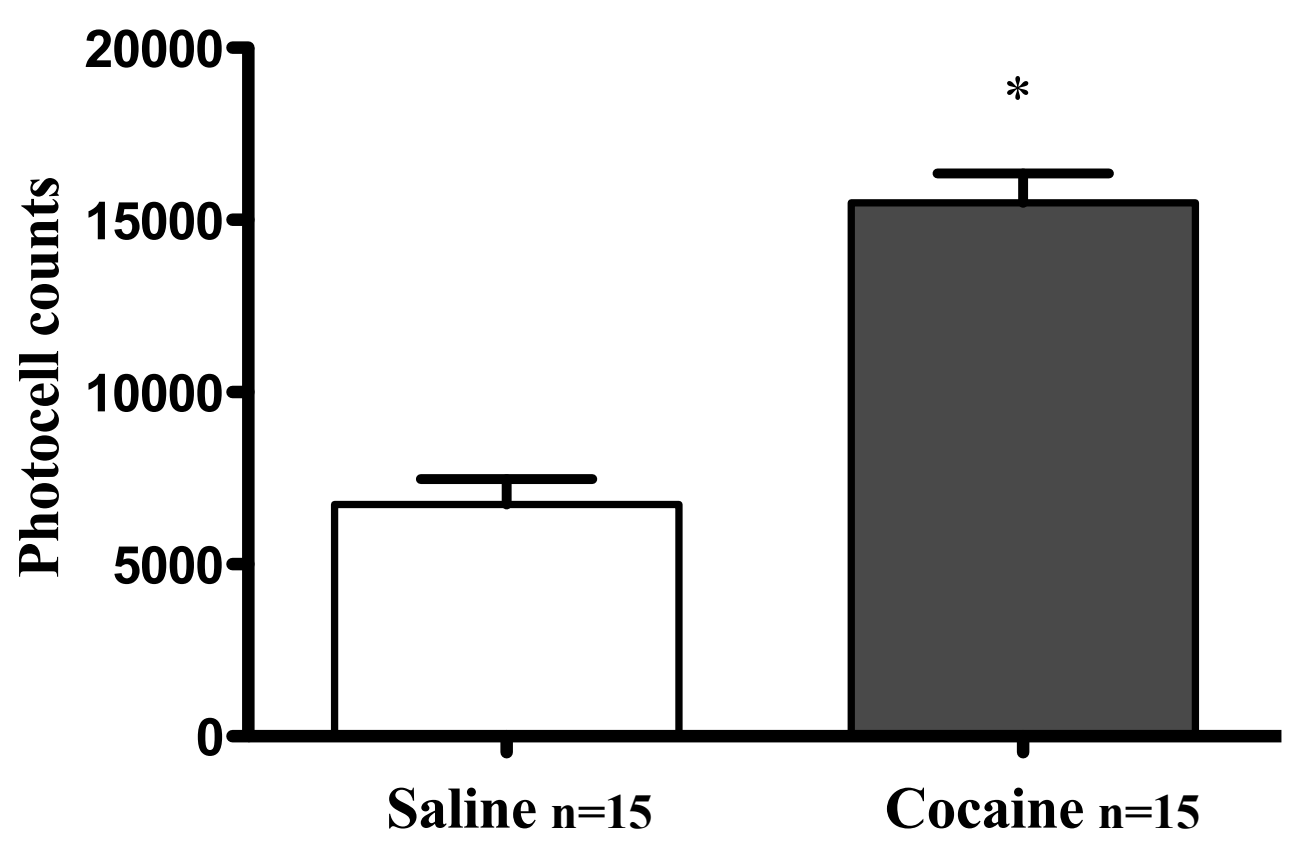

Figure 7. Effect of Repeated Cocaine Exposure on Cocaine-Induced Locomotion. Locomotor behavior (photocell counts) in response to a challenge injection of cocaine is shown for sensitized animals and saline controls. ${ }^{*}=\mathrm{p}<0.05$ 

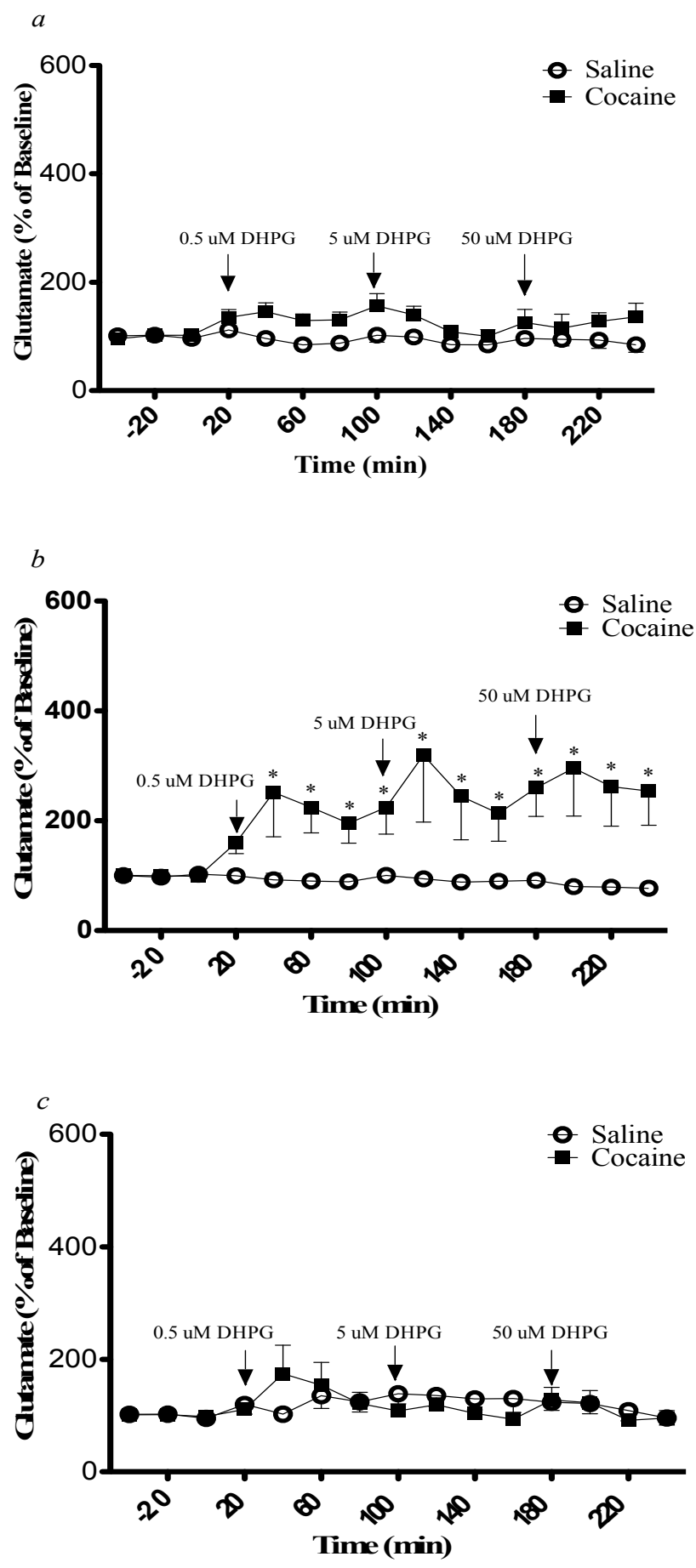

Figure 8. Effect of Intra-mPFC mGluR5 Activation on mPFC Glutamate Levels. $\mathrm{mPFC}$ glutamate levels (shown as \% of baseline) are displayed over $240 \mathrm{~min}$ for cocainesensitized and control animals in response to 3 concentrations of DHPG $(0.5,5,50 \mathrm{uM})$ at $1(\mathrm{a}), 7(\mathrm{~b})$, and 21 (c) days withdrawal. ${ }^{*}=\mathrm{p}<0.05$ between saline and cocaine animals. 

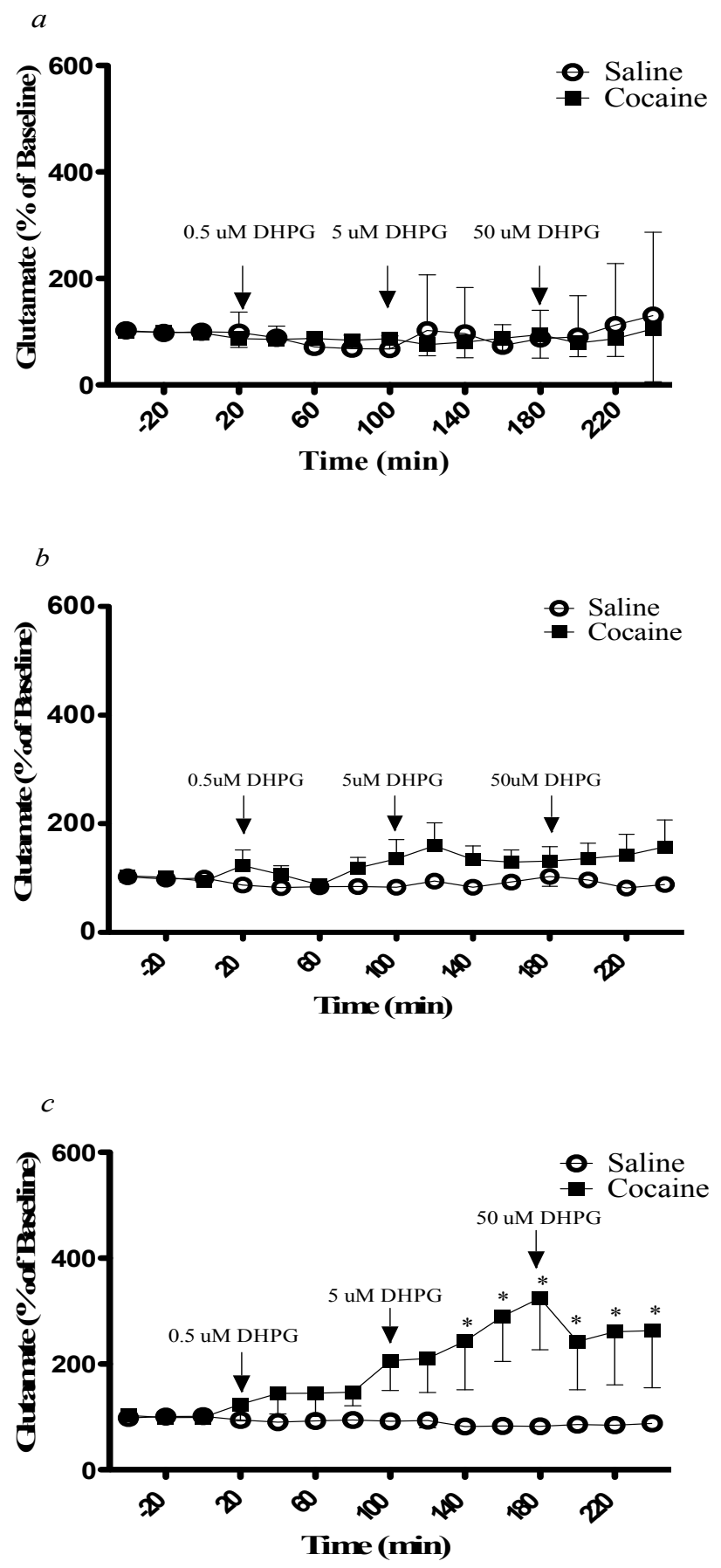

Figure 9. Effect of Intra-mPFC mGluR5 Activation on NAc Glutamate Levels. NAc glutamate levels (shown as \% of baseline) are displayed over $240 \mathrm{~min}$ for cocainesensitized and control animals in response to 3 concentrations of DHPG $(0.5,5,50 \mathrm{uM})$ at $1(\mathrm{a}), 7(\mathrm{~b})$, and $21(\mathrm{c})$ days withdrawal. ${ }^{*}=\mathrm{p}<0.05$ between saline and cocaine animals. 
When infused into the mPFC, DHPG significantly increased NAC glutamate levels in cocaine-pretreated rats at 21 days post-injection (Figure 9c) (Interaction: $\mathrm{F}(14$, $140)=1.963, p=0.0249$; Treatment: $F(1,140)=7.373, p=0.0217$; Time: $F(14,140)=1.431$, $\mathrm{p}=0.1461)$. NAC glutamate levels did not differ between cocaine- and saline-pretreated rats at 1 (Figure 9a) or 7 (Figure 9b) days post-injection (1 Day: Interaction: F(14, $168)=0.4758, \mathrm{p}=0.9435$; Treatment: $\mathrm{F}(1,168)=0.04225, \mathrm{p}=0.8406$; Time: $\mathrm{F}(14$, $168)=0.9407, p=0.5167)(7$ Days: Interaction: $F(14,154)=1.233, p=0.2566$; Treatment: $\mathrm{F}(1,154)=2.150, \mathrm{p}=0.1706$; Time: $\mathrm{F}(14,154)=1.018, \mathrm{p}=0.4386)$. There were no significant differences in baseline glutamate levels between the two groups at any of the three time points.

Figure 10 depicts VTA glutamate levels following intra-mPFC DHPG infusion $(0.5,5$ and $50 \mathrm{uM})$ in cocaine- and saline-pretreated rats at 1 (Figure 10a), 7 (Figure 10b) and 21 (Figure 10c) days post-injection. The data was analyzed using a two-way repeated measures ANOVA.

Intra-mPFC DHPG administration did not differentially affect VTA glutamate levels in saline- and cocaine-pretreated rats at 1, 7 or 21 days post-injection, however, a trend towards increased glutamate levels in cocaine-pretreated rats was observed at 7 days post-injection (Figure 10b) (1 Day: Interaction: $\mathrm{F}(14,140)=0.8216, \mathrm{p}=0.6447$; Treatment: $F(1,140)=0.0042, p=0.9491$; Time: $F(14,140)=1.071, p=0.3888)$ (7 Days: Interaction: $F(14,168)=1.084, p=0.3755$; Treatment: $F(1,168)=5.729, p=0.0339$; Time: $\mathrm{F}(14,168)=0.7618, \mathrm{p}=0.07090)(21$ Days: Interaction: $\mathrm{F}(14,154)=0.8385, \mathrm{p}=0.6266$; Treatment: $F(1,154)=0.7894, p=0.3933$; Time: $F(14,154)=1.032, p=0.4245)$. Baseline glutamate levels did not differ significantly between the two groups at any of the three time points.

\section{Histology}

Photomicrographs of typical microdialysis probe tracks in the mPFC, NAc and VTA are shown in Figure 11. In the $\mathrm{mPFC}$, dialysis probes were located in the $\mathrm{Cg} 3$ or infralimbic regions (Figure 11a). Dialysis probes in the NAc were medial to the anterior commissure (ac) and within the core or shell of the NAc (Figure 11b). In the VTA, microdialysis probes were medial to the substantia nigra ( $\mathrm{SnC}, \mathrm{SnR})$ and adjacent to the paranigral nucleus (PN) and parabrachial pigmented nucleus (PBP) (Figure 11c).

\section{Discussion}

The effects of mPFC mGluR5 activation on mPFC, VTA and NAc glutamate levels in sensitized and non-sensitized animals were explored in the present study. We did not observe an effect of intra-mPFC mGluR5 activation on glutamate levels in any brain region at any time point in control animals. However, our data show that $\mathrm{mPFC}$ mGluR5 stimulation increases glutamate levels within the mPFC at 7 days, but not 1 or 

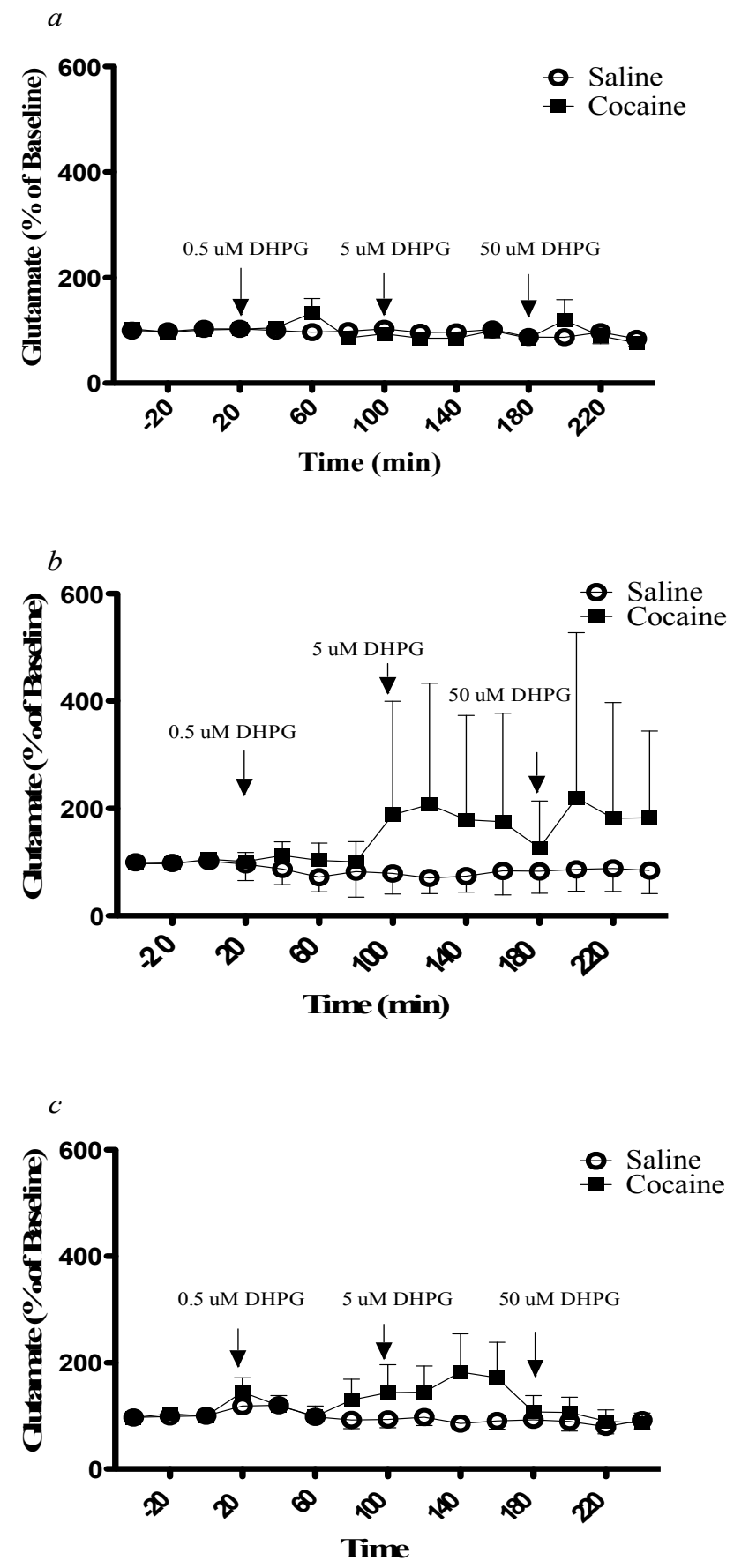

Figure 10. Effect of Intra-mPFC mGluR5 Activation on VTA Glutamate Levels. VTA glutamate levels (shown as \% of baseline) are displayed over $240 \mathrm{~min}$ for cocainesensitized and control animals in response to 3 concentrations of DHPG $(0.5,5,50 \mathrm{uM})$ at 1(a), 7(b), and 21(c) days withdrawal. 


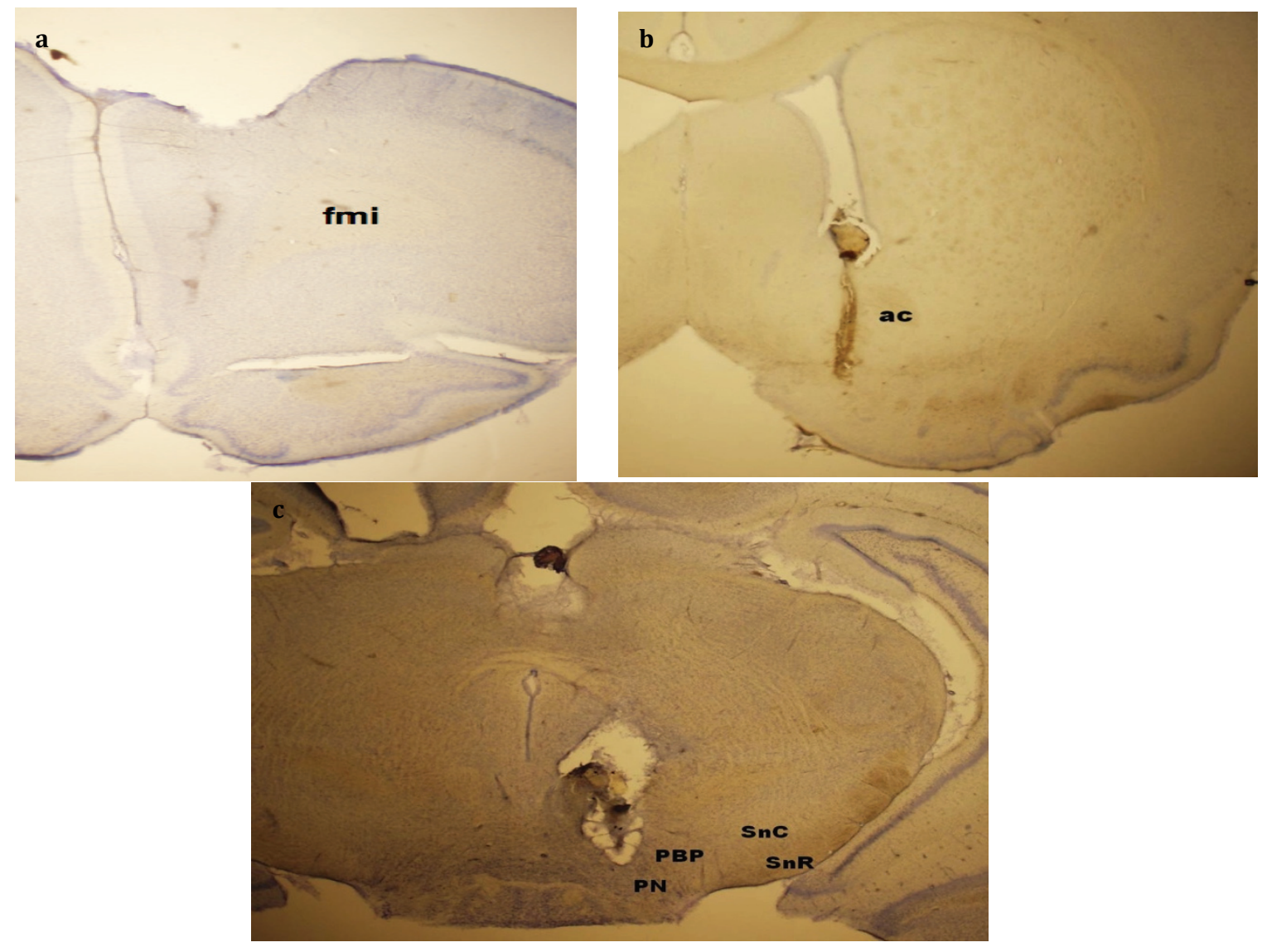

Figure 11. Microdialysis Probe Placement in the mPFC, NAc, and VTA.

Representative photomicrographs of microdialysis probe sites in the mPFC (a), Nac (b), and VTA (c). fmi $=$ forcepts minor corpus callosum, $a c=$ anterior commissure, $\mathrm{PBP}=$ parabrachial pigmented nuclei, $\mathrm{PN}=$ paranigral nuclei, $\mathrm{SnC}=$ substantia nigra compacta, $\mathrm{SnR}=$ substantia nigra reticulata. 
21 days, withdrawal in sensitized rats. In the NAc, intra-mPFC mGluR5 activation leads to elevated glutamate levels at 21 , but not 7 or 1, days post-injection in sensitized animals. mPFC mGluR5 stimulation did not significantly alter glutamate levels in the VTA at any time point, however, a subset of animals exhibited an increase in glutamate levels at 7 days withdrawal. These results imply repeated cocaine exposure leads to a transient mPFC mGluR5-mediated glutamate increase in the mPFC and a delayed, but possibly lasting, mPFC mGluR5-induced increase in NAc glutamate levels.

\section{MPFC mGluR5 and mPFC Glutamate}

The present data show that intra-mPFC mGluR5 activation increases $\mathrm{mPFC}$ glutamate levels at 7 , but not 1 or 21 , days following the last sensitizing cocaine injection. This suggests repeated cocaine exposure may transiently alter mGluR5 activity in a manner that yields $\mathrm{mPFC}$-specific glutamate increases, or induce temporary mGluR5-independent neuronal changes that result in heightened glutamate release following mGluR5 stimulation. mGluR5 is generally located postsynaptically and serves to increase the excitability of mPFC pyramidal neurons (Homayoun and Moghaddam, 2010; Kew and Kemp, 2005).

Given that the $\mathrm{mPFC}$ contains projections that terminate in various brain regions (Hoover and Vertes, 2007; Sesack et al., 1989), including the mPFC, one possibility is that sensitization-induced changes occur earlier in mGluR5-bearing mPFC-projecting neurons than in mGluR5-containing neurons that project to other brain areas, such as the NAc. As discussed in the following section, we observed elevated NAc glutamate levels at 21 days withdrawal in sensitized rats in response to $\mathrm{mPFC}$ mGluR5 stimulation, suggesting $\mathrm{mPFC}$ mGluR5 increases neuronal firing during late sensitization. It is conceivable that early glutamate release via local $\mathrm{mPFC}$ neurons play a role in facilitating later adaptations in NAc projections. A previous study demonstrated increased cocaineinduced mPFC glutamate in sensitized animals at 7, but not 30, days withdrawal (Williams and Steketee, 2004), suggesting transient mPFC glutamate alterations occur during early sensitization. mGluR5 activation in a select group of local $\mathrm{mPFC}$ projection neurons may contribute to early mPFC glutamate elevations. Selective mediation of sensitization by a subset of neurons was recently demonstrated in the NAc. Sensitizationinduced increases in AMPA and NMDA receptors were shown in the neurons associated with sensitization, but not the ones that were unassociated (Koya et al. 2012). Future studies examining potential differences in mGluR5 distribution and function on distinct projection neurons within the mPFC could be useful.

\section{mPFC mGluR5 and NAc Glutamate}

Intra-mPFC activation of mGluR5 increased NAc glutamate levels at 21, but not 1 or 7, days withdrawal in sensitized animals. This escalation likely results from two factors. The first is the reduction in cysteine-glutamate antiporter function that decreases intra-NAc baseline glutamate levels and is known to occur during late sensitization 
(Baker et al., 2003) and the second is the increased firing of NAc-terminating projections within the $\mathrm{mPFC}$ following $\mathrm{mPFC}$ mGluR5 activation.

Evidence suggests alterations in the NAc play a significant role in the loss-ofcontrol over drug-seeking behavior that ultimately leads to relapse. In agreement with this, a number of studies have uncovered lasting, NAc-specific changes observable during late, but not early, withdrawal, and many of these adaptations involve glutamate transmission and plasticity (Churchill et al., 1999; Kourrich et al., 2007; Schumann and Yaka, 2009). As previously mentioned, sensitization is associated with cocaine-induced hyperexcitability of mPFC projection neurons in rodents (Ford et al., 2009; Nasif et al., 2005) (Hu, 2007), and imaging studies in addicts show heightened $\mathrm{mPFC}$ activity in response to cocaine and cocaine-related cues (Goldstein and Volkow, 2011). Taken together, one might suppose that the combination of low baseline glutamate levels within the NAc and heightened cocaine-induced mPFC glutamatergic transmission to the NAc sets the stage for cocaine and cocaine-associated cues to stimulate NAc output, thus facilitating addictive behavior. Our finding that intra-mPFC mGluR5 activation increases NAc glutamate levels during late sensitization may suggest mGluR5 contributes to the hyperexcitability of $\mathrm{mPFC}$ pyramidal neurons following repeated cocaine exposure. Our present data also corroborates our previous finding that mPFC mGluR5 blockade prevents late, but not early sensitization (Timmer and Steketee, 2012).

\section{mPFC mGluR5 and VTA Glutamate}

mPFC mGluR5 activation did not significantly increase glutamate levels in the VTA in sensitized or control animals. However, we observed that a subset of sensitized animals showed substantially higher glutamate levels at 7 days withdrawal following intra-mPFC mGluR5 stimulation, but the extent of variability between the animals that displayed an increase and those that did not prevented a significant interaction effect.

One interesting aspect of our findings is the lack of a glutamate increase in the VTA at 21 days abstinence in sensitized rats following intra-mPFC mGluR5 activation. In the previous two paragraphs, we propose that cocaine-induced alterations in $\mathrm{mPFC}$ mGluR5 may occur earlier in local mPFC projection neurons, and later in projections to other brain areas. Our data showing that intra-mPFC mGluR5 activation increases NAc glutamate at 21 days withdrawal in sensitized animals supports this explanation, however if mGluR5 stimulation induces greater excitation of extra-mPFC mGluR5-bearing projection neurons during late sensitization, one might expect a concomitant increase in VTA glutamate levels. One possible reason why we did not observe a glutamate increase in the VTA is because $\mathrm{mPFC}$ projections to this region did not become more excitable following mGluR5 stimulation, or glutamate increases in the VTA were too small to measure. However, as previously mentioned, we did observe increased VTA glutamate following intra-mPFC mGluR5 activation in roughly half of sensitized animals at 7 days withdrawal, suggesting alterations in mPFC mGluR5 may have occurred on mPFC-VTA projections during early sensitization. We may not have observed this in all of our animals due to differences in microdialysis probe placement within the mPFC or VTA, or 
the degree of sensitization within the animals, which is known to vary (Hooks et al., 1991). In support of this, the VTA is thought to be involved with the initiation phase of sensitization and cocaine-induced alterations demonstrated to occur in this region tend to be transient (Pierce and Kalivas, 1997; Zhang et al., 1997).

In a previous study, we demonstrated that repeated intra-mPFC mGluR5 stimulation induced a cross-sensitization to cocaine that could be prevented via AMPA receptor blockade within the VTA prior to $\mathrm{mPFC}$ mGluR5 activation. This finding led us to hypothesize that repeated $\mathrm{mPFC}$ mGluR5 stimulation increases VTA glutamatergic transmission, thus facilitating dopaminergic input from the VTA to the NAc and inducing sensitization. Based on these results, glutamate increases in the VTA following mPFC mGluR5 activation might be expected in saline control animals. One potential reason why we did not observe an increase is that while mPFC mGluR5 activation induces glutamate release in the VTA sufficient to activate dopaminergic projection neurons, the glutamate fluctuations are too slight to measure via microdialysis. A second possibility is that intra-mPFC mGluR5 activation increases VTA glutamate to a greater extent with each successive application of the agonist. Perhaps we would have observed an increase in VTA glutamate levels following intra-mPFC mGluR5 activation if we measured the levels over the course of several days.

\section{Conclusions}

Data from the present study show mPFC mGluR5 activation increases mPFC glutamate levels during early, and NAc glutamate levels during late, sensitization. Excitatory input from the mPFC to the NAc is necessary for the expression of sensitization (Pierce et al., 1998) (Steketee, 2003) and mPFC projection neurons are hyperexcitable in response to cocaine following sensitization (Nasif et al., 2005) (Ford et al., 2009; Hu, 2007)). mGluR5 is a modulatory receptor that has been shown to increase firing frequency in mPFC pyramidal neurons (Fitzjohn et al., 1999; Marek and Zhang, 2008; Marino et al., 2001) (Homayoun and Moghaddam, 2010). Our results indicate mGluR5 within the $\mathrm{mPFC}$ increases firing of $\mathrm{mPFC}-\mathrm{Nac}$ projections during late sensitization, pointing to a role for mGluR5 in sensitization-affiliated neuronal hyperexcitability in the mPFC. Our data showing an mGluR5-mediated mPFC glutamate increase at 7 days withdrawal may suggest early changes in the excitability of local mPFC projections that are transient, but influential in shaping later alterations in NAc projection neurons. 


\section{Chapter 4. Role of Metabotropic Glutamate Receptor 5 in the Medial Prefrontal Cortex on Drug-Seeking Behavior}

\section{Introduction}

Cocaine addiction carries a notoriously high risk of relapse, even following years of abstinence. Consequently, the discovery of ways to prevent relapse is the predominant goal of addiction research. There is increasing evidence that mGluR5 modulation may attenuate the risk of relapse. Systemic administration of an mGluR5 antagonist dosedependently decreased cue- and cocaine-induced reinstatement (Backstrom and Hyytia, 2006; Kumaresan et al., 2009) and it has been suggested the effect of mGluR5 antagonism on cocaine self-administration results from an mGluR5-mediated decrease in the rewarding properties of cocaine (Kenny et al., 2005; Platt et al., 2008). A primary way in which mGluR5 antagonism could attenuate the rewarding effects of cocaine is by reducing transmission through the mesocorticolimbic circuit. Within the $\mathrm{mPFC}$, mGluR5 is primarily located postsynaptically on pyramidal projection neurons that terminate in reward-associated regions such as the VTA and NAc, and the activation of mPFC mGluR5 has been shown to increase neuronal excitability (Homayoun and Moghaddam, 2010; Kew and Kemp, 2005). Evidence suggests cocaine sensitization leads to increased cocaine-induced excitability of mPFC pyramidal neurons (Nasif et al., 2005), a consequence of which might be increased glutamatergic input to the VTA and NAc. One might expect that if $\mathrm{mPFC}$ mGluR5 activation increased neuronal activity in sensitized animals, intra-mPFC mGluR5 blockade would prevent and intra-mPFC mGluR5 stimulation would facilitate behavioral and neurochemical indicators of addiction. In support of this, we previously demonstrated that intra-mPFC mGluR5 blockade prevented late expression (Timmer and Steketee, 2012) and intra-mPFC mGluR5 activation increased glutamate levels in the NAc at 21-days withdrawal in sensitized animals (Chapter 3 ). We consequently became interested in the relationship between mPFC mGluR5 and drug-seeking, a behavior that can be initiated by cocaine or associated cues and that, most importantly, precedes relapse

Both contingent and noncontingent models of addiction have yielded a great deal of information over the past few decades, however, there has been some debate over the validity of noncontingent methods. Conversely, while it is not without its flaws (Epstein et al., 2006), the self-administration model possesses more "real-world" attributes of addiction because the animal is choosing to take the drug rather than receiving it from the experimenter. However, self-administration experiments can be more time-consuming and cumbersome than noncontingent studies of sensitization. Therefore, an ideal strategy would be to employ noncontingent methods as a first-pass screening for prospective influential factors in addiction and, if a relationship is found, contingent experiments may follow. Thus, an ancillary inquiry within this study is whether our previous results obtained with a noncontingent method are consistent with our current findings.

Therefore, in the present study, we investigated in a self-administration paradigm the effect of mPFC mGluR5 blockade on cue- and drug-induced drug seeking behavior 
following extended cocaine withdrawal. Our results indicate a nonsignificant trend towards an attenuation of cue-induced, but not drug-induced, drug-seeking following mPFC mGluR5 blockade.

\section{Methods}

\section{Animals and Surgery}

Male Sprague-Dawley (Harlan, Indianapolis, IN) rats weighing 275-300 g at the time of surgery were housed under a reverse $12 \mathrm{~h}$ light/dark cycle and had ad libitum access to food and water. Animals were anesthetized with a ketamine $(80$ $\mathrm{mg} / \mathrm{kg}) / \mathrm{xylazine}(6.0 \mathrm{mg} / \mathrm{kg})$ cocktail $(1.0 \mathrm{ml} / \mathrm{kg}$, i.p.). Jugular catheters were composed of an injection pedestal (Plastics One) bent to 90 degrees and attached to silastic tubing. The pedestal was affixed to hernia meshing via dental acrylic (Jet-Set, Lang Dental, Germany). The back-mounted catheters were threaded into the jugular vein and lowered to a point just above the heart. Following insertion, heparinized saline was injected through the pedestal to confirm clarity and animals were given Rimadyl ( $1 \mathrm{ml} / \mathrm{kg}$, i.p.). Immediately following catheterization surgery, animals heads were placed in a stereotaxic frame (Kopf Instruments) and bilateral cannulae (25 gauge, $14 \mathrm{~mm}$, stainless steel) were inserted $1 \mathrm{~mm}$ above the $\mathrm{mPFC}(\mathrm{A} / \mathrm{P}+3.3 \mathrm{~mm}$; M/L+.6 mm; D/V $-3.5 \mathrm{~mm})$. Obturators (32 gauge, $14 \mathrm{~mm}$, stainless steel) were implanted in the cannulae to prevent occlusion. Animals were given at least one week of recovery time prior to the commencement of experiments. Procedures were carried out in accordance with the NIH Guide for the Care and Use of Laboratory Animals and all experiments were approved by the University of Tennessee Health Science Center Animal Resource Advisory Committee.

\section{Cocaine Self-Administration Training}

Rats were trained to self-administer cocaine via lever-press in an operant box (Med Associates) containing 2 levers (active and inactive) and 2 cue lights. Animals were first trained under a FR1 schedule that increased to FR2 once criterion (9 correct responses) was met. Once FR2 criterion (18 correct responses) was met, the schedule increased to FR5 and continued as such for the remainder of the training phase. $0.05 \mathrm{~mL}$ of cocaine $(0.25 \mathrm{mg})$ was delivered over the course of 1 second in response to the correct number of lever presses on the active lever in the presence of the cue light. The training session ended after $3 \mathrm{hr}$ or 9,18 or 29 infusions for the FR1, FR2 and FR5 schedules, respectively. Animals were trained every day for ten days and considered to have learned the task if 29 infusions were obtained for at least the final 3 days of training. Animals that did not meet this criteria were excluded from the study. After the final training day, animals returned to their home cages for 21 days. 


\section{Microinjections}

Intra-mPFC microinjections were made using stainless steel injectors (32 gauge, $15 \mathrm{~mm}$ ) connected via PE20 tubing to $1 \mathrm{uL}$ syringes attached to an injector pump (Sage Instruments) that delivered drug at the rate of $5 \mathrm{uL} / \mathrm{min}$. After 21 days abstinence, animals were tested for 4 consecutive days. On day 1, animals received an intra-mPFC microinjection (15 mm, 32 gauge) of mGluR5-antagonist MTEP (15 nmol/side) or saline and were placed in the operant boxes wherein lever-presses were recorded for $1 \mathrm{hr}$. On day 2, animals received an intra-mPFC microinjection of MTEP or saline (determined by which one was not received on day 1) and were placed in the operant chambers where lever-presses were recorded for $1 \mathrm{hr}$. On day 3, animals received an intra-mPFC microinjection of MTEP or saline followed by a systemic cocaine injection $(15 \mathrm{mg} / \mathrm{kg}$, i.p.). After receiving cocaine, rats were immediately placed in the chambers for $1 \mathrm{hr}$ and lever-presses were recorded. On day 4, animals received an intra-mPFC microinjection of MTEP or saline (dependent on which was not administered on day 3 ) followed by a systemic cocaine injection $(15 \mathrm{mg} / \mathrm{kg}$, i.p.). Immediately after receiving the cocaine injection, animals were placed in the boxes for $1 \mathrm{hr}$ and lever-pressing was recorded. The order of microinjection treatment (saline/MTEP) was counterbalanced.

\section{Histology and Statistics}

At the end of experiments, animals were deeply anesthetized with sodium pentothal $(333 \mathrm{mg} / \mathrm{kg})$ and transcardially perfused with $50 \mathrm{~mL}$ phosphate-buffered saline followed by $50 \mathrm{~mL} \mathrm{10 \%} \mathrm{paraformaldehyde.} \mathrm{Brains} \mathrm{were} \mathrm{removed} \mathrm{from} \mathrm{the} \mathrm{skull} \mathrm{cavity}$ and placed in formaldehyde-filled vials for at least a week. Brains were then sliced into 100 micron sections, mounted onto gelatin-coated slides and stained with cresyl violet. Injector placement was then verified via light microscopy using a rat brain atlas (Paxinos and Watson 1997). Animals with injector placements outside of the mPFC were excluded from the analysis.

Lever-presses recorded in MTEP and saline conditions on Day 1 and 2 (cueinduced drug-seeking) were compared using a paired t-test. Lever-presses recorded in MTEP and saline conditions on Day 3 and 4 (drug-induced drug-seeking) were compared using an paired t-test.

\section{Drugs}

Cocaine hydrochloride (Sigma Chemical, St. Louis, MO) and MTEP ((3)(2methyl-4-thiazolyl)ethynyl)pyridine hydrochloride), TOCRIS Bioscience, Ellisville, MO) were diluted with isotonic saline (0.9 units sodium chloride). The dose of MTEP (30 $\mathrm{mM}$ ) was chosen based on previous experiments (Timmer and Steketee 2012) 


\section{Results}

\section{Repeated Training Increased Cue-Induced Cocaine Self-Administration}

Animals were trained to lever-press for cocaine for 10 days, a time period sufficient to facilitate learning based on previous literature. Figure 12 shows mean responses (lever-presses) over the 10 training days. All animals included in the study increased active lever responding to the maximum number of responses (145 correct lever-presses) within a FR5 schedule and maintained that response level for at least the last 3 days of training.

\section{Effect of Intra-mPFC mGluR5 Blockade on Cue-Induced Drug-Seeking}

We hypothesized that intra-mPFC MTEP infusion would attenuate drug-seeking behavior, as measured by the number of responses (lever-presses), based on our previous data demonstrating that mPFC mGluR5 blockade prevented late expression. Figure 13 shows the mean number of responses from animals when given intra-mPFC saline and MTEP. A nonsignificant trend toward an MTEP-induced reduction in responding was observed $(\mathrm{t}=2.133, \mathrm{p}=0.07)$.

\section{Effect of Intra-mPFC mGluR5 Blockade on Cocaine-Induced Drug-Seeking}

Our previous data demonstrate a reduction in locomotor response to cocaine following intra-mPFC MTEP administration during late expression (Timmer and Steketee 2012). Figure 14 shows the mean responses of animals when given an intra$\mathrm{mPFC}$ microinjection of saline or MTEP followed by a systemic injection of cocaine (15 $\mathrm{mg} / \mathrm{kg}$, i.p.). No significant differences were found following analysis with a paired $\mathrm{t}$ test.

\section{Differential Effect of mPFC mGluR5 Blockade on High-and Low-Responding Rats}

We observed that, when given intra-mPFC saline, roughly half of our animals exhibited a high response rate ( $>50$ lever-presses) while the other half displayed a lower response rate $(<50$ lever-presses). On account of data suggesting intrinsic differences between "high-responders" and "low-responders"(Flagel et al., 2009), we segregated and reanalyzed our data based on these categories. Figure 15 shows mean responses of highresponding (a) and low-responding (b) rats when given an intra-mPFC microinjection of saline or MTEP. MTEP significantly reduced cue-induced responding in high-responding $(\mathrm{t}=3.277, \mathrm{p}<.05)$, but not low-responding $(\mathrm{t}=0.1628, \mathrm{p}=0.88)$, animals. Figure 16 shows mean responses of high-responding (a) and low-responding (b) animals when given an intra-mPFC microinjection of saline or MTEP followed by systemic cocaine $(15 \mathrm{mg} / \mathrm{kg}$, i.p.). No significant differences were observed between the groups. 


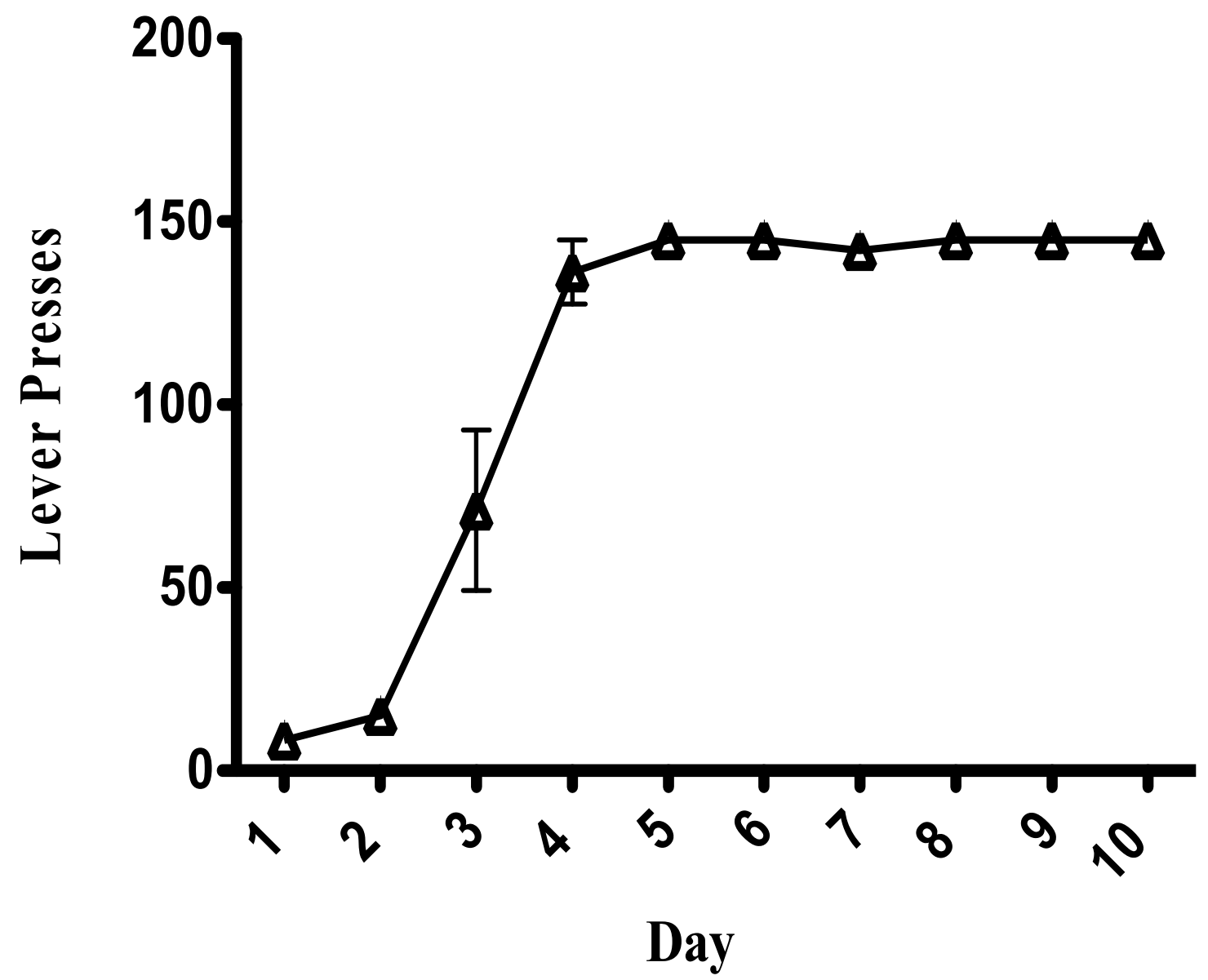

Figure 12. Effect of Self-Administration Training on Responses. Mean responses on active lever from animals $(n=8)$. Over the 10-day training period, responses increased to the FR5 criterion of 145 lever-presses per session. 


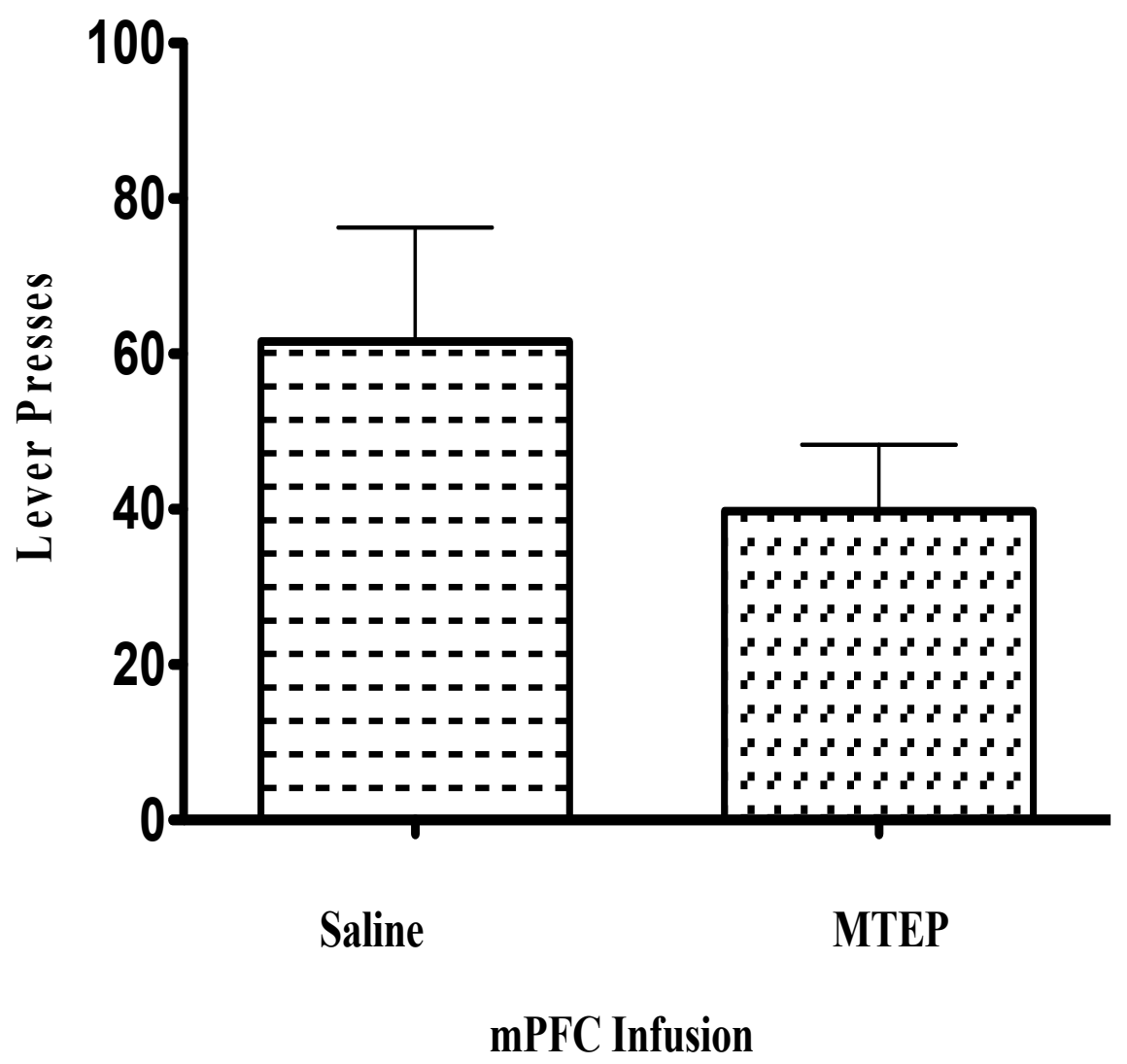

Figure 13. Effect of Intra-mPFC mGluR5 Activation on Cue-Induced Drug-Seeking. Mean responses (lever-presses) of animals $(n=8)$ given an intra-mPFC injection of saline and MTEP are shown. 


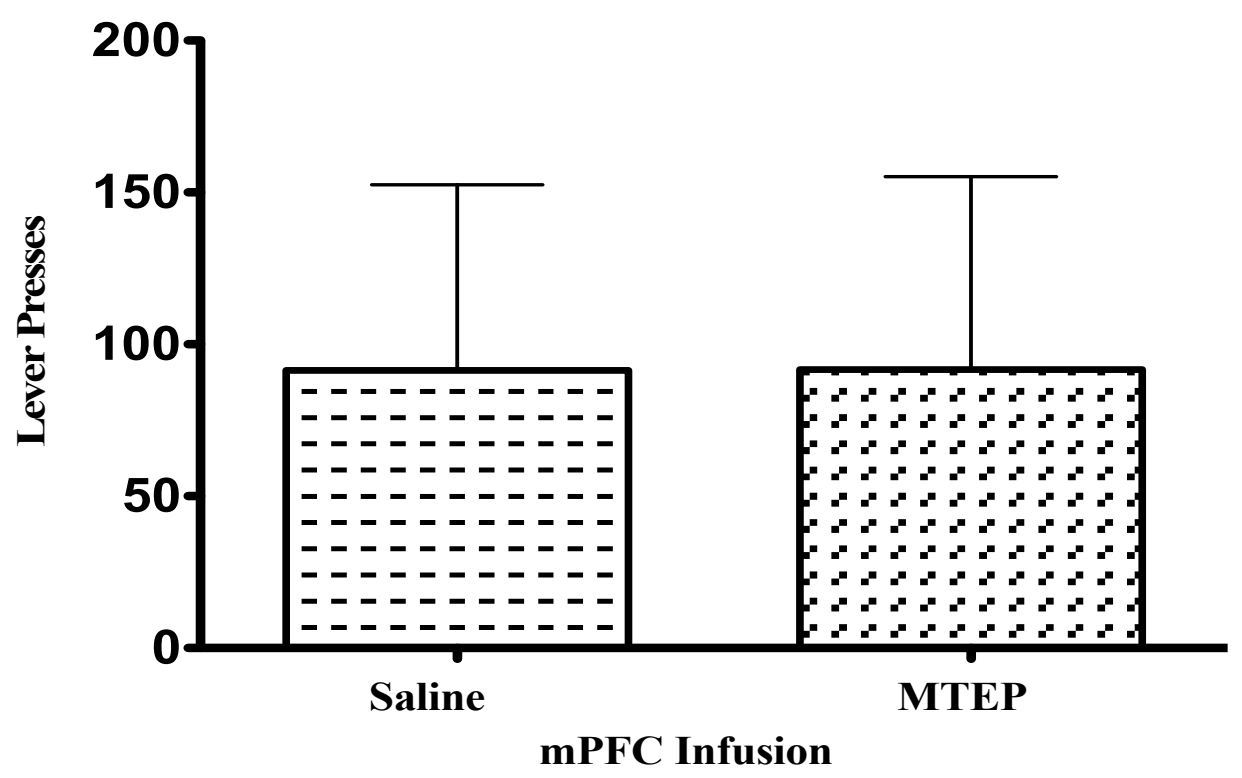

Figure 14. Effect of Intra-mPFC mGluR5 Activation on Cocaine-Induced DrugSeeking. Mean responses (lever-presses) from animals $(n=8)$ given an intra-mPFC microinjection of saline and MTEP followed by systemic cocaine $(15 \mathrm{mg} / \mathrm{kg}$, i.p.) are shown. 

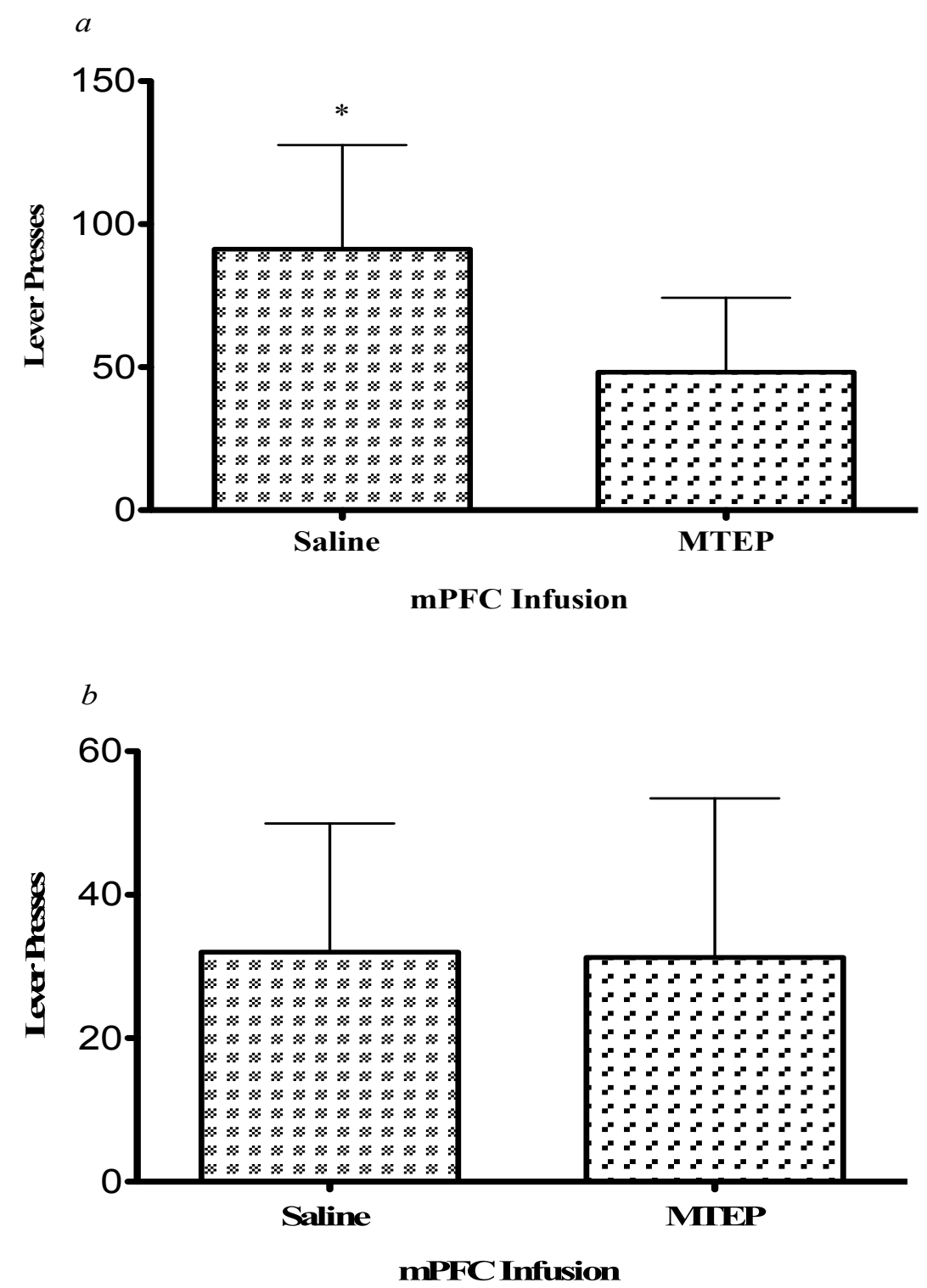

Figure 15. Effect of Intra-mPFC mGluR5 Activation on Cue-Induced Drug-Seeking on High- and Low-Responding Rats. Mean responses (lever-presses) of highresponding ( $>50$ saline, $\mathrm{n}=4)(a)$ and low-responding $(<50$ saline, $\mathrm{n}=4)(b)$ rats in response to a cocaine-associated cue following an intra-mPFC microinjection of saline or MTEP. ${ }^{*}=\mathrm{p}<0.05$. 


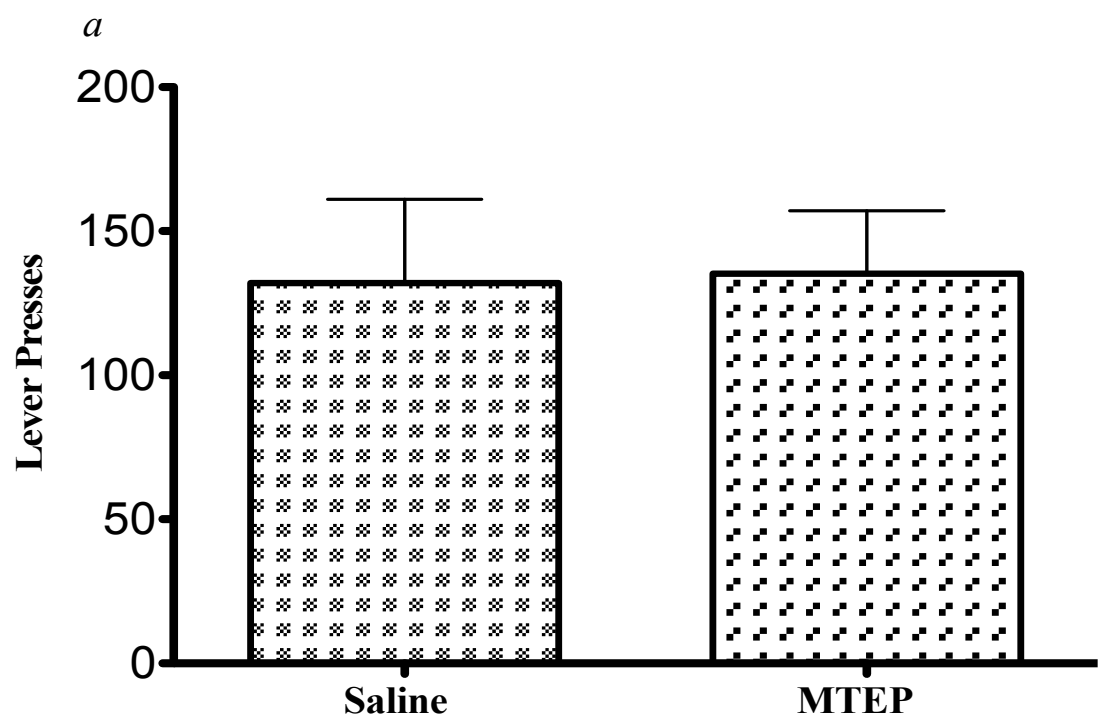

mPFC Infusion

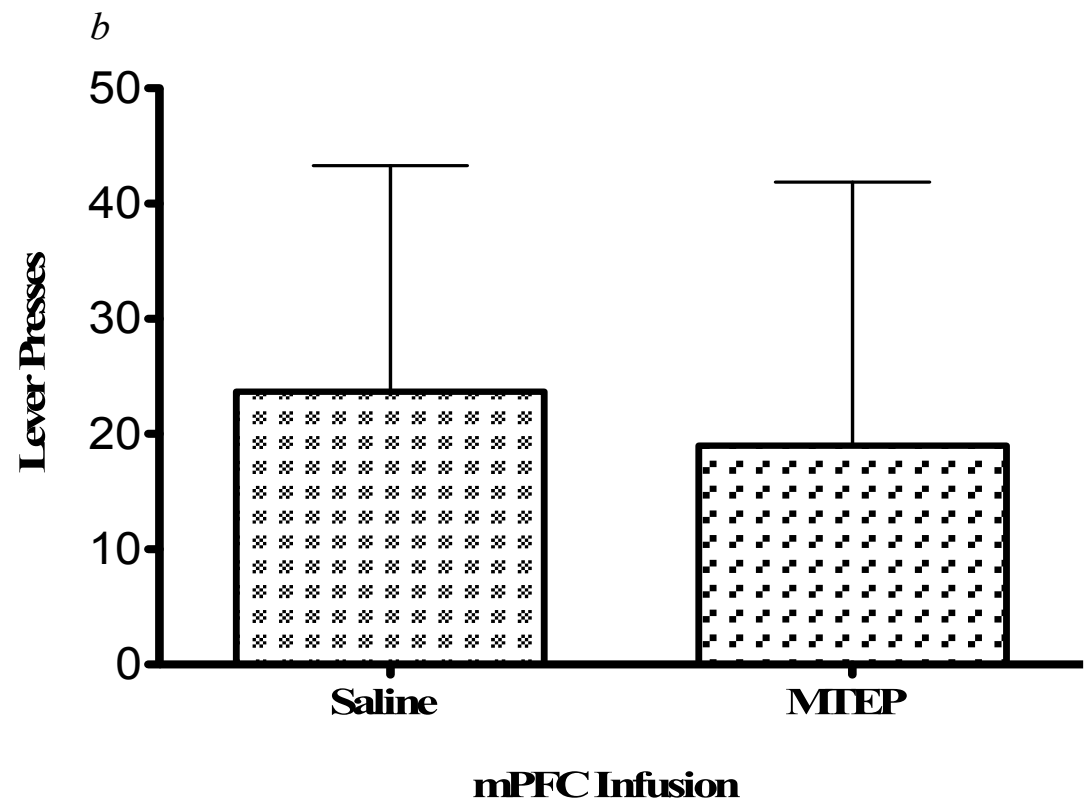

Figure 16. Effect of Intra-mPFC mGluR5 Activation on Cocaine-Induced DrugSeeking on High- and Low-Responding Rats. Mean responses (lever-presses) of highresponding ( $>50$ saline, $n=5)(a)$ and low-responding ( $<50$ saline, $n=3)(b)$ rats in response to an intra-mPFC microinjection of saline or MTEP followed by systemic cocaine $(15 \mathrm{mg} / \mathrm{kg}$, i.p.). 


\section{Discussion}

The present study examined the role of mPFC mGluR5 in cue- and cocaineinduced drug-seeking. The data demonstrate that $\mathrm{mPFC}$ mGluR5 blockade may attenuate cue-induced drug-seeking, but does not affect cocaine-induced drug seeking. Further, intra-mPFC mGluR5 blockade differentially affected cue-induced drug-seeking in highresponding and low-responding animals.

We previously demonstrated that intra-mPFC mGluR5 antagonism via MTEP significantly reduced the expression of locomotor sensitization at 21-days withdrawal. Thus, we were curious whether MTEP would produce any discernable decrease in drugseeking behavior at this time point. In the present study, intra-mPFC mGluR5 blockade facilitated a nonsignificant decrease in cue-induced drug-seeking. Moreover, while the previous MTEP-induced reduction in sensitization followed a cocaine injection, the present data show no effect of MTEP on drug-seeking behavior following cocaine administration. Several explanations for our findings are explored below.

One possible reason for the decrease in the MTEP-mediated effect on drugseeking relative to sensitization could be the design of our self-administration experiments. Prior to cocaine self-administration training, it is common for animals to be trained to self-administer food pellets in the same chambers where they will later administer cocaine. Food training can result in greater acquisition rates in cocaine training, and possibly a more robust association between the task and a reward (Koob et al 2007). We did not train our animals to lever-press for food prior to cocaine training. While our animals displayed strong and stable acquisition rates (Figure 12), it is possible that their training was not as robust as it would have been had they been food-trained, especially after a 21-day lapse.

Perhaps the most interesting aspect of our data is the discrepancy in the effect of MTEP on drug-seeking in high- and low-responding animals. Some of the animals in our study responded at relatively low levels on Days 1 and 2 (cue-induced test), and while responding was generally decreased in these animals following MTEP, the difference in responding between MTEP and saline conditions was not substantial because of the overall low level of response. By contrast, on Days 3 and 4 (cocaine-induced test), some of the previously low-responding animals drastically increased their responding following cocaine administration. One possible explanation, as described in the previous paragraph, is that task learning in some animals was not robust enough for the cue alone

to generate the combination of drug-wanting and task- remembering necessary for a high response rate. However, following cocaine administration, drug-wanting dramatically increased and the memory of acquiring the drug was enhanced (Saunders and Robinson, 2011), which resulted in a higher response rate. Differences between saline and MTEP conditions in cue-induced drug-seeking may have been more apparent in our lowresponding animals if we took measures to ensure they acquired a strong association between the cue and cocaine. 
Alternatively, the difference we observed between high- and low-responding animals may have resulted from cue-strength variation suggested to occur in rodents (Meyer et al., 2012). In addicted animals, the cocaine-associated cue is thought to acquire an incentive salience that presumably facilitates drug-wanting and drug-seeking. However, recent studies suggest the cue does not become intrinsically rewarding to all animals and those animals that do not find the cue itself rewarding may be less vulnerable to addiction (Flagel et al., 2009)). It is possible that the low-responding animals in our study were not as motivated by the cue as the high-responders and consequently experienced less drug-wanting than the high-responders. If the high-responders were then, by this definition, more addicted than the low-responders, this indicates that mPFC mGluR5 antagonism is effective in reducing drug-seeking in addicted animals. The significant reduction in cue-induced drug-seeking following intra-mPFC mGluR5 blockade we observed in high-responding animals supports this idea. However, the resultant low sample size following data segregation and the increase in responses in previously low-responding animals following cocaine administration precludes us from being certain our lack of an overall effect results from individual differences in cue evaluation rather than a learning impairment in low-responding animals. Additional experiments employing techniques to facilitate more robust learning, such as prior food training, should be conducted.

A second reason why mPFC mGluR5 blockade may not have exerted a significant reduction in cue-induced drug-seeking is because the $\mathrm{mPFC}$ neuroadaptations that accompany learning to associate a cue with cocaine may be more extensive than those affiliated with simply receiving the drug on multiple occasions. In our previous study, we had proposed that MTEP reduced locomotor sensitization by decreasing the firing of $\mathrm{mPFC}$ pyramidal projection neurons, leading to a decrease in glutamatergic input to the NAc (Timmer and Steketee, 2012). Perhaps the mPFC plasticity that follows cue-induced learning serves to increase pyramidal neuronal firing to a greater extent than does the plasticity that accompanies a noncontingent regime, thus rendering mPFC mGluR5 blockade less effective. If this proves true, the clinical implications of mPFC mGluR5 modulation alone will be decreased, however, a better understanding of the relationship between cocaine-induced mPFC mGluR5 modifications and other alterations that may influence excitability could potentially pave the way for an effective pharmacological means of preventing relapse.

Our data showed that mPFC mGluR5 antagonism did not prevent cocaine-induced drug-seeking. This finding is somewhat unsurprising, however, because cocaine is a more potent motivator than a cue alone and previous self-administration studies have failed to uncover an effect of a manipulation following drug administration, even when the given manipulation attenuated cue-induced drug-seeking (Pockros et al., 2011)(Chauvet et al., 2009; Leri et al., 2002). What makes this finding perplexing is the stark inconsistency with our previous finding of an intra-mPFC MTEP-induced reduction in sensitization following cocaine administration. One might assume that if cocaine obliterated any effect of mGluR5 antagonism observed in its absence in a self-administration paradigm, we would be unlikely to find an effect of intra-mPFC MTEP on sensitization. However, it should be noted that while our previous finding showed a significant MTEP-induced 
decrease in sensitization, sensitized animals that received MTEP still exhibited greater locomotion than saline controls, suggesting mPFC mGluR5 antagonism did not completely block the effects of cocaine. Given the abovementioned suggestion that the associative learning inherent in a self-administration paradigm induces an mPFC plasticity more effective at heightening neuronal excitability in the presence of cocaine and its cues, it is possible that the compounding of that plasticity with cocaine prevented MTEP from exerting any measurable effect on drug-seeking. Another possibility is that the effects of intra-mPFC mGluR5 blockade on cocaine-induced drug-seeking may have been too slight to measure within the self-administration paradigm. Nevertheless, our data strongly suggest $\mathrm{mPFC}$ mGluR5 antagonism does not reduce cocaine-induced drugseeking.

Finally, the implications of this study on the role of sensitization in addiction research should be addressed. Despite the nonsignificant effect of intra-mPFC mGluR5 antagonism on cue- and drug-induced drug-seeking, the observed trend towards an MTEP-induced reduction and significant MTEP-induced high-responder reduction in drug-seeking suggests that mPFC mGluR5 plays a role in addiction, which supports the usefulness of the simpler noncontingent method as a screening tool for addiction-relevant factors. As discussed above, the reasons for a lack of a significant overall effect could result from flaws in experimental design that affected learning, individual differences that influenced cue-induced motivation, or inherent differences in the plasticity induced by contingent and noncontingent administration techniques. A future study employing methods proven to maximize learning and increasing the sample size to acquire more high-responders might reveal a greater effect of mPFC mGlur5 antagonism on drugseeking, or better describe the differences between high- and low-responding animals. If not, the combinatorial effect of mPFC mGluR5 blockade and other mPFC manipulations could be explored. 


\title{
Chapter 5. General Discussion
}

\author{
Summary of Findings
}

\section{Chapter 2}

Repeated intra-mPFC administration of Group I agonist DHPG induced crosssensitization to cocaine. This cross sensitization could be prevented via co-administration of mGluR5 antagonist MTEP, suggesting it was mediated by mGluR5 rather than mGluR1. Intra-mPFC DHPG-induced cross-sensitization could also be prevented by intra-VTA injections of AMPA receptor antagonist CNQX administered immediately prior to intra-mPFC DHPG, indicating dependence on VTA glutamatergic transmission. mPFC mGluR5 antagonism did not prevent the initiation of sensitization, or the early ( 7 days withdrawal) expression of sensitization. However, intra-mPFC mGluR5 blockade did significantly attenuate late (21 days withdrawal) expression, suggesting alterations in mPFC mGluR5 may represent a lasting adaptation brought on by repeated cocaine exposure.

\section{Chapter 3}

Rats received daily systemic cocaine ( $15 \mathrm{mg} / \mathrm{kg}$ i.p.) or saline injections for 4 consecutive days. One, 7 , or 21 days from the last injection, an in vivo reverse microdialysis experiment was conducted wherein 3 escalating concentrations $(0.05 \mathrm{uM}$, $5 \mathrm{uM}, 50 \mathrm{uM}$ ) of Group I mGluR agonist DHPG were infused into the mPFC and samples were collected from the mPFC and NAc or the MPFC and VTA for later analysis of glutamate concentration. Results showed intra-mPFC DHPG increased mPFC glutamate levels at 7 days withdrawal, and NAc glutamate levels at 21 days withdrawal in sensitized, but not control, animals. These findings suggest mPFC mGluR5 activation may contribute to increased excitatory input from the mPFC to the NAc during late sensitization. Our data also indicate that early sensitization-induced mGluR5 alterations in local mPFC neurons may set the stage for later changes in NAc-projecting, mGluR5bearing neurons within the $\mathrm{mPFC}$.

\section{Chapter 4}

Animals were trained to self-administer cocaine in an operant box for 10 consecutive days. At the conclusion of training, rats were returned to their home cages for 21 days. Following this withdrawal period, the effect of intra-mPFC blockade via mGluR5 antagonist MTEP on cue- and cocaine-induced drug-seeking was assessed. We observed a nonsignificant trend towards decreased cue-induced drug-seeking following MTEP relative to saline, and no effect of MTEP on cocaine-induced drug-seeking. 


\section{General Discussion}

Cocaine addicts experience a lifelong struggle to control drug-seeking behavior and many relapse, even after years of withdrawal. Therefore, the overarching goal of addiction research is to understand the mechanisms that contribute to relapse. Imaging studies in cocaine addicts have revealed increased $\mathrm{mPFC}$ activity in response to cocaine and related cues, and decreased $\mathrm{mPFC}$ activity in response to other stimuli (Goldstein and Volkow, 2011). Similarly, non-human studies have demonstrated increased cocaineinduced excitability of mPFC pyramidal neurons in sensitized animals, a phenomenon that might ultimately result in increased excitatory input to reward-associated brain regions, such as the NAc. Furthermore, given the role of the mPFC in excutive functions, increased $\mathrm{mPFC}$ responsiveness to cocaine and its cues at the expense of non-drug information may contribute to the seemingly irrational and sometimes self-destructive decisions an addict will make to obtain cocaine. Consequently, an understanding of the processes that give rise to the $\mathrm{mPFC}$ excitability that follows repeated cocaine exposure may open new doors for lessening the risk of relapse.

The data from the present studies suggest mPFC mGluR5 contributes to the regulation of the excitability of $\mathrm{mPFC}$ projections to the NAc during late, but not early, sensitization. We first showed that intra-mPFC blockade significantly attenuated the locomotor response to cocaine in sensitized rats at 21 , but not 7 , days withdrawal. Then, we observed increased NAc glutamate levels following mPFC mGluR5 activation at 21 days withdrawal in sensitized animals. Finally, we noted a nonsignificant trend towards a reduction in cue-induced drug-seeking following intra-mPFC mGluR5 antagonism at 21 days withdrawal.

The key finding from our first set of experiments (chapter 2) was the reduction in late expression following mPFC mGluR5 blockade, however, the failure of intra-mPFC mGluR5 blockade to prevent early expression was somewhat puzzling. One explanation we offered at the time was that cocaine-induced mPFC glutamate levels were too high to reveal an effect of mGluR5 blockade during early expression. A second possibility we proposed was that, due to alterations in mGluR5 itself or other late-sensitizationassociated cellular changes, mGluR5 activation was more influential over mPFC neuronal output during late sensitization. Results from our second set of experiments (chapter 3) suggest the latter explanation may be more accurate because we observed a glutamate increase in the NAc following mPFC mGluR5 stimulation during late, but not early, expression. Future studies could explore potential changes in mGluR5-bearing NAc projections within the mPFC from early to late expression.

An interesting question our findings raise is whether and how early changes in the $\mathrm{mPFC}$ glutamate system give rise to later alterations in communication between the mPFC and other regions, such as the NAc. We showed that mPFC mGluR5 activation increased $\mathrm{mPFC}$ glutamate levels at 7 days withdrawal in sensitized animals, an effect that was not present during late sensitization. As previously discussed, repeated cocaine exposure may induce alterations in mGluR5-bearing local $\mathrm{mPFC}$ projections earlier than in neurons that project to other brain regions. As is the case with mGluR5 alterations that 
are associated with late sensitization, we do not know whether mGluR5 is altered in local projections during early sensitization or if other cellular properties are changed in a way that makes mGluR5 activation more likely to increase firing. Nonetheless, it is possible that early mGluR5-associated changes could represent a critical step in more permanent mGluR5-affiliated alterations in mPFC projection neurons. Differences in mGluR5 presence and activity in local and NAc-projecting $\mathrm{MPFC}$ neurons could be explored in the future, as could related alterations that may potentially affect the influence of mGluR5 over neuronal excitability.

The significant decrease in late expression and the nonsignificant but notable reduction in cue-induced drug-seeking observed in animals following intra-mPFC mGluR5 blockade suggests mPFC mGluR5 is involved with processes that mediate longterm cocaine addiction. While we did not observe an effect of mPFC mGluR5 antagonism on cocaine-induced drug-seeking, our data still suggest that mPFC mGluR5 antagonism reduces the influence of cocaine and related cues on addictive behavior. That said, as discussed earlier, further studies employing the self-administration paradigm should be conducted in a manner than maximizes task acquisition and contains a sample size sufficient to yield a suitable number of high-responding animals. Such an experiment will shed light on whether the failure of mPFC mGluR5 antagonism to significantly reduce cue-induced drug-seeking resulted from experimental design, individual differences or the lack of a substantial role of mGluR5 in drug-seeking.

An ancillary objective of our self-administration experiments was to assess the congruency of findings obtained using a contingent and a noncontingent method. As previously discussed, the discrepancy in drug administration that exists between the noncontingent method and the process addicts undergo while becoming dependent on cocaine has called into question the usefulness of the noncontingent method in addiction research. Since our data collected using a contingent method showed a nonsignificant reduction in cue-induced drug-seeking following intra-mPFC mGluR5 antagonism that may be more pronounced under different experimental conditions, and our data obtained using a noncontingent methods showed an mPFC mGluR5-mediated reduction in late expression, a substantial degree of similarity appears to exist. Given the simplicity and straightforwardness of the noncontingent method, its employment as a screening technique performed prior to more involved experiments seems suitable.

Taken together, our experiments are the first to explore the role of mPFC mGluR5 in cocaine addiction and our data suggest this receptor may contribute to the enhanced excitability of sensitized mPFC pyramidal cells. Given that the effects of intra-mPFC mGluR5 manipulations were observable during late sensitization, alterations in $\mathrm{mPFC}$ mGluR5 may represent a lasting neuroadaptation brought on by repeated cocaine exposure. 


\section{LIST OF REFERENCES}

Addy NA, Daberkow DP, Ford JN, Garris PA, Wightman RM. 2010. Sensitization of rapid dopamine signaling in the nucleus accumbens core and shell after repeated cocaine in rats. Journal of neurophysiology 104(2):922-931.

Awad H, Hubert GW, Smith Y, Levey AI, Conn PJ. 2000. Activation of metabotropic glutamate receptor 5 has direct excitatory effects and potentiates NMDA receptor currents in neurons of the subthalamic nucleus. The Journal of neuroscience : the official journal of the Society for Neuroscience 20(21):7871-7879.

Backstrom P, Hyytia P. 2006. Ionotropic and metabotropic glutamate receptor antagonism attenuates cue-induced cocaine seeking. Neuropsychopharmacology : official publication of the American College of Neuropsychopharmacology 31(4):778-786.

Bailey ME, Fraire AE, Greenberg SD, Barnard J, Cagle PT. 1994. Pulmonary histopathology in cocaine abusers. Human pathology 25(2):203-207.

Baker DA, McFarland K, Lake RW, Shen H, Tang XC, Toda S, Kalivas PW. 2003. Neuroadaptations in cystine-glutamate exchange underlie cocaine relapse. Nature neuroscience 6(7):743-749.

Baker DA, Shen H, Kalivas PW. 2002. Cystine/glutamate exchange serves as the source for extracellular glutamate: modifications by repeated cocaine administration. Amino acids 23(1-3):161-162.

Bandrowski AE, Huguenard JR, Prince DA. 2003. Baseline glutamate levels affect group I and II mGluRs in layer V pyramidal neurons of rat sensorimotor cortex. Journal of neurophysiology 89(3):1308-1316.

Barth CW, 3rd, Bray M, Roberts WC. 1986. Rupture of the ascending aorta during cocaine intoxication. The American journal of cardiology 57(6):496.

Benchimol A, Bartall H, Desser KB. 1978. Accelerated ventricular rhythm and cocaine abuse. Annals of internal medicine 88(4):519-520.

Benowitz NL. 1993. Clinical pharmacology and toxicology of cocaine. Pharmacology \& toxicology 72(1):3-12.

Beyer CE, Steketee JD. 2002. Cocaine sensitization: modulation by dopamine D2 receptors. Cereb Cortex 12(5):526-535.

Boghdadi MS, Henning RJ. 1997. Cocaine: pathophysiology and clinical toxicology. Heart \& lung : the journal of critical care 26(6):466-483; quiz 484-465. 
Bolla K, Ernst M, Kiehl K, Mouratidis M, Eldreth D, Contoreggi C, Matochik J, Kurian V, Cadet J, Kimes A, Funderburk F, London E. 2004. Prefrontal cortical dysfunction in abstinent cocaine abusers. The Journal of neuropsychiatry and clinical neurosciences 16(4):456-464.

Bowers MS, McFarland K, Lake RW, Peterson YK, Lapish CC, Gregory ML, Lanier SM, Kalivas PW. 2004. Activator of G protein signaling 3: a gatekeeper of cocaine sensitization and drug seeking. Neuron 42(2):269-281.

Brewer JA, Worhunsky PD, Carroll KM, Rounsaville BJ, Potenza MN. 2008. Pretreatment brain activation during stroop task is associated with outcomes in cocaine-dependent patients. Biological psychiatry 64(11):998-1004.

Brown DN, Rosenholtz MJ, Marshall JB. 1994. Ischemic colitis related to cocaine abuse. The American journal of gastroenterology 89(9):1558-1561.

Burkett G, Yasin S, Palow D. 1990. Perinatal implications of cocaine exposure. The Journal of reproductive medicine 35(1):35-42.

Carlezon WA, Jr., Nestler EJ. 2002. Elevated levels of GluR1 in the midbrain: a trigger for sensitization to drugs of abuse? Trends in neurosciences 25(12):610-615.

Chambers HF, Morris DL, Tauber MG, Modin G. 1987. Cocaine use and the risk for endocarditis in intravenous drug users. Annals of internal medicine 106(6):833836.

Chasnoff IJ, Burns WJ, Schnoll SH, Burns KA. 1985. Cocaine use in pregnancy. The New England journal of medicine 313(11):666-669.

Chasnoff IJ, Lewis DE, Griffith DR, Willey S. 1989. Cocaine and pregnancy: clinical and toxicological implications for the neonate. Clinical chemistry 35(7):1276-1278.

Chauvet C, Lardeux V, Goldberg SR, Jaber M, Solinas M. 2009. Environmental enrichment reduces cocaine seeking and reinstatement induced by cues and stress but not by cocaine. Neuropsychopharmacology : official publication of the American College of Neuropsychopharmacology 34(13):2767-2778.

Chiamulera C, Epping-Jordan MP, Zocchi A, Marcon C, Cottiny C, Tacconi S, Corsi M, Orzi F, Conquet F. 2001. Reinforcing and locomotor stimulant effects of cocaine are absent in mGluR5 null mutant mice. Nature neuroscience 4(9):873-874.

Churchill L, Swanson CJ, Urbina M, Kalivas PW. 1999. Repeated cocaine alters glutamate receptor subunit levels in the nucleus accumbens and ventral tegmental area of rats that develop behavioral sensitization. Journal of neurochemistry 72(6):2397-2403. 
Cornish JL, Kalivas PW. 2000. Glutamate transmission in the nucleus accumbens mediates relapse in cocaine addiction. The Journal of neuroscience : the official journal of the Society for Neuroscience 20(15):RC89.

Cornish JL, Kalivas PW. 2001. Repeated cocaine administration into the rat ventral tegmental area produces behavioral sensitization to a systemic cocaine challenge. Behavioural brain research 126(1-2):205-209.

D'Esposito M, Chen AJ. 2006. Neural mechanisms of prefrontal cortical function: implications for cognitive rehabilitation. Progress in brain research 157:123-139.

Dalley JW, Cardinal RN, Robbins TW. 2004. Prefrontal executive and cognitive functions in rodents: neural and neurochemical substrates. Neuroscience and biobehavioral reviews 28(7):771-784.

Das G. 1993. Cocaine abuse in North America: a milestone in history. Journal of clinical pharmacology 33(4):296-310.

Das G, Laddu A. 1993. Cocaine: friend or foe? (Part 1). International journal of clinical pharmacology, therapy, and toxicology 31(9):449-455.

DeVries AC, Taymans SE, Sundstrom JM, Pert A. 1998. Conditioned release of corticosterone by contextual stimuli associated with cocaine is mediated by corticotropin-releasing factor. Brain research 786(1-2):39-46.

Dhuna A, Pascual-Leone A, Langendorf F, Anderson DC. 1991. Epileptogenic properties of cocaine in humans. Neurotoxicology 12(3):621-626.

Dunn JM, Inderwies BR, Licata SC, Pierce RC. 2005. Repeated administration of AMPA or a metabotropic glutamate receptor agonist into the rat ventral tegmental area augments the subsequent behavioral hyperactivity induced by cocaine. Psychopharmacology 179(1):172-180.

Epstein DH, Preston KL, Stewart J, Shaham Y. 2006. Toward a model of drug relapse: an assessment of the validity of the reinstatement procedure. Psychopharmacology 189(1):1-16.

Fitzgerald LW, Ortiz J, Hamedani AG, Nestler EJ. 1996. Drugs of abuse and stress increase the expression of GluR1 and NMDAR1 glutamate receptor subunits in the rat ventral tegmental area: common adaptations among cross-sensitizing agents. J Neurosci 16(1):274-282.

Fitzjohn SM, Kingston AE, Lodge D, Collingridge GL. 1999. DHPG-induced LTD in area $\mathrm{CA} 1$ of juvenile rat hippocampus; characterisation and sensitivity to novel mGlu receptor antagonists. Neuropharmacology 38(10):1577-1583. 
Flagel SB, Akil H, Robinson TE. 2009. Individual differences in the attribution of incentive salience to reward-related cues: Implications for addiction. Neuropharmacology 56 Suppl 1:139-148.

Fleming JA, Byck R, Barash PG. 1990. Pharmacology and therapeutic applications of cocaine. Anesthesiology 73(3):518-531.

Ford KA, Wolf ME, Hu XT. 2009. Plasticity of L-type Ca2+ channels after cocaine withdrawal. Synapse 63(8):690-697.

Freudenberger RS, Cappell MS, Hutt DA. 1990. Intestinal infarction after intravenous cocaine administration. Annals of internal medicine 113(9):715-716.

Fukunaga I, Yeo CH, Batchelor AM. 2007. Potent and specific action of the mGlu1 antagonists YM-298198 and JNJ16259685 on synaptic transmission in rat cerebellar slices. British journal of pharmacology 151(6):870-876.

Garavan H, Kaufman JN, Hester R. 2008. Acute effects of cocaine on the neurobiology of cognitive control. Philosophical transactions of the Royal Society of London Series B, Biological sciences 363(1507):3267-3276.

Giorgetti M, Hotsenpiller G, Ward P, Teppen T, Wolf ME. 2001. Amphetamine-induced plasticity of AMPA receptors in the ventral tegmental area: effects on extracellular levels of dopamine and glutamate in freely moving rats. The Journal of neuroscience : the official journal of the Society for Neuroscience 21(16):63626369.

Giros B, Jaber M, Jones SR, Wightman RM, Caron MG. 1996. Hyperlocomotion and indifference to cocaine and amphetamine in mice lacking the dopamine transporter. Nature 379(6566):606-612.

Goldstein RZ, Tomasi D, Alia-Klein N, Cottone LA, Zhang L, Telang F, Volkow ND. 2007. Subjective sensitivity to monetary gradients is associated with frontolimbic activation to reward in cocaine abusers. Drug and alcohol dependence 87(23):233-240.

Goldstein RZ, Volkow ND. 2011. Dysfunction of the prefrontal cortex in addiction: neuroimaging findings and clinical implications. Nature reviews Neuroscience 12(11):652-669.

Goldstein RZ, Woicik PA, Maloney T, Tomasi D, Alia-Klein N, Shan J, Honorio J, Samaras D, Wang R, Telang F, Wang GJ, Volkow ND. 2010. Oral methylphenidate normalizes cingulate activity in cocaine addiction during a salient cognitive task. Proceedings of the National Academy of Sciences of the United States of America 107(38):16667-16672. 
Handler A, Kistin N, Davis F, Ferre C. 1991. Cocaine use during pregnancy: perinatal outcomes. American journal of epidemiology 133(8):818-825.

Hegarty AM, Lipton RB, Merriam AE, Freeman K. 1991. Cocaine as a risk factor for acute dystonic reactions. Neurology 41(10):1670-1672.

Henry DJ, White FJ. 1991. Repeated cocaine administration causes persistent enhancement of D1 dopamine receptor sensitivity within the rat nucleus accumbens. The Journal of pharmacology and experimental therapeutics 258(3):882-890.

Hoffman CK, Goodman PC. 1989. Pulmonary edema in cocaine smokers. Radiology 172(2):463-465.

Hoffman RS, Henry GC, Howland MA, Weisman RS, Weil L, Goldfrank LR. 1992. Association between life-threatening cocaine toxicity and plasma cholinesterase activity. Annals of emergency medicine 21(3):247-253.

Homayoun H, Moghaddam B. 2006. Bursting of prefrontal cortex neurons in awake rats is regulated by metabotropic glutamate 5 (mGlu5) receptors: rate-dependent influence and interaction with NMDA receptors. Cereb Cortex 16(1):93-105.

Homayoun H, Moghaddam B. 2010. Group 5 metabotropic glutamate receptors: role in modulating cortical activity and relevance to cognition. European journal of pharmacology 639(1-3):33-39.

Hooks MS, Jones GH, Smith AD, Neill DB, Justice JB, Jr. 1991. Individual differences in locomotor activity and sensitization. Pharmacology, biochemistry, and behavior 38(2):467-470.

Hoover WB, Vertes RP. 2007. Anatomical analysis of afferent projections to the medial prefrontal cortex in the rat. Brain structure \& function 212(2):149-179.

Hu XT. 2007. Cocaine withdrawal and neuro-adaptations in ion channel function. Molecular neurobiology 35(1):95-112.

Huang CC, Lin HJ, Hsu KS. 2007. Repeated cocaine administration promotes long-term potentiation induction in rat medial prefrontal cortex. Cereb Cortex 17(8):18771888.

Isner JM, Estes NA, 3rd, Thompson PD, Costanzo-Nordin MR, Subramanian R, Miller G, Katsas G, Sweeney K, Sturner WQ. 1986. Acute cardiac events temporally related to cocaine abuse. The New England journal of medicine 315(23):14381443. 
Javaid JI, Fischman MW, Schuster CR, Dekirmenjian H, Davis JM. 1978. Cocaine plasma concentration: relation to physiological and subjective effects in humans. Science 202(4364):227-228.

Javaid JI, Musa MN, Fischman M, Schuster CR, Davis JM. 1983. Kinetics of cocaine in humans after intravenous and intranasal administration. Biopharmaceutics \& drug disposition 4(1):9-18.

Johanson CE, Fischman MW. 1989. The pharmacology of cocaine related to its abuse. Pharmacological reviews 41(1):3-52.

Kalivas PW, Alesdatter JE. 1993. Involvement of N-methyl-D-aspartate receptor stimulation in the ventral tegmental area and amygdala in behavioral sensitization to cocaine. The Journal of pharmacology and experimental therapeutics 267(1):486-495.

Kalivas PW, Duffy P. 1990. Effect of acute and daily cocaine treatment on extracellular dopamine in the nucleus accumbens. Synapse 5(1):48-58.

Kalivas PW, Duffy P. 1993. Time course of extracellular dopamine and behavioral sensitization to cocaine. I. Dopamine axon terminals. The Journal of neuroscience : the official journal of the Society for Neuroscience 13(1):266-275.

Kalivas PW, Duffy P. 1998. Repeated cocaine administration alters extracellular glutamate in the ventral tegmental area. Journal of neurochemistry 70(4):14971502.

Kalivas PW, Pierce RC, Cornish J, Sorg BA. 1998. A role for sensitization in craving and relapse in cocaine addiction. J Psychopharmacol 12(1):49-53.

Karlsson RM, Hefner KR, Sibley DR, Holmes A. 2008. Comparison of dopamine D1 and D5 receptor knockout mice for cocaine locomotor sensitization. Psychopharmacology 200(1):117-127.

Kauer JA. 2004. Learning mechanisms in addiction: synaptic plasticity in the ventral tegmental area as a result of exposure to drugs of abuse. Annual review of physiology 66:447-475.

Kaufman JN, Ross TJ, Stein EA, Garavan H. 2003. Cingulate hypoactivity in cocaine users during a GO-NOGO task as revealed by event-related functional magnetic resonance imaging. The Journal of neuroscience : the official journal of the Society for Neuroscience 23(21):7839-7843.

Kenny PJ, Boutrel B, Gasparini F, Koob GF, Markou A. 2005. Metabotropic glutamate 5 receptor blockade may attenuate cocaine self-administration by decreasing brain reward function in rats. Psychopharmacology 179(1):247-254. 
Kenny PJ, Paterson NE, Boutrel B, Semenova S, Harrison AA, Gasparini F, Koob GF, Skoubis PD, Markou A. 2003. Metabotropic glutamate 5 receptor antagonist MPEP decreased nicotine and cocaine self-administration but not nicotine and cocaine-induced facilitation of brain reward function in rats. Annals of the New York Academy of Sciences 1003:415-418.

Kew JN, Kemp JA. 2005. Ionotropic and metabotropic glutamate receptor structure and pharmacology. Psychopharmacology 179(1):4-29.

Khalsa ME, Tashkin DP, Perrochet B. 1992. Smoked cocaine: patterns of use and pulmonary consequences. Journal of psychoactive drugs 24(3):265-272.

Knackstedt LA, Moussawi K, Lalumiere R, Schwendt M, Klugmann M, Kalivas PW. 2010. Extinction training after cocaine self-administration induces glutamatergic plasticity to inhibit cocaine seeking. The Journal of neuroscience : the official journal of the Society for Neuroscience 30(23):7984-7992.

Koob GF, Stinus L, Le Moal M. 1981. Hyperactivity and hypoactivity produced by lesions to the mesolimbic dopamine system. Behavioural brain research 3(3):341359.

Kourrich S, Rothwell PE, Klug JR, Thomas MJ. 2007. Cocaine experience controls bidirectional synaptic plasticity in the nucleus accumbens. The Journal of neuroscience : the official journal of the Society for Neuroscience 27(30):79217928.

Kram HB, Hardin E, Clark SR, Shoemaker WC. 1992. Perforated ulcers related to smoking "crack" cocaine. The American surgeon 58(5):293-294.

Kramer RK, Turner RC. 1993. Renal infarction associated with cocaine use and latent protein C deficiency. Southern medical journal 86(12):1436-1438.

Kufahl P, Li Z, Risinger R, Rainey C, Piacentine L, Wu G, Bloom A, Yang Z, Li SJ. 2008. Expectation modulates human brain responses to acute cocaine: a functional magnetic resonance imaging study. Biological psychiatry 63(2):222230.

Kufahl PR, Li Z, Risinger RC, Rainey CJ, Wu G, Bloom AS, Li SJ. 2005. Neural responses to acute cocaine administration in the human brain detected by fMRI. NeuroImage 28(4):904-914.

Kumaresan V, Yuan M, Yee J, Famous KR, Anderson SM, Schmidt HD, Pierce RC. 2009. Metabotropic glutamate receptor 5 (mGluR5) antagonists attenuate cocaine priming- and cue-induced reinstatement of cocaine seeking. Behavioural brain research 202(2):238-244. 
Lea PMt, Faden AI. 2006. Metabotropic glutamate receptor subtype 5 antagonists MPEP and MTEP. CNS drug reviews 12(2):149-166.

Leri F, Flores J, Rodaros D, Stewart J. 2002. Blockade of stress-induced but not cocaineinduced reinstatement by infusion of noradrenergic antagonists into the bed nucleus of the stria terminalis or the central nucleus of the amygdala. The Journal of neuroscience : the official journal of the Society for Neuroscience 22(13):57135718.

Levine SR, Brust JC, Futrell N, Brass LM, Blake D, Fayad P, Schultz LR, Millikan CH, Ho KL, Welch KM. 1991. A comparative study of the cerebrovascular complications of cocaine: alkaloidal versus hydrochloride--a review. Neurology 41(8):1173-1177.

Li Y, Hu XT, Berney TG, Vartanian AJ, Stine CD, Wolf ME, White FJ. 1999. Both glutamate receptor antagonists and prefrontal cortex lesions prevent induction of cocaine sensitization and associated neuroadaptations. Synapse 34(3):169-180.

Liu K, Steketee JD. 2011. Repeated exposure to cocaine alters medial prefrontal cortex dopamine $\mathrm{D}(2)$-like receptor modulation of glutamate and dopamine neurotransmission within the mesocorticolimbic system. Journal of neurochemistry 119(2):332-341.

Liu QS, Pu L, Poo MM. 2005. Repeated cocaine exposure in vivo facilitates LTP induction in midbrain dopamine neurons. Nature 437(7061):1027-1031.

Madayag A, Lobner D, Kau KS, Mantsch JR, Abdulhameed O, Hearing M, Grier MD, Baker DA. 2007. Repeated N-acetylcysteine administration alters plasticitydependent effects of cocaine. The Journal of neuroscience : the official journal of the Society for Neuroscience 27(51):13968-13976.

Marek GJ, Zhang C. 2008. Activation of metabotropic glutamate 5 (mGlu5) receptors induces spontaneous excitatory synaptic currents in layer V pyramidal cells of the rat prefrontal cortex. Neuroscience letters 442(3):239-243.

Marino MJ, Wittmann M, Bradley SR, Hubert GW, Smith Y, Conn PJ. 2001. Activation of group I metabotropic glutamate receptors produces a direct excitation and disinhibition of GABAergic projection neurons in the substantia nigra pars reticulata. The Journal of neuroscience : the official journal of the Society for Neuroscience 21(18):7001-7012.

Martin-Fardon R, Weiss F. 2013. Modeling Relapse in Animals. Curr Top Behav Neurosci 13: 403-32. 
Melendez RI, Kalivas PW. 2003. Metabotropic glutamate receptor regulation of extracellular glutamate levels in the prefrontal cortex. Annals of the New York Academy of Sciences 1003:443-444.

Merigian KS, Roberts JR. 1987. Cocaine intoxication: hyperpyrexia, rhabdomyolysis and acute renal failure. Journal of toxicology Clinical toxicology 25(1-2):135-148.

Meyer PJ, Ma ST, Robinson TE. 2012. A cocaine cue is more preferred and evokes more frequency-modulated $50-\mathrm{kHz}$ ultrasonic vocalizations in rats prone to attribute incentive salience to a food cue. Psychopharmacology 219(4):999-1009.

Murray RJ, Albin RJ, Mergner W, Criner GJ. 1988. Diffuse alveolar hemorrhage temporally related to cocaine smoking. Chest 93(2):427-429.

Nasif FJ, Hu XT, White FJ. 2005. Repeated cocaine administration increases voltagesensitive calcium currents in response to membrane depolarization in medial prefrontal cortex pyramidal neurons. J Neurosci 25(14):3674-3679.

Nestler EJ. 2005. The neurobiology of cocaine addiction. Science \& practice perspectives / a publication of the National Institute on Drug Abuse, National Institutes of Health 3(1):4-10.

Nolte KB. 1991. Rhabdomyolysis associated with cocaine abuse. Human pathology 22(11):1141-1145.

Novak M, Halbout B, O'Connor EC, Rodriguez Parkitna J, Su T, Chai M, Crombag HS, Bilbao A, Spanagel R, Stephens DN, Schutz G, Engblom D. 2010. Incentive learning underlying cocaine-seeking requires mGluR5 receptors located on dopamine D1 receptor-expressing neurons. The Journal of neuroscience : the official journal of the Society for Neuroscience 30(36):11973-11982.

Oades RD, Halliday GM. 1987. Ventral tegmental (A10) system: neurobiology. 1. Anatomy and connectivity. Brain research 434(2):117-165.

Olive MF. 2009. Metabotropic glutamate receptor ligands as potential therapeutics for addiction. Curr Drug Abuse Rev 2(1):83-98.

Om A, Ellahham S, Ornato JP. 1992. Reversibility of cocaine-induced cardiomyopathy. American heart journal 124(6):1639-1641.

Park WK, Bari AA, Jey AR, Anderson SM, Spealman RD, Rowlett JK, Pierce RC. 2002. Cocaine administered into the medial prefrontal cortex reinstates cocaine-seeking behavior by increasing AMPA receptor-mediated glutamate transmission in the nucleus accumbens. The Journal of neuroscience : the official journal of the Society for Neuroscience 22(7):2916-2925. 
Perry JL, Joseph JE, Jiang Y, Zimmerman RS, Kelly TH, Darna M, Huettl P, Dwoskin LP, Bardo MT. 2011. Prefrontal cortex and drug abuse vulnerability: translation to prevention and treatment interventions. Brain research reviews 65(2):124-149.

Pierce RC, Born B, Adams M, Kalivas PW. 1996. Repeated intra-ventral tegmental area administration of SKF-38393 induces behavioral and neurochemical sensitization to a subsequent cocaine challenge. The Journal of pharmacology and experimental therapeutics 278(1):384-392.

Pierce RC, Kalivas PW. 1997. A circuitry model of the expression of behavioral sensitization to amphetamine-like psychostimulants. Brain research Brain research reviews 25(2):192-216.

Pierce RC, Reeder DC, Hicks J, Morgan ZR, Kalivas PW. 1998. Ibotenic acid lesions of the dorsal prefrontal cortex disrupt the expression of behavioral sensitization to cocaine. Neuroscience 82(4):1103-1114.

Platt DM, Rowlett JK, Spealman RD. 2008. Attenuation of cocaine self-administration in squirrel monkeys following repeated administration of the mGluR5 antagonist MPEP: comparison with dizocilpine. Psychopharmacology 200(2):167-176.

Pockros LA, Pentkowski NS, Swinford SE, Neisewander JL. 2011. Blockade of 5-HT2A receptors in the medial prefrontal cortex attenuates reinstatement of cue-elicited cocaine-seeking behavior in rats. Psychopharmacology 213(2-3):307-320.

Reid MS, Berger SP. 1996. Evidence for sensitization of cocaine-induced nucleus accumbens glutamate release. Neuroreport 7(7):1325-1329.

Ridderinkhof KR, van den Wildenberg WP, Segalowitz SJ, Carter CS. 2004. Neurocognitive mechanisms of cognitive control: the role of prefrontal cortex in action selection, response inhibition, performance monitoring, and reward-based learning. Brain and cognition 56(2):129-140.

Robinson TE, Becker JB. 1986. Enduring changes in brain and behavior produced by chronic amphetamine administration: a review and evaluation of animal models of amphetamine psychosis. Brain research 396(2):157-198.

Robinson TE, Berridge KC. 1993. The neural basis of drug craving: an incentivesensitization theory of addiction. Brain research Brain research reviews 18(3):247-291.

Saunders BT, Robinson TE. 2011. Individual variation in the motivational properties of cocaine. Neuropsychopharmacology : official publication of the American College of Neuropsychopharmacology 36(8):1668-1676. 
Schumann J, Yaka R. 2009. Prolonged withdrawal from repeated noncontingent cocaine exposure increases NMDA receptor expression and ERK activity in the nucleus accumbens. The Journal of neuroscience : the official journal of the Society for Neuroscience 29(21):6955-6963.

Seamans JK, Yang CR. 2004. The principal features and mechanisms of dopamine modulation in the prefrontal cortex. Progress in neurobiology 74(1):1-58.

Sesack SR, Deutch AY, Roth RH, Bunney BS. 1989. Topographical organization of the efferent projections of the medial prefrontal cortex in the rat: an anterograde tracttracing study with Phaseolus vulgaris leucoagglutinin. The Journal of comparative neurology 290(2):213-242.

Sesack SR, Pickel VM. 1992. Prefrontal cortical efferents in the rat synapse on unlabeled neuronal targets of catecholamine terminals in the nucleus accumbens septi and on dopamine neurons in the ventral tegmental area. The Journal of comparative neurology 320(2):145-160.

Shaham Y, Shalev U, Lu L, De Wit H, Stewart J. 2003. The reinstatement model of drug relapse: history, methodology and major findings. Psychopharmacology 168(12):3-20.

Steketee JD. 1998. Repeated injection of GBR 12909, but not cocaine or WIN 35,065-2, into the ventral tegmental area induces behavioral sensitization. Behavioural brain research 97(1-2):39-48.

Steketee JD. 2003. Neurotransmitter systems of the medial prefrontal cortex: potential role in sensitization to psychostimulants. Brain research Brain research reviews 41(2-3):203-228.

Steketee JD. 2005. Cortical mechanisms of cocaine sensitization. Critical reviews in neurobiology 17(2):69-86.

Steketee JD, Beyer CE. 2005. Injections of baclofen into the ventral medial prefrontal cortex block the initiation, but not the expression, of cocaine sensitization in rats. Psychopharmacology 180(2):352-358.

Steketee JD, Kalivas PW. 2011. Drug wanting: behavioral sensitization and relapse to drug-seeking behavior. Pharmacological reviews 63(2):348-365.

Suto N, Tanabe LM, Austin JD, Creekmore E, Pham CT, Vezina P. 2004. Previous exposure to psychostimulants enhances the reinstatement of cocaine seeking by nucleus accumbens AMPA. Neuropsychopharmacology : official publication of the American College of Neuropsychopharmacology 29(12):2149-2159. 
Thomas MJ, Malenka RC. 2003. Synaptic plasticity in the mesolimbic dopamine system. Philosophical transactions of the Royal Society of London Series B, Biological sciences 358(1432):815-819.

Timmer KM, Steketee JD. 2012. Examination of a role for metabotropic glutamate receptor 5 in the medial prefrontal cortex in cocaine sensitization in rats. Psychopharmacology 221(1):91-100.

Titley HK, Heskin-Sweezie R, Broussard DM. 2010. The bidirectionality of motor learning in the vestibulo-ocular reflex is a function of cerebellar mGluR1 receptors. Journal of neurophysiology 104(6):3657-3666.

Torregrossa MM, Tang XC, Kalivas PW. 2008. The glutamatergic projection from the prefrontal cortex to the nucleus accumbens core is required for cocaine-induced decreases in ventral pallidal GABA. Neuroscience letters 438(2):142-145.

Tzschentke TM, Schmidt WJ. 1998. Discrete quinolinic acid lesions of the rat prelimbic medial prefrontal cortex affect cocaine- and MK-801-, but not morphine- and amphetamine-induced reward and psychomotor activation as measured with the place preference conditioning paradigm. Behavioural brain research 97(1-2):115127.

Tzschentke TM, Schmidt WJ. 2003. Glutamatergic mechanisms in addiction. Molecular psychiatry 8(4):373-382.

Ungless MA, Whistler JL, Malenka RC, Bonci A. 2001. Single cocaine exposure in vivo induces long-term potentiation in dopamine neurons. Nature 411(6837):583-587.

Wang X, Moussawi K, Knackstedt L, Shen H, Kalivas PW. 2012. Role of mGluR5 neurotransmission in reinstated cocaine-seeking. Addiction biology.

Warner EA. 1993. Cocaine abuse. Annals of internal medicine 119(3):226-235.

White FJ, Hu XT, Zhang XF, Wolf ME. 1995. Repeated administration of cocaine or amphetamine alters neuronal responses to glutamate in the mesoaccumbens dopamine system. The Journal of pharmacology and experimental therapeutics 273(1):445-454.

White FJ, Kalivas PW. 1998. Neuroadaptations involved in amphetamine and cocaine addiction. Drug and alcohol dependence 51(1-2):141-153.

Williams JM, Steketee JD. 2004. Cocaine increases medial prefrontal cortical glutamate overflow in cocaine-sensitized rats: a time course study. The European journal of neuroscience 20(6):1639-1646. 
Williams JM, Steketee JD. 2005. Time-dependent effects of repeated cocaine administration on dopamine transmission in the medial prefrontal cortex. Neuropharmacology 48(1):51-61.

Wisniewski K, Car H. 2002. (S)-3,5-DHPG: a review. CNS drug reviews 8(1):101-116.

Xie X, Steketee JD. 2008. Repeated exposure to cocaine alters the modulation of mesocorticolimbic glutamate transmission by medial prefrontal cortex Group II metabotropic glutamate receptors. J Neurochem 107(1):186-196.

Xie X, Steketee JD. 2009. Effects of repeated exposure to cocaine on group II metabotropic glutamate receptor function in the rat medial prefrontal cortex: behavioral and neurochemical studies. Psychopharmacology 203(3):501-510.

Zhang XF, Hu XT, White FJ, Wolf ME. 1997. Increased responsiveness of ventral tegmental area dopamine neurons to glutamate after repeated administration of cocaine or amphetamine is transient and selectively involves AMPA receptors. The Journal of pharmacology and experimental therapeutics 281(2):699-706. 


\section{VITA}

Kristin Marie Timmer was born in Emerson, NJ in 1978 and attended West Windsor Plainsboro High School for a short time before completing the General Educational Development (GED) assessment in 1995. Kristin then obtained a Bachelors degree in Psychology from Kean University in Union, NJ in 2002, followed by a Masters degree in Experimental Psychology from Radford University in Radford, VA in 2004. In 2012, Kristin completed her doctoral work in Biomedical Sciences at the University of Tennessee Health Science Center. 